\title{
IV CONGRESO ARGENTINO DE ANATOMÍA CLÍNICA. I CONGRESO INTERNACIONAL DE ANATOMÍA CLÍNICA. XII CONGRESO DE LA SOCIEDAD ARGENTINA DE ANATOMÍA CLÍNICA. I SIMPOSIO DEL FORO ARGENTINO DE CÁTEDRAS DE ANATOMÍA Y CIENCIAS MORFOLÓGICAS
}

\author{
Buenos Aires, Argentina, 24 al 26 de Setiembre de 2015
}

\author{
Conferencias y Mesas Redondas
}

\section{RECENT PROGRESSES OF THE CLINICAL ANATOMY OF THE SHOULDER JOINT WITH SPECIAL REFERENCE TO THE ROTATOR CUFF MUSCLES \\ Keiichi AKITA, Akimoto NIMURA} Department of Clinical Anatomy, Tokyo Medical and Dental University (TMDU), Tokyo, Japan

It had been generally accepted Anatomy of the rotator cuff muscles as common senses for 500 years. However, operating procedures of the shoulder region have been rapidly progressed recently, and new anatomical findings have been reported according to demands for new operating procedures. Here, we are making a presentation of a series of such new findings based on our studies as follows. Based on anatomic textbooks, the greater tuberosity is marked by three flat impressions: the highest impression gives insertion to the supraspinatus muscle, the middle to the infraspinatus. Most anatomy textbooks and authors of several anatomic studies have stated that the supraspinatus inserts into the highest impression of the greater tuberosity of and the infraspinatus inserts into the middle impression of the greater tuberosity. However, the supraspinatus inserts only into the anteromedial area of the highest impression. The anteriormost region of the infraspinatus also reaches the anterior margin of the highest impression. According to the findings of the 3D reconstructions of the micro-CT images, the "lateral impression" could be consistently identified, which was composed of the border with the highest impression, the border with the middle impression, and the border with the lateral wall of the greater tuberosity. The "lateral impression" was confirmed to correspond to the anterior border of the insertion of the infraspinatus tendon. The teres minor muscle can be separated into the superior bundle which inserts to the lowest impression as an ova footprint, and the inferior bundle which inserts into the distal to the lowest impression as a linear shape. At the border between the infraspinatus and teres minor, the thick attachment of the articular capsule compensates for the lack of tendinous insertion. The subscapularis muscle insertion is composed of the superior two-thirds tendinous insertion and the inferior one-third insertion where the muscle attaches to the humerus almost directly by way of a thin membranous structure. The superior-most insertion of the subscapularis tendon is wide in the uppermost margin of the lesser tuberosity, and the superior-most insertion of the subscapularis tendon extends a thin tendinous slip, which attaches to the fovea capitis of the humerus. The coracohumeral ligament could be divided into two parts: one part spread fibers over the rotator interval to the posterior portion of the greater tuberosity, and the other part extends fibers to envelop the subscapularis muscle.

\section{ANATOMÍA QUIRÚRGICA DEL ESPACIO PLEURAL \\ Rubén D. ALGIERI \\ $3^{a}$ Cátedra de Anatomía, Facultad de Medicina, \\ U.B.A.; Servicio de Cirugía General, Hospital \\ Aeronáutico Central. Buenos Aires, Argentina} La pleura está constituida por dos hojas contiguas entre sí, la visceral que tapiza íntimamente la superficie pulmonar, y la parietal que cubre la pared torácica; entre ambas se constituye la cavidad pleural; la cual es un espacio potencial en estado normal, pero aumenta su volumen cuando es ocupado por gas (neumotórax) o líquidos (hidrotórax, hemotórax, quilotórax, piotórax). En condiciones normales tiene aproximadamente $10 \mathrm{ml}$ de líquido seroso a baja presión (vacío pleural), el cual se origina en la microvellosidades localizadas en ambas hojas pleurales (visceral y parietal); las funciones de éste líquido es lubricar y aumentar la adherencia en dichas hojas, permitiendo su desplazamiento y dificultando su 
separación. Cuando el vacío pleural es destruido por la entrada de aire, sangre o algún otro líquido contenido en la cavidad pleural, la ventilación se perturba en forma considerable. Existen diferentes patologías que afectan la anatomía normal de la cavidad pleural y que requieren de la realización de procedimientos quirúrgicos de urgencia (toracocentesis, avenamiento pleural bajo agua, toracotomía) para su tratamiento. Así, mencionamos, el neumotórax simple que constituye una entidad donde se presenta aire en la cavidad pleural debida al pasaje a través de una perforación de la pleura, y el origen del mismo puede ser espontáneo o traumático. Se produce un colapso parcial o total del lóbulo pulmonar afectado por el aire acumulado en el espacio pleural. Se clasifican en grados (clínica e imagenológicamente) de acuerdo al colapso pulmonar. El neumotórax hipertensivo es una entidad clínica que ocurre por un mecanismo valvular unidireccional, y como consecuencia ocurre el colapso pulmonar total con desplazamiento mediastinal hacia contralateral. Se debe actuar rápidamente mediante descompresión con aguja para prevenir el colapso circulatorio con interrupción del retorno venoso y consecuente paro cardíaco. El hemotórax se caracteriza por la acumulación de sangre en el espacio pleural y también se clasifica por grados de acuerdo a la cantidad de sangre en el espacio pleural. En la actualidad, un programa de salud que contemple la educación médica continua en anatomía clínico-quirúrgica desde los inicios de la formación profesional, donde se desarrolle un sistema de capacitación que incluya la posibilidad de la aplicación de conceptos clínico quirúrgicos a la anatomía humana con la oportunidad de realizar procedimientos que se sustentan en la anatomía, resulta fundamental en la educación de grado y pilar para el desarrollo, capacitación y entrenamiento de los mismos en el postgrado.

\section{BASES ANATÓMICAS DE LA EXPLORACIÓN ELECTROFISIOLÓGICA DE LA CARA José L. ALLENDE}

$2^{a}$ Cátedra de Anatomía, Facultad de Medicina,

U.B.A.; Área de Neurología, Instituto de Trasplante-

GCABA; Servicio de Neurología, Investigaciones Médicas S.A. Buenos Aires, Argentina

La exploración funcional de los nervios trigémino y facial es frecuente en la valoración médico-legal de traumatismos, heridas y complicaciones de procedimientos estéticos en la cara. Los métodos electrofisiológicos de aplicación habitual son: 1) Electromiografía de los músculos de la expresión facial y de la masticación, 2) Velocidad de conducción del nervio facial, 3) Potenciales evocados del nervio trigémino, 4) Estudio del reflejo de parpadeo. La electromiografía combinada con la velocidad de conducción del facial puede ser muy precisa en la valoración del déficit motor, aún en territorios específicos o debido a lesiones limitadas. Se debe tener en cuenta que la estimulación del nervio facial se puede efectuar sólo en un punto de su trayecto, en la parte superior de la región carotídea, entre el borde anterior del músculo esternocleidomastoideo y el ángulo de la mandíbula. Esta limitación queda compensada por la extensión del territorio en que se pueden obtener respuestas, desde el músculo frontal hasta el platisma, lo que da como resultado una buena definición topográfica en, por ejemplo, heridas cortantes de escasa extensión. Las alteraciones sensitivas se pueden objetivar con los potenciales evocados trigeminales, pero los resultados con adecuada validación están limitados a los territorios de las ramas maxilar y mandibular. Las respuestas reproducibles se obtienen con la estimulación directa del nervio infraorbitario en la proyección del agujero homónimo, o de la piel de los labios; existen respuestas validadas para la estimulación separada de cada labio o para la estimulación simultánea de ambos. El estudio electrofisiológico del reflejo de parpadeo permite explorar el territorio de la rama oftálmica del trigémino, ya que se aplica el estímulo al nervio supraorbitario. Además, aporta información acerca de rama motora del reflejo (facial) y de las conexiones centrales del reflejo en el tronco cerebral.

\section{MODELOS DE APRENDIZAJE CON RECURSOS E-LEARNING}

\section{Nancy AMICONE}

Cátedra de Informática Médica, Facultad de Medicina, Universidad Nacional de Tucumán, Argentina

La informática médica tuvo sus inicios en la década de los años 50, con el crecimiento de los dispositivos computacionales utilizables. Su rápido avance, en especial, durante los últimos 25 años, se debe al creciente reconocimiento de la imposibilidad de manejar las bases del conocimiento de la medicina con los métodos tradicionales basados en el papel y la convicción de que el proceso de toma de decisiones informadas es importante en la medicina moderna. La Informática Médica es una disciplina emergenteintegradora que surge producto de la intersección sinérgica de la Informática con la Medicina, estudia la estructura, el comportamiento y la interacción de los sistemas médicos y las tecnologías de la información; así como los procesos de obtención, organización, almacenamiento, recuperación y uso de la información médica en los sistemas de salud, entre otros aspectos. Comprende las principales esferas del quehacer en salud: asistencia, educación, investigación y dirección. Para mejorar la salud global y bienestar de una población se requiere, entre otros factores, de recursos humanos capacitados, no solo en el campo de la medicina y salud, sino también en el campo de la informática, ya que hoy en día, la tecnología puede permitir mejoras sustanciales en diversos aspectos. Las tecnologías de la información y comunicación (TIC) tienen el potencial de beneficiar a países desarrollados y países en desarrollo. La Organización Mundial de la Salud identificó al uso de las TIC como habilidad prioritaria para el desarrollo de los recursos humanos en salud. Además, el uso de las TIC se reconoce cada vez más como un elemento crucial para la mejora de los sistemas de salud y como un medio para poder llegar a alcanzar los Objetivos de Desarrollo del Milenio. Así, el desarrollo e implementación de programas de entrenamiento e investigación en informática biomédica se convierte en necesidades cruciales para crear una masa crítica de profesionales adecuadamente capacitados que respondan a las necesidades locales y regionales. Desde esta mirada, 
la Cátedra de Informática Médica ofrece una propuesta de capacitación a distancia en modalidad blended learning, combinando los encuentros presenciales con la modalidad virtual para el dictado del Módulo de Capacitación en Informática Médica. El objetivo del módulo es que los futuros médicos aprendan a valerse por sí mismos en lo que se refiere al uso de la tecnología de la informática en su desempeño, adquiriendo aptitudes básicas que la Organización Mundial de la Salud recomienda como habilidades necesarias.

\section{ANATOMÍA QUIRÚRGICA DE LA GLÁNDULA TIROIDES \\ Gustavo ARMAND UGON}

Depto. de Anatomía de la Facultad de Medicina UDELAR; Hospital Central de las Fuerzas Armadas y del Hospital Evangélico. Montevideo, Uruguay La anatomía constituye el punto de arranque y base de todo el saber médico, siendo la disección uno de los recursos más antiguos de educación médica. El cuello representa el $1 \%$ de la superficie corporal, concentra gran cantidad de estructuras vitales estrechamente relacionadas entre sí, por cuanto el conocimiento anatómico se torna indispensable al momento del abordaje quirúrgico y constituye la piedra angular del mismo. Los procedimientos quirúrgicos sobre la glándula tiroides están orientados a evitar la lesión de los nervios laríngeos recurrentes y la exéresis y/o devascularización de las glándulas paratiroides. Menos frecuente es la lesión de los nervios laríngeos superiores. De la anatomía de superficie destacamos: borde anterior de los músculos esternocleidomastoideos, horquilla esternal y hueso hioides, reperes sumamente útiles, enmarcan la región infrahioidea. También los cartílagos tiroides, cricoides y primeros anillos traqueales. La clásica cervicotomía transversa arciforme respeta las líneas de tracción del cuello, lo que sumado a un emplazamiento bajo de la incisión asegura un buen resultado estético. El músculo platisma del cuello debe ser reconstruido para separar la sutura cutánea de la aponeurótica, evitando así adherencias del plano cutáneo al aponeurótico y un mal resultado estético. Lo mismo sucede si no se conserva la integridad de la aponeurosis cervical superficial. La apertura de la línea blanca anterior del cuello, avascular, permite el abordaje de la celda tiroidea. Los músculos infrahioideos se separan hacia los lados, de necesidad pueden seccionarse en su tercio superior respetando así su inervación que los alcanza en su tercio inferior. La glándula tiroides se separa fácilmente de las paredes de la celda tiroidea, se trata de un plano avascular con tejido celuloso laxo. Los pedículos tiroideos, superior e inferior, están ampliamente anastomosados entré sí en cada lóbulo, y, a través de los arcos vasculares supra e infra ístmicos con los contralaterales. La vena tiroidea media, inconstante, termina abocándose en la vena yugular interna homolateral, su lesión equivale a una lesión lateral de la yugular interna. Los nervios laríngeos recurrentes, siendo el izquierdo más vertical y más cercano al eje visceral antes de contactar con la glándula tiroides, establecen estrecha relación con los pedículos tiroideos inferiores. Transcurren luego entre la glán- dula tiroides y la tráquea antes de pasar por debajo del cartílago cricoides y alcanzar la laringe. Las glándulas paratiroides, con diferente origen embriológico las superiores y las inferiores, están en estrecho contacto con la glándula tiroides con quien comparten vascularización.

\section{GENÉTICA DEL DESARROLLO: DE LA} MORFOGÉNESIS A LA DISMORFOGÉNESIS Clara E. ARTEAGA DÍAZ

Universidad Nacional de Colombia en el Instituto de Genética, el Hospital Instituto Materno Infantil y Hospital de la Misericordia

Las malformaciones estructurales mayores y los defectos congénitos afectan aproximadamente al 3\% de los recién nacidos en todas las poblaciones y son causa primordial de mortalidad infantil y neonatal. En los últimos años la investigación en embriología molecular, ha mostrado que una importante proporción del genoma humano está implicado en procesos de embriogénesis y desarrollo. Se calcula por ejemplo que para desarrollar un sistema nervioso son necesarios más del $60 \%$ de los genes del genoma humano. Esto supone, que con alta probabilidad mutaciones genéticas o alteraciones cromosómicas producirán anomalías del desarrollo fetal que dependiendo de su gravedad llevarán a la muerte fetal o a defectos estructurales o funcionales evidenciables al nacimiento. El desarrollo y la morfogénesis cráneofacial es uno de los más complejos eventos de la embriogénesis y del desarrollo y por supuesto uno de los más costosos en términos de genes implicados. Una serie de cascadas de señales iniciadas en tejidos de primordios faciales mediando redes que actúan dirigiendo procesos fundamentales tales como proliferación celular, diferenciación, migración y muerte celular programada establecieran las estructuras faciales definitivas. La enorme complejidad de estos procesos implica también su labilidad reflejada en la alta incidencia de anomalías congénitas que comprometen las estructuras craneofaciales y también por supuesto, sutiles variaciones genéticas también explicaran la gran variación en la apariencia facial humana normal. Se ha podido establecer que la apariencia facial humana muestra un gran componente genético con una heredabilidad tan alta como de 0.8 , siendo por ejemplo, la altura de la cara y la posición de la mandíbula, los rasgos con mayor componente genético. Sin embargo, las bases genéticas relacionadas con la variación interindividual no han sido elucidadas del todo. Posiblemente una mayor comprensión de los eventos genéticos del desarrollo craneofacial normal, podrá permitir predecir la apariencia facial individual a partir de las variaciones en el DNA, tal como es posible hoy predecir rasgos como el color de los ojos y del cabello. El avance en la tecnología genética, particularmente los estudios de genómica global, han empezado a relacionar variaciones frecuentes en el genoma humano, tales como los SNPs con variantes morfológicas normales, expresando cómo la variación humana normal representa un espectro continuo con la variación anormal. Una conexión entre la morfogénesis y la dismorfogénesis. 


\section{ANATOMIA REAL O VIRTUAL}

Nelson ARVELO

Facultad de Medicina. Escuela "Luis Razetti"; Hospital

"Ricardo Baquero Gonzalez". Caracas, Venezuela

El siglo XXI llegó con grandes avances tecnológicos a los cuales no ha escapado la medicina, haciendo realidad el pensamiento de Mc Luham (Padre de la Comunicación Social) en relación a la aldea global, lo cual nos ha colocado en la globalización y en la "sociedad del conocimiento", definida ésta como una sociedad con capacidad para generar apropiar y utilizar el conocimiento para atender las necesidades de su desarrollo y así construir su propio futuro, convirtiendo la creación en herramientas de la sociedad para su propio beneficio, planteando nuevas exigencias a los sistemas educativos y las universidades. En el campo de la anatomía hay una necesidad urgente de orientarse hacia la clínica, a fin de maximizar la experiencia de aprendizaje, y no solo debe incluir principios aplicables a los humanos también principios relevantes a los aspectos conductuales sociales de salud y enfermedad. Para quienes defienden una anatomía real (presencial) la actividad practica sigue siendo ineludible e irremplazable para la docencia, para otros la disección es consumidora de tiempo unido al problema de adquisición, preservación y mantenimiento de cadáveres. Por su parte, la anatomía virtual proporciona representación visual de órganos y sistemas no accesibles al alumno estimulando la producción, reproducción y restructuración de los contenidos. Ante este panorama que hacer: ¿Anatomía real ó virtual? Las experiencia de aprendizaje en línea podrían ser más efectivas que las tradicionales si especialmente se combinan con las presenciales, lo cual nos lleva al B-learning que combina ambas modalidades: presencial y virtual, conjuga los medios, recursos, tecnologías, metodologías, actividades y estrategias para mover al estudiante de un papel pasivo a otro más activo y beneficiarse del abundante material disponible en la red. Por último la clave del cambio metodológico no es aprender más sino aprender diferente.

\section{ROL DE LOS TEXTOS ANATOMICOS EN EL SIGLO XXI}

Nelson ARVELO

Facultad de Medicina. Escuela "Luis Razetti"; Hospital

"Ricardo Baquero Gonzalez". Caracas, Venezuela

La sociedad del conocimiento plantea nuevas exigencias a los sistemas educativos y por tanto, también a las universidades que cada vez deben responder con más calidad a las demandas sociales. Las instituciones de enseñanza superior están siendo requeridas para dar repuestas a demandas de formación más flexibles y adaptadas, y a la necesidad de incorporar nuevos sistemas pedagógicos que en buena medida deben vincularse al uso del las T.I.C. Ahora bien, si la enseñanza de anatomía debe renovarse, que sea útil, orientarla hacia la clínica, anatomía de superficie, establecer la relación estructurafunción, imagenología, donde el alumno sea el actor principal familiarizarlo con el método científico y la investigación para crear conocimiento, que " aprenda a aprender" a través del b-learning deberíamos preguntarnos ¿es correcto limitarlo a un texto de anatomía?. En lo personal no le veo vigencia a un texto descriptivo y racista, ni a los que presentan al cuerpo humano como un tipo idealizado irreconciliable con la realidad en muchos aspectos sin tomar en cuenta las variaciones anatómicas. En el caso de Latinoamérica los textos cargados de errores de traducción son abundantes y crean confusión al alumnado.

\section{NUEVA TERMINOLOGÍA EMBRIOLÓGICA INTERNACIONAL \\ Rodolfo E. AVILA}

Cátedra de Histología y Embriología, Facultad de Ciencias Médicas, Universidad Nacional de Córdoba, Argentina

La comunicación en las ciencias de la salud requiere de una terminología clara y precisa. Sin embargo, en las ciencias morfológicas (anatomía, histología y embriología) se mantienen diversas denominaciones para diferentes estructuras, basadas en analogías de forma, nombre de maestros, sinónimos y epónimos. Para superar estas imprecisiones resulta necesaria la terminología morfológica internacional. La terminología embriológica fue discutida, consensuada y aprobada en el XVII Congreso Internacional de Anatomía en Ciudad del Cabo, África del Sur, en agosto del 2009. Estas terminologías morfológicas internacionales son resultado de reuniones de expertos que constituyen el FICAT. Por otra parte, en los Simposios íberoLatinoamericanos de Terminología Anatómica, Histológica y Embriológica (SILAT) de la Asociación Panamericana de Anatomía (APA) se reúnen los Comités de expertos formados por profesores e investigadores universitarios ibero-latinoamericanos dedicados a esta problemática. En dichos simposios se difunde, estudia y traduce al español y portugués la terminología presentada por el Comité Federal sobre la Terminología Anatómica (FICAT), órgano especializado de la Federación Internacional de Asociaciones de Anatomía (IFAA). EI SILAT intenta que el término acordado sea lo más descriptivo y explicativo posible, con el objeto de otorgar el sentido y el significado de la palabra elegida para identificar una estructura. Actualmente las Tecnología de Información y Comunicación (TIC) son herramientas usadas en la educación médica continua como medio para facilitar la información requerida previa al proceso de aprendizaje presencial. El objetivo de la presente comunicación es dar a conocer a- nuestra experiencia de trabajo y los resultados en Terminología Embriológica en los Simposios Iberolatinoamericanos de Terminología (SILAT), b- nuestra propuesta de difusión de la nueva terminología mediante las Tecnología de Información y Comunicación (TIC) usando website y redes sociales. La terminología en latín sirvió como guía para consensuar la terminología en español. También utilizamos los enlaces gratuitos de la terminología embriológica disponibles en inglés las páginas del Programa de la Federación Internacional de Terminología Anatómica (FICAT) perteneciente a la Federación Internacional de Asociaciones de Anatomistas (IFAA) www.ifaa.net/ index.php/fipat. Concluimos que mediante la modalidad de trabajo implementada en la disciplina 
Embriología cumplimentamos objetivos de los SILAT superando imprecisiones y contradicciones en la terminología. Las recomendaciones y conclusiones de estos Simposios Iberolatinoamericanos, sirven de base para conocer y conciliar términos "panamericanos". También creemos importante la difusión de la nueva terminología de Embriología por medio del uso de internet como una vía universal y común de la comunicación en la educación médica continua y por el impacto en la práctica de la clínica médica.

\section{MEASUREMENT ERRORS: HOW RELIABLE DO WE MEASURE?}

Cagatay BARUT

Department of Anatomy, School of Medicine, Bulent Ecevit University, Zonguldak, Turkey

Any aspect of physiological function depends on the underlying morphology, and the objective way of evaluating and comparing aspects of morphology is measurement. Measurements constitute a basis for quantitative analysis of size and shape of organisms or organs which can be referred as morphometrics or morphometry. Morphometric data are important source of information to understand many biological phenomena. Thus the morphometric measurements should be made in a standardized way. As with any use of quantitative biological measures, it is important to minimize error, and to know and understand the various ways in which it is estimated and assessed. Without quantification of measurement error the acceptability of measured variables for subsequent analyses in the main study is unknown. Hence as part of any study, an estimate of measurement error is needed. The most commonly used measures of this are the technical error of measurement (TEM), relative technical error of measurement (rTEM) and coefficient of reliability (R). TEM "provides a standard deviationlike measure of the magnitude of error and it is in the original units of measurement." rTEM represents an estimate of error magnitude relative to the size of the measurement and expressed as a percentage. $R$ represents the proportion of between-subject variance free from measurement error. The aim of this study is to provide estimates of intra-observer precision for various anthropometric measurements. Precision estimates obtained from three studies regarding hand measurements and one study regarding facial morphometry is presented. The results suggest that an acceptable degree of intra-observer precision was obtained for the morphometric measurements for each study. Size of measurement error is of great importance for the interpretation of morphometric data collected, because high measurement error can adversely affect statistical results.

\section{THE ANALYSIS OF THE MAXILLARY SINUS VASCULAR ANASTOMOSIS: AN IN VIVO INVESTIGATION Sara BERNARDI \\ University of L'Aquila, Italy}

The arterial vascular supply of maxillary sinus has to be considered in all the surgical procedures where it is involved. This region indeed is a concern for dental surgeons who have to perform implant dentistry interventions. In particular, the intra-osseous anastomosis between the posterior superior alveolar artery and the infraorbital artery branches in the bony canal can be tricky to a not well aware clinician. Aim of this report is to investigate the arterial blood supply of the maxillary sinus in vivo to give clinicians the basis for a better understanding of vascular complications that can derive from surgical procedures at this level. 100 Cone Beam Computed Tomography (CBCT) were analyzed by the Imaging software for 3D images, i-Dixel 2.0. The considered parameters have been the presence (i), the calibre (ii), the dorso-ventral length (iii) and the craniocaudal distance evaluated from the alveolar crest/root apex to the anastomosis (iv) of the vessels. The data have been processed evaluating Means, Standard Deviations and verifying them by T-Student test. The statistical outputs showed that the $38 \%$ of samples presented the intraosseous anastomosis. These anastomosis resulted long in dorso-ventral direction, both on left $(12,55 \pm 4,3 \mathrm{~mm})$ and on right side $(12,4 \pm$ $4,3 \mathrm{~mm}$ ). The mean cranio-caudal distance resulted $15,71 \pm 5,08 \mathrm{~mm}$ on the left and 14,73 $\pm 4,74 \mathrm{~mm}$ long on right side. The calibre measurements resulted quite big as well: $1,68+0,3 \mathrm{~mm}$ on the left and 1,54+0,38 $\mathrm{mm}$ on the right. The differences between the right and left sides were found not statistically significant. The principal surgical technique used in this region is the sinus floor lift procedure, with a lateral approach. In this procedure, the knowledge of the vascular supply of this region is mandatory, to avoid unwanted hemorrhagic complications and to guarantee a good vascularization for the grafted material. This in vivo investigation shows how a knowledge of the maxillary sinus vascular supply is essential during the programming phase of surgical intervention, in order to prevent abnormal bleeding and big hematomas in this region.

\section{PROCURACIÓN DE CADÁVERES:}

\section{PROGRAMAS, MODALIDAD Y OBSTÁCULOS} - SITUACIÓN INTERNACIONAL

Susana N. BIASUTTO ${ }^{1}$ (Coordinadora), Bernard J. MOXHAM $^{2}$, Keiichi AKITA ${ }^{3}$, Jennifer McBRIDE ${ }^{4}$, Namita SHARMA ${ }^{5}$, Mirna D. BARROS ${ }^{6}$

${ }^{1}$ Universidad Nacional de Cordoba, Cordoba, Argentina; ${ }^{2}$ Universidad de Cardiff, Cardiff, Reino Unido; ${ }^{3}$ Universidad de Medicina y Odontología de Tokio, Tokio, Japón; ${ }^{4}$ Cleveland Clinic, Cleveland, Ohio, Estados Unidos de Norte América; ${ }^{5}$ Facultad y Hospital de Odontología Bharati Vidyapeeth, Pune, India; ${ }^{6}$ Escuela de Ciencias Médicas de la Santa Casa, San Pablo, Brasil

En el Debate publicado en los números 2 y 3 del Volumen 6 de la Revista Argentina de Anatomía Clínica ha quedado bien establecida la importancia que se le asigna al material cadavérico para la docencia e investigación en Medicina. Independientemente de la utilización de variados recursos y la más alta tecnología, el cadáver humano continúa siendo un elemento insustituible para el estudiante de Medicina $y$, en general, de las Ciencias de la Salud. Sin embargo, en muchos países, entre los que nos incluimos, al igual que la mayoría de Sudamérica, Asia y África, la disponibilidad de cadáveres humanos en las Cátedras de Anatomía ha disminuido a niveles preocupantes. Los participantes de la Mesa Redonda, 
provenientes de variados países y continentes, expondrán sobre las características particulares que adquiere la procuración de cadáveres en sus respectivos lugares. La exposición, especialmente orientada hacia los programas de donación de cadáveres, las facilidades y obstáculos que afrontan, nos permitirá comprender cómo las características religiosas, étnicas y culturales de cada sociedad influyen en este aspecto de la enseñanza. Por otro lado, los países que han desarrollado durante décadas sus programas de donación en forma exitosa, exhiben condiciones de trabajo y recursos cadavéricos envidiables para aquellas comunidades cuyos programas son recientes o inexistentes. Las leyes de donación de material cadavérico humano para la docencia e investigación en Anatomía son un recurso invaluable siempre que estén bien reglamentadas e instrumentadas, a fin de garantizar su objetivo y evitar abusos. Esperamos que se genere un rico intercambio con el público que contribuya a nutrir el debate sobre este tema y que contribuya para incentivar el desarrollo de programas locales y el trabajo sobre una ley nacional de donación.

\section{TERMINOLOGÍA ANATÓMICA MEDIEVAL Y ACTUAL: LA ESCUELA DE TRADUCTORES DE TOLEDO}

José L BUENO-LÓPEZ ${ }^{1}$, Luis A ARRÁEZ-AYBAR ${ }^{2}$

${ }^{1}$ Departamento de Neurociencias, Facultad de

Medicina y Odontología, Universidad del País Vasco

(UPV/EHU), Leioa (Vizcaya), España, ${ }^{2}$ Departamento

de Anatomía Humana y Embriología, Facultad de

Medicina, Universidad Complutense de Madrid, Madrid, España

La terminología anatómica está compuesta en Latín. Pero tanto sus voces como el Latín en el que estas están escritas son históricamente recientes. En el Renacimiento, los anatomistas quisieron depurar el Latín medieval y retomar el elegante Latín clásico. Antes del Renacimiento la denominación minuciosa de las partes del cuerpo humano integró voces de diferentes lenguajes. De todos es conocido que en el período greco-romano los materiales filosóficocientíficos fueron escritos principalmente en Griego. Los escritos greco-romanos pasaron después al Siriaco y al Árabe clásico. El Árabe clásico y el Hebreo arabizado medieval recogieron además el crecimiento del saber médico-anatómico producido en Oriente Medio y parte de la Península Ibérica. Este conjunto de conocimientos pasó inevitablemente por traducciones y finalmente fluyó al Latín medieval europeo. En este último paso, las traducciones hechas en Toledo en los siglos XII-XIII fueron sobresalientes. Los traductores eran parte de la Juventus mundi venida de toda Europa atraída por la accesibilidad a las fuentes del saber que había en Toledo, por causa de la tolerancia entre culturas promovida por los gobernantes políticos y religiosos del Reino de Castilla durante los siglos XII-XIII. El conjunto de traductores es conocido como la Escuela de Traductores de Toledo. Al volver a sus países de origen, traductores y eruditos todos contribuyeron a diseminar el saber adquirido. En Toledo, Gerardo de Cremona tradujo el Canon de Avicena, la obra clave de la medicina de la Edad de Oro Islámica. Alberto Magno, Mondino de
Luzzi y Guy de Chauliac, los principales autores de voces anatómicas en Latín medieval, basaron sus libros en las traducciones de Gerardo. Pero toda traducción es peliaguda. Más si atañe a conocimientos difíciles de adquirir y no fácilmente visibles. En ocasiones, Gerardo desconocía gran parte de la materia traducida - la disección de cadáveres humanos faltó largamente o no estuvo al alcance de todos; las ilustraciones anatómicas detalladas aparecieron con el Renacimiento. El propósito de la presente comunicación es renovar la atención sobre la principalísima influencia que la Escuela de Traductores de Toledo ha tenido en la terminología anatómica. Verbigracia, términos traducidos/acuñados por Gerardo mantuvieron su ascendencia hasta el Renacimiento y en ocasiones más acá. Así, voces inventadas por él, como diafragma, orbita, pupila o sagittal, son hoy relevantes. También se produjeron equívocos: revisaremos la curiosa onomástica de otras voces anatómicas de Gerardo de Cremona (additamentum; rostrum corvi; [costae] falsae; [os] femoris/coxae/pubis; panniculus; spondylus; sutura cortical; pectus; cartilago eppiglotale...).

\section{ANATOMY, RESEARCH AND TRAINING IN ORTHOPEDIC SURGERY}

\author{
Fabrice DUPARC
}

Anatomy, Orthopedic and Traumatology Department, Rouen University, France

The place of the Laboratory of Anatomy is essential for the future orthopedic surgeon and for the graduated surgeon. As Professor of Anatomy and Orthopedic surgeon, but also through expertises, it appears that lack of knowledge in Anatomy and biomechanics is related to difficulties for clinical examination and for understanding the medical imaging, to delayed diagnosis or wrong decision, to per-operative risk and iatrogenous complications, and to increased cost of cares. Our aim, with the French College of Anatomists and the French College of Orthopedic and Trauma Surgeons, was to try to reinforce the ability of the pregraduate and postgraduate surgeons in Anatomy. This involved the basics in Anatomy, for medical students and residents, the research for residents and fellows, and the training for all levels of learning and practice. At each level, the evaluation must be considered. The basics in Anatomy: what do we need to teach, and to whom? The medical student needs to be able to examine the complete human body, to understand the basics of biomechanics. If he wants to specialize as resident in bone and joints surgery, he must complete his knowledge, and be aware about muscles and nerves. The peripheral nervous system is one of the weaker points of the future surgeons. A recent survey showed they were also very interested in anatomical variations, and especially in trauma surgery. Which level can we require for residents in Anatomy? For becoming fellows, the residents need to defend reports for specialization and medical thesis. The research becomes very important, and may be fundamental and/or translational research. The fellows are more and more hyperspecialists in specific fields. The training does not only concern the technical ability, but also the evaluation. As they are in charge of the residents, they should be able to teach anatomy. 
Which level can we require for fellows in Anatomy? The post graduate surgeon has to face a double requirement: maintaining the level of knowledge in Anatomy, developing new techniques, new approaches, new implants. The intra-articular anatomy is of great importance due to the arthroscopic and endoscopic procedures, and needs to be teached. All the levels of training, from the beginning to the continuous graduation, need to be evaluated in Anatomy: is it the responsibility of the anatomists?

\section{ANATOMICAL VARIATIONS: WHICH PLACE IN SCIENTIFIC PUBLICATIONS?} Fabrice DUPARC

Laboratory of Anatomy, University of Rouen, France. Surgical and Radiologic Anatomy, Springer

Submissions of manuscripts about anatomical variations are quite frequent. Conversely, the place for publishing articles becomes more and more reduced, due to the increasing number of manuscripts. These variations were seen during dissection courses, or in clinical practice (preoperative) or on medical imaging. The management of these manuscripts is quite time consuming for the editorial activity: For the editorial board: A submitted manuscript about anatomical variation will follow the same procedure as any manuscript: an associate editor will invite 2 or 3 reviewers for giving their comments. This represents a constant rate of manuscripts: $27.5 \%$ in $2010,28.4 \%$ in 2014 , and $25.6 \%$ in 2015 . $70 \%$ to $87 \%$ have been rejected at the time of original submission, $13 \%$ to $30 \%$ needed revisions. The presentation is not adapted in about $62 \%$ of the submitted manuscripts, with no respect given to the Instructions for Authors. In the whole manuscript, it should be avoided to use "anomalous", but "variant" of "unusual". It should be avoided:" this is the first report..." no one can be sure that he has read all the books and all the journals in all the languages from all countries. The contents: the main reason of immediate rejection is "well known variation..." It shows a lack of studying the literature (or missing access?), through journals but also textbooks. It may also show a lack of diffusion of the anatomical knowledge and culture. For the journal: This is not a scientific argument, but publishing articles about anatomical variation will not lead to a better Impact Factor, because these articles will not be cited, or not two years after their publication. For the authors: in a report during competition for a new position: a detailed counting will not take the publications about variations at the same level as original articles of research. Conclusion: Anatomical variations are part of the anatomical knowledge and culture. New anatomical variations are still possible to describe, but they wil become more and rarer. They need to be published, with an easy and fast access. Numeric supports are quite adapted, through journals websites or direct websites about variations.

\section{BASES ANATÓMICAS DE LA ECOGRAFÍA EN TRAUMA}

María Soledad FERRANTE

$3^{a}$ Cátedra de Anatomía, Facultad de Medicina, U.B.A.; Servicio de Cirugía General, Hospital Aeronáutico Central. Buenos Aires, Argentina
La ecografía es un método diagnóstico por imágenes obtenidas por la acción de pulsos de ondas ultrasonográficas, y mediante el procesamiento de los ecos reflejados por las estructuras del cuerpo. La anatomía ecográfica se basa en el reconocimiento de la anatomía y la ecogenicidad, siendo esta última el patrón que tiene un órgano a la visualización ecográfica. El conocimiento anatómico y la disponibilidad de un método diagnóstico rápido, hacende la ultrasonografía una herramienta muy valiosa a la hora de la toma de decisiones quirúrgicas en trauma debido a la gran disponibilidad de dispositivos portátiles que facilitan la identificación temprana de lesiones que ponen en riesgo la vida del paciente, de manera no invasiva en comparación con otros métodos diagnósticos. En sus inicios, el examen se enfocaba en el abdomen, y así se denominó FAST (Focused Abdominal Sonogram for Trauma); el cual se comenzó a utilizar en los programas de "Apoyo Vital Avanzado en Trauma" (Advanced Trauma Life Support - ATLS American College of Surgeons) y se amplió su definición a Evaluación Enfocada por Ecografía para el Paciente con Trauma (Focused Assesment with Sonography for Trauma). La técnica del FAST se define como una ecografía en tiempo real de distintas regiones del cuerpo que se definen como "las 4 P": Pericárdico, perihepático, periesplénico y pélvico, en la búsqueda de líquido libre. La secuencia del examen es variable, pudiendo comenzar por la exploración del pericardio o de la región perihepática. Según diferentes estudios, en el FAST pueden visualizarse cantidades desde $250 \mathrm{cc}$. Así, ante la presencia de pacientes hemodinámicamente inestables, el FAST (+) sugiere hemoperitoneo, con lo cual le sigue la laparotomía exploradora; ante un FAST (-), se deberán descartar otros sitios de sangrado; y ante pacientes hemodinámicamente estables con FAST (+), se deberá realizar una TAC de abdomen para determinar las características de las lesiones. La extensión del protocolo FAST a EXTENDED-FAST (EFAST - Extended Focused Assessment with Sonography for Trauma) fue desarrollada para ampliar la evaluación del pericardio y del abdomen al tórax, permitiendo el diagnóstico de aquellas patologías pleuropulmonares (hemotórax y neumotórax) no incluidas por este método anteriormente. Debido a que la ultrasonografía es un método operador dependiente, para su utilización es importante el entrenamiento técnico constante de los médicos de Emergencias, pero es fundamental el conocimiento anatómico del área a estudiar ya que su aplicación en la interpretación de imágenes obtenidas por ultrasonografía permite disminuir notablemente la morbilidad del paciente politraumatizado.

\section{LA COMPRENSIÓN DE LA ANATOMÍA ES UN ASUNTO DE MANEJO DEL LENGUAJE Carlos A. FLORIDO CAICEDO \\ Departamento de Morfología de la Universidad Nacional de Colombia, Bogotá, Colombia}

Más que un asunto de memoria, la comprensión y el aprendizaje de la anatomía humana es un problema de manejo de lenguaje. Siempre se ha dicho que el estudio de la anatomía es un ejercicio para la memoria; de ahí que sea tal vez esta y ninguna otra la 
disciplina médica en la que más se utilizan las llamadas mnemotecnias. El más importante aporte que se hizo a la anatomía humana durante el siglo $X X$ sin duda fue la Nómina Anatómica, con la que se pretendió unificar el lenguaje anatómico, estandarizarlo y facilitar el estudio de esta ciencia, adscribiéndolo a un idioma, eliminando los epónimos y dando a las estructuras nombres lógicos. La importancia del lenguaje anatómico no sólo radica en que facilita el entendimiento de la morfología del cuerpo humano sino en que por la vía del currículo oculto, se convierte en el primer contacto con el lenguaje médico que será el que utilizará el resto de su vida profesional. El conocimiento, el manejo y el dominio del lenguaje anatómico, comienzan el primer día de clase cuando los estudiantes se enteran de la posición anatómica y de los términos anatómicos de posición y de movimiento. Esta sin duda, es su lección más importante.

Bibliografía:

Real Academia Española. Asociación de academias española de la lengua. 2010. Nueva gramática española. Ed. Planeta. Bogotá..

Vivaldi G, Sánchez P. 2011. Curso de redacción. Teoría y práctica de la composición y del estilo. 33a Ed. Cenage learning. Mexico D.F.

Feneis H., Wolfang D. 2006. Nomenclatura anatómica ilustrada $5^{a}$ Ed. Elsevier Masson. Barcelona.

Reyes J., Núñez C. 1988. Nomenclatura anatómica internacional. Editorial médica panamericana, Facultad de Medicina Universidad Nacional Autónoma de México. México D.F.

\section{EL SISTEMA LÍMBICO - ESTRUCTURA, CONEXIONES Y SÍNTESIS FUNCIONAL - CONCEPTOS DE ACTUALIDAD Y APLICACIONES CLÍNICAS}

\section{Germán FORERO BULLA}

Servicio de cirugía de nervio periférico y tratamiento quirúrgico del dolor. Hospital San José Infantil;

Cátedra de Morfología. Universidad Militar Nueva Granada. Bogotá, Colombia

El Sistema Límbico, o mejor el Área límbica comprende una serie de estructuras del encéfalo que se interrelacionan para intervenir decisivamente en múltiples funciones nerviosas: regulación de la actividad vegetativa del organismo, rotulo emocional de los diferentes estímulos, influencia en el interés, la motivación, la memoria y obviamente en el aprendizaje. En vista de que su influencia sobre otras partes del Sistema Nervioso es determinante para la conducta normal de los seres humanos, hoy se acepta que gran parte de las enfermedades psiquiátricas tienen que ver con la disfunción grave o sutil de su integridad. En la actualidad el concepto de Sistema Límbico desborda de lejos la idea primitiva de lóbulo límbico, cuya anatomía ha sido ampliamente estudiada y comprende un conjunto más amplio de estructuras relacionadas. Desde el concepto simple de áreas funcionales del cerebro, formadas por la agrupación de neuronas encargadas de hacer el mismo trabajo, y de la interrelación de las mismas a través de complejos fascículos, debe comprenderse como se construye una verdadera red límbica que a su vez esta extensamente comunicada con otras áreas del sistema nervioso. Dentro de esta red se deben destacar algunos componentes como el hipotálamo, que además de estar integrado dentro de los circuitos límbicos, constituye una importantísima estructura efectora del sistema para actuar sobre el medio interno y coordinar las respuestas periféricas del organismo en relación con las emociones. Se establecerán utilizando datos obtenidos de la experimentación clínica conceptos modernos en relación con la función de áreas como la formación hipocampal, a la cual se le había asignado un papel importante en relación con las conductas emocionales y motivacionales y hoy se acepta su papel fundamental para la denominada Memoria explicita o declarativa, además con base en los mismos experimentos, hoy se sabe que la formación del hipocampo lo que permite es captar datos nuevos y retenerlos por un tiempo, siendo además muy importante en la orientación espacial. Estos avances en el conocimiento del sistema han permitido realizar una planeación, mucho más precisa para los abordajes en Neurocirugía, ya que aunque si bien es cierto que el concepto de áreas "silenciosas y elocuentes" sigue vigente, también lo es el hecho de que se prefiere planear una aproximación segura y lo más inocua posible en el tratamiento quirúrgico de lesiones del sistema nervioso.

\section{SURGICAL TRAINING WITH LAPAROSCOPIC TECHNIQUES IN EMBALMED HUMAN CORPSES \\ Joao E. GOYRI-O'NEILL ${ }^{1}$, Novo MATOS ${ }^{2}$, Diogo PAIS $^{1}$ \\ ${ }^{1}$ Anatomy, New Medical School, FCM-UNL; ${ }^{2}$ HCLC. Portugal \\ Maintaining the regular practice of cadaveric dissection} has always been one of the main issues, since the foundation of the Anatomy Department of the Faculty of Medical Sciences in Lisbon. This implies the commitment to develop and improve new cadaveric conservation techniques, the careful maintenance and amplification of the list of donators, and the regular training of dissection skills by the staff. The Anatomy Department of the New University of Lisbon is well equipped to receive and conserve every cadaveric donation and the "Lisbon Dissection Room" is well equipped to receive several working stations simultaneously. In relation to undergraduate studies, the regular practice of annual cadaveric dissections is done with the participation of every student enrolled in the discipline of Anatomy. In terms of Post-graduation courses, the Anatomy Department has organized and prepared from 2009 to 2015, 14 by year.. All of our post-graduation courses are prepared, following strict standard ethical and legal premises according to European ruling laws. The human cadavers used for surgical training is obtained only from voluntary personal donations, after legalized personal consent. All of our post-graduation and hands-on surgical training courses are prepared and accredited according to the European Credit Transfer System, (E.C.T.S). We organize every year, since 2011 the "Human Cadaveric Advanced Laparoscopic Surgery Course - Training on Embalmed Cadaver". We give to all participants a theoretical monograph and a bibliography research plan. In addition, one month 
after they have three days of full practice on cadaver "hands-on", 8 to 9 hours by day. The participants are divided by three for tables and their practice is made under 6 experts supervision. All participants will be evaluated by a theoretical and practical final examination and must do an anonymous evaluation of the course. The classification of the course made by the participants must be very good/excellent to maintain the course next year. The addressers are last year residents of General Surgery and Gynecology and Surgeons. They made all kind of technical surgeries, namely cholecystectomy, Nissen fundoplication, right hemicolectomy, left hemicolectomy, sigmoidectomy, splenectomy, anexectomy, tubal ligature, total abdominal hysterectomy and radical pelvic lymphadenectomy. Our video shows our methodology of teaching all these techniques. This update post-graduated Course has 34 Presence Hours, 336 Workload and ECTS 12.

\section{OUR EXPERIENCE WITH THE INTRODUCTION OF THE CLINICAL ANATOMY INTO THE EDUCATION AND WITH OUR PROGRAM OF THE BODY DONATION} Zora HAVIAROVÁ

Institute of Anatomy, Medical Faculty, Comenius University, Bratislava, Slovakia

The history of our Institute of Anatomy (Faculty of Medicine, Comenius University, Bratislava, Slovakia) started in 1922, the first Slovak Head of Institue Prof. J.L.Ladziansky led the Institute in 1936-1943 years. In the past, the personal and scientific orientation of our Institute was more experimental. It was just from 2009 that we have started introduction of the clinical anatomy into the education of the anatomy more seriously, what was based due to the establishemnt of our nowadays Head of Institute (formerly a paediatric surgeon). The academic staff of our Instute now includes 1 professor, 4 assistant professors, 12 assistant lecturers and lecturers, 1 artist and 2 scientists. We educate annually mainly 300 Slovak students in General Medicine branch (teaching in 3 semesters) together with cca 200 English Programme and 40 Slovak Dentistry branch students (teaching in 2 semesters +1 semester of the Topographic Anatomy of Head and Neck) together with 40 English Programme Dentistry students. Prior to meet the various demands of the clinical colleagues for their cooperation with our Institute, the better conditions must be established on our Institute including a quite broad reconstruction (held in yrs. 2012-2014) with improving our technical equipment and also using of the THIEL's embalming method of human bodies (enabling realizations of anatomical-clinical workshops). For the undergraduate students of the 4th Year General Medicine branch we have prepared an new textbook (Topographical and Clinical Anatomy, now in print), which is planned to be implemented from the next academic year (together with the same subject). For the financial support of the Clinical Anatomy expansion on our Institute we have established the civic association VESALIUS. For the education of the human anatomy the real human bodies are essential, so the history of their obtaining lasts nearly from the beginning of the Institute. Nowadays we have actually 507 living donors, 37 bodies we have received in last 6 years, our exclusion criterias are HIV and TBC infections. The bodies are fixed by 2 embalming methods (standard formaline and THIEL's) - the decision to which embalming method the body will be submitted depends mainly on its BMI. Those embalmed with the standard formaline method are then used for the Anatomy undergraduate education: peripheral vessels and nerves, thoracic and abdominal cavities, CNS, muscles, bones. The bodies embalmed by Thiel method are used for the clinical workshops. The human remains are buried together with those from the University Hospital.

\section{OOCYTE AGING: SUBCELLULAR MORPHODYNAMIC}

Guido MACCHIARELLI ${ }^{1}$, S. BIANCHI ${ }^{1}$, Stefania A. NOTTOLA ${ }^{3}$

${ }^{1}$ Dept. of Life, Health and Environmental Sciences, University of L'Aquila, Italy; ${ }^{2}$ Dept. of Anatomy,

Histology, Forensic Medicine and Orthopaedics, University of Rome, Italy

Introduction: Delayed childbearing may contribute to the increasing number of subfertile couples recurring to assisted reproduction technology (ART). Deterioration of oocyte quality, due to reproductive aging, likely may cause subfertility. Prolonged culture, also called "in vitro aging", may damage oocyte functions. Indeed, we previously showed that oocyte ultrastructure integrity is essential for a positive ART outcome. In this study, we evaluated the ultrastructure of oocytes from aged women undergoing to ART procedures. Material and Methods: We used MII oocytes, from women, enrolled in this study after informed consent, under 35 and over 35 years old (assumed as age watershed) fixed at pick up (reproductive aging) or after $24 \mathrm{~h}$ culture (in vitro aging). We analyzed ultrastructural and morphometric data. Results: Transmission electron microscopy showed several subcellular changes especially in oocytes from aged women and subjected to prolonged culture, as compared to young, fresh oocyte. These changes mainly consisted in increasing of vacuoles, decreasing of mitochondria-smooth endoplasmic reticulum aggregates, increasing of mitochondriavesicle complexes density, decreasing of cortical granules and microvilli, as well as various alterations of zona pellucida. Discussion: The above subcellular alterations typically reflect an impairment of oocyte developmental competence. Therefore, our data demonstrated that aging affects oocyte quality parameters and that the oocytes from younger women are less sensitive to prolonged culture (in vitro aging) than the oocytes from aged women. Key words: oocyte, aging, human, ultrastructure

\section{FUNDAMENTOS ANÁTOMO-FUNCIONALES DE LOS DEFECTOS DE LA PARED ABDOMINAL \\ Carlos MEDÁN \\ Hospital Naval; $2^{a}$ Cátedra de Anatomía, Facultad de Medicina, U.B.A.; Universidad Nacional de José C. \\ Paz; Universidad Nacional de Tres de Febrero. Buenos Aires, Argentina.}

La pared abdominal constituye no solamente el soporte del contenido visceral sino que cumple importantes funciones en la evacuación, la tos, el 
vómito, el parto. Interviene en la mecánica de la respiración, sirviendo de apoyo al diafragma en la inspiración y actuando activamente en la espiración. Los defectos anatómicos como las hernias y los post quirúrgicos como las eventraciones generan importantes cambios en la fisiología de la pared que deben ser tenidos en cuenta a la hora de su reparación. Se describen los recursos con que cuenta el cirujano para reparar estos defectos restableciendo una funcionalidad adecuada.

\section{PARÁMETROS ANATÓMICOS PARA DEFINIR LA ESTADIFICACIÓN Y RESECABILIDAD DE LAS NEOPLASIAS CERVICALES}

\author{
Blás A. MEDINA RUÍZ
}

Instituto Nacional del Cáncer del Paraguay; Cátedra

de anatomía descriptiva y Topográfica, Fac. de

Ciencias Médicas de la Universidad Nacional de Asunción. Paraguay.

La estadificación es un paso trascendental en el manejo de los pacientes oncológicos, pues además de determinar el pronóstico de los mismos, posibilita unificar criterios terapéuticos y de seguimiento intra e interinstitucional. Esta estadificación considera tres parámetros, en primer lugar el tamaño y penetración tumoral $(T)$, en segundo lugar la presencia de metástasis regional, manifestada en el compromiso linfonodal del cuello $(\mathrm{N})$ y por último la diseminación a distancia (M). Los dos últimos, toman en cuenta criterios semejantes para casi todos los tumores del área, con la excepción de los cánceres originados en la rinofaringe y en la glándula tiroides, mientras que el $\mathrm{T}$ depende de las características propias del sitio primario en que se origina el proceso, aunque en líneas generales tampoco existe marcadas diferencias entre éstos. La evaluación del $\mathrm{T}$ y del $\mathrm{N}$, de manera protocolizada, se fundamentan en un examen físico e instrumental del área de la cabeza y el cuello, mientras que el parámetro $\mathrm{M}$ requiere indefectiblemente de métodos auxiliares de diagnóstico. Así, la tomografía (TC) tórax con contraste endovenoso es un estudio por imágenes que debe ser tenido en cuenta $y$ estudiado minuciosamente. En los últimos años va adquiriendo mayor valor el PET-Scam. Si bien la evaluación por imágenes del $\mathrm{T}$, hasta el presente no modifica el estadiaje, es de suma utilidad para determinar la penetración del tumor a estructuras adyacentes y por lo tanto determinar las secuelas estéticas y funcionales de una resección quirúrgica. Tanto la tomografía computada como la resonancia nuclear magnética, en mayor medida, ayudan en este sentido. Los criterios de irresecabilidad del $\mathrm{T}$, el compromiso de la arteria carótida interna y de la fascia prevertebral pueden ser determinados por estos métodos, y estadifican al T como T4b. Por otro lado, la tomografía con contraste endovenoso, permite individualizar el compromiso linfonodal del cuello, aún en aquellos pacientes sin adenopatías palpables, es decir en cuellos N0. Esta situación tampoco modifica el estadiaje, sin embargo permite no solo hacer punciones guiadas para estudios citológicos sino que también ayuda a planificar el acto quirúrgico. La TC del cuello permite evaluar todos y cada uno de los niveles linfonodales y aquellos grupos no incluidos en los mismos, como los retrofaríngeos, parotideos u occipitales. Si bien no está aún contemplado en los protocolos de estadificación, es éste el componente, sobre todo cuando afecta a los niveles yugulocarotideos (niveles II, III y IV), el que determina muchas veces la irresecabilidad del proceso tumoral al englobar y comprometer a la arteria carótida interna. Se hace una revisión de los detalles anatómicos a considerar en estudios tomográficos del cuello en cuanto la estadificación y determinación de resecabilidad de los cánceres de cabeza y cuello.

\section{HOW DO WE KNOW WHAT ASPECTS OF GROSS ANATOMY TO TEACH TO OUR STUDENTS? CAN CORE SYLLABUSES FOR THE ANATOMICAL SCIENCES BE DEVELOPED AND ACCEPTED? \\ Bernard J. MOXHAM \\ Cardiff School of Biosciences, Cardiff University, United Kingdom}

There is increasingly a call for clinical relevance in the teaching of the biomedical sciences within all health care programmes. This presupposes that there is an understanding of what is "core" material within the curriculum. To date, the anatomical sciences have been poorly served by the development of core syllabuses, although there have been commendable attempts to define a core syllabus for gross anatomy in medicine and for some medical specialties. The International Federation of Associations of Anatomists (IFAA) and of the European Federation for Experimental Morphology (EFEM) aims to formulate, on an international basis, core syllabuses for all branches of the anatomical sciences. This is being undertaken at the initial stage using Delphi Panels consisting of a team of anatomists, scientists and clinicians who evaluate syllabus content and accord each element/topic "essential", "important", "acceptable" or "not required" status. Their initial conjectures, published on the IFAA website, provide merely a framework to enable anatomical (and other cognate learned) societies and individual anatomists, clinicians and students to comment upon the syllabuses. Here is presented the concepts and methodological approaches underlying the hybrid Delphi process employed. Findings relating to the development of a neuroanatomy core syllabus are provided to illustrate the methods initially employed by a Delphi Panel. The approach is novel in that it is international in scope, is conceptually democratic, and is developmentally fluid in terms of availability for amendment. The aim is to set internationally recognized standards and thus to provide guidelines concerning anatomical knowledge when engaged in course development.

\section{EFFECTS OF CRYOPRESERVATION ON THE ULTRASTRUCTURE OF HUMAN OOCYTES IN ASSISTED REPRODUCTIVE TECHNOLOGY}

Stefania A. NOTTOLA ${ }^{1}$, Guido MACCHIARELLI ${ }^{2}$

${ }^{1}$ Department of Anatomy, Histology, Forensic Medicine and Orthopaedics, Sapienza University, Rome, Italy.

${ }^{2}$ Department of Life, Health and Environmental

Sciences, University of L'Aquila, L'Aquila, Italy Introduction: Oocyte cryopreservation protocols have not been fully optimized yet and overall clinical 
success remains suboptimal. Further experimental and clinical studies seem thus necessary in order to better understand the effects on human oocytes of all factors associated with freezing and to tailor the best protocol for human oocyte cryopreservation. Our aims were to evaluate and compare the ultrastructure of human mature oocytes frozen-thawed $(F / T)$ with either slow freezing or vitrification, with both closed and open systems. Material and Methods: The oocytes, obtained from consenting IVF patients, were fixed at sampling (fresh controls) and after freeze/thawing. Fresh and F/T oocytes were processed for light and transmission electron microscopy (LM and TEM) observations. Results: By $\mathrm{LM}$, both fresh and $\mathrm{F} / \mathrm{T}$ oocytes were generally rounded, 90-100 microns in diameter, provided with an ooplasm showing a uniform distribution of organelles and surrounded by an intact zona pellucida. By TEM, slight to moderate vacuolization was found in the cytoplasm of $F / T$ oocytes subjected to slow freezing. The oocytes vitrified with a closed device also might show slight vacuolization. On the contrary, vacuoles were, in general, only occasionally detected in F/T oocytes after vitrification with an open device and in fresh controls as well. Amount and density of cortical granules (CGs) appeared abnormally reduced in F/T oocytes, irrespective of the protocol applied (slow freezing or vitrification). Discussion: In conclusion, a) the cryopreservation protocols currently in use, ensure a good overall preservation of the oocyte; b) however, vacuolization appears persistently as a recurrent form of cell damage during slow freezing and, at a lesser extent, during vitrification using a closed device; the quasi absence of vacuoles seems instead the most relevant marker of quality in oocytes vitrified with an open device; c) premature CG exocytosis during cryopreservation seems a non-specific, ubiquitous phenomenon occurring during freeze/thawing suggesting the appropriateness of the use of ICSI as the preferred insemination method after cryopreservation. Key words: oocyte, cryopreservation, human, ultrastructure

\section{SIMULADORES CADAVÉRICOS PARA ADQUIRIR DESTREZAS EN CURSOS DE ESPECIALIDADES MÉDICAS} Eduardo OLIVERA

Universidad de la República, Montevideo, Uruguay

La medicina en las últimas décadas ha avanzado más rápidamente de lo que cualquiera se hubiera podido imaginar. Basta hablar del trasplante de órganos, la cirugía laparoscópica o las nuevas tecnologías que cada vez más vertiginosamente se incorporan. Este desarrollo trae aparejado la adquisición de destrezas o la realización de nuevas técnicas para lograr un mejor resultado en los diferentes tratamientos. Por otra parte, razones éticas nos imponen que la curva de aprendizaje no sea realizada a expensas de mayores complicaciones en nuestros pacientes. En este contexto es que la posibilidad de realizar el aprendizaje en simuladores se hace parte vital para acreditarnos en un determinado procedimiento. La industria de la simulación nos ha invadido con diferentes modelos inanimados, digitales y robóticos, pero a un alto costo para nuestras economías. De todas maneras, aún no se logra con ellos reproducir las características de los órganos humanos, es por ello que aún hoy a nivel Internacional continúan siendo los cursos con prácticas cadavéricas de gran interés y alta concurrencia. Mostramos nuestra experiencia en el desarrollo de cursos de Especialización de diferentes áreas utilizando modelos cadavéricos. Los mismos presentan un fuerte componente de enseñanza de la anatomía normal y la aplicación de su conocimiento para lograr los objetivos de aprendizaje estipulados. Se adecúa el número de cadáveres o piezas especialmente preparadas para la práctica de las técnicas a desarrollar según los objetivos planteados y el número de participantes.

\section{CAUSAS EXTRAUTERINAS DE SANGRADO OBSTÉTRICO GRAVE}

José M PALACIOS JARAQUEMADA

$1^{a}$ Cátedra de Anatomía, Facultad de Medicina U.B.A., Buenos Aires, Argentina

La atonía o inercia uterina es la principal causa de sangrado uterino postparto. En ella, la falta de contracción uterina mantiene el sangrado continuo por el lecho placentario, hecho que predispone a la coagulopatía siendo la principal causa de histerectomía postparto. En segundo lugar, los trastornos adherenciales placentarios son causa reconocida de sangrado. Su asociación con a operación cesárea hace que su incidencia haya aumentado notablemente. Sin embargo, existen otras causas menos frecuentes aunque potencialmente graves de hemorragia postparto no relacionadas con el útero. Este tipo de hemorragias suelen originarse por debajo de la reflexión peritoneal e incluyen el tracto reproductivo inferior y elementos del piso pelviano, tales como las lesiones en el músculo elevador del ano y la túnica muscular de la vagina. Los hematomas puerperales suelen ser autolimitados, de origen venoso y poco frecuentes. Cuando esto no es así, pueden producir inestabilidad hemodinámica, hemorragia oculta e incluso la muerte. Uno de los principales problemas es su detección, ya que suelen ser muy difíciles de diagnosticar por ecografía, especialmente porque suelen extenderse al retroperitoneo. Clínicamente no dan manifestaciones evidentes, tales como una hemorragia vaginal o hematomas externos. Esto produce una espera terapéutica que puede resultar contraproducente a corto y mediano plazo. Hay una disociación clínica, ya que existe un shock hipovolémico de causa no determinada. Si el sangrado es producido por una lesión arterial es común episodios de hipotensión y descompensación cada 2 a 4 horas. Si bien la arteriografía puede ser diagnóstica y terapéutica, debe tener la precaución de explorar la rama posterior de la arteria ilíaca interna. Muchas veces esto no sucede, ya que se supone que todos los vasos colaterales al útero y vagina son originados de la divsión anterior de la arteria ilíaca interna, hecho que es incorrecto. Incluso cuando el diagnóstico arteriográfico pueda evidenciar el sitio de sangrado, el cateterismo específico sule ser dificultoso y no siempre efectivo. Muchos casos evolucionan al shock hipovolémico ante la imposibilidad de acceder al sitio de sangrado. Sin embargo, el acceso a través del espacio de Retzius permite 
acceder fácilmente a la vagina media, inferior y también al músculo elevador del ano. Este acceso suele ser desconocido y no incluido en los programas de entrenamiento. Por este motivo, se explica su anatomía específica marcando el acceso a los elementos viscerales, vasculares así como su abordaje anatómico.

\section{EL CLAUSTRO: EXTENSAMENTE COMUNICADO CON LA CORTEZA CEREBRAL PERO TODAVÍA OSCURO Y ELUSIVO}

Concepción REBLET, José L BUENO-LÓPEZ

Departamento de Neurociencias, Facultad de

Medicina, Universidad del País Vasco (UPV/EHU), Leioa (Vizcaya), España

El claustro está ubicado entre la corteza cerebral insular y el putamen. El claustro se extiende ventralmente en el lóbulo piriforme, ventral y lateralmente a la sustancia perforada anterior y la amigdala. Algunos autores han afirmado que el origen neuroepitelial del claustro es similar al cortical, mientras que otros favorecieron la similitud con el estriado. Este debate empezó en el Siglo XIX y continuó en el Siglo XX. Numerosos trabajos experimentales han aportado luz a esta cuestión en los últimos años. En nuestro laboratorio hemos estudiado el desarrollo del claustro del conejo bajo diferentes enfoques: locus neuroepitelial originario, tiempos de generación neuronal y citoquímico. Vista con marcado anti-vimentina, la glía radial anclada en el neuroepitelio lateroventral atraviesa el claustro adyacente para alcanzar la corteza palial lateroventral. La aparición de la expresión inmunocitoquimica de las proteínas ligadoras de calcio calbindina y calrretinina coincide temporalmente en células precursoras del neuroepitelio lateroventral y en jóvenes neuronas del claustro y la corteza radialmente adyacentes. Además, hemos mostrado que la proporción de neuronas GABAérgicas es similar en el claustro adulto respecto de la corteza cerebral pero muy distinta respecto del estriado. Estos trabajos nos permitieron concluir, en concordancia con estudios genéticos de otros en el ratón, que el claustro procede del neuroepitelio palial lateroventral, pero no de las eminencias gangliónicas. En el conejo adulto hemos mostrado además mediante inyecciones de trazadores retrogrados y anterógrados que el claustro tiene conexiones recíprocas y topográficas (grosso modo) con la mayoría de las áreas neocorticales y alocorticales. La conectividad del claustro con áreas cingulares es especialmente relevante tanto en el conejo como en otras especies. Existen dos tipos de neuronas corticales de proyección córtico-claustral: células piramidales de las capas 5 y 6 y células invertidas espinosas de la capa 6. En esta comunicación discutiremos la implicación de estas dos poblaciones de neuronas córtico-claustrales en relación con los circuitos córtico-corticales y córtico-estriados. Nuestros estudios con inyecciones de biocitina en el claustro del conejo nos permitieron mostrar además como primicia la diferencia morfológica existente entre los axones claustro-corticales en áreas visuales y cingulares. Los segundos son más gruesos, más ramificados y con mayor número de botones sinápticos. La especial relación del claustro con áreas límbicas nos hace pensar que el claustro interviene en la modulación de las redes corticales implicadas en respuestas rápidas ante señales relevantes. En la presente comunicación también discutiremos las semejanzas y diferencias entre el claustro y la amígdala en las redes corticales.

\section{HISTOLOGIA CLINICA: TUMORES DE GLANDULAS SALIVALES}

María E. SAMAR

Cátedra A de Histología y Embriología, Facultad de

Odontología. Universidad Nacional de Córdoba, Argentina

Las glándulas salivales son el sitio de un amplio espectro de tipos histológicos de tumores benignos y malignos poco comunes que representan menos del $2 \%$ de todas las neoplasias humanas y entre el 2 y $6,5 \%$ de todos los tumores de cabeza y cuello. Forman el grupo tumoral con la mayor variabilidad histológica, citológica y estructural en patología neoplásica humana, con formas sorprendentemente variadas y múltiples. Una vez establecida la sospecha clínica y radiológica, el diagnóstico de certeza de una neoplasia salival requiere el estudio directo del tejido tumoral obtenido mediante biopsia o resección quirúrgica. El tumor salival maligno más frecuente es el carcinoma mucoepidermoide. Este tumor fue descrito por primera vez por Stewart et al, en el año 1945. La Organización Mundial de la Salud lo define como una neoplasia epitelial glandular maligna con células mucosas, epidermoides e intermedias, células columnares, claras y rasgos oncocitoide. Su aspecto microscópico depende de su grado histológico de diferenciación: grados de malignidad bajo, intermedio y alto. En el carcinoma mucoepidermoide de bajo grado de malignidad predominan las áreas quísticas con mucocitos bien diferenciados y secreción de mucinas. Los tumores de grado intermedio presentan menor contenido de mucinas y sus tipos celulares son semejantes al carcinoma mucoepidermoide de bajo grado de malignidad. En cuanto al tumor de alto grado de malignidad, presenta células anaplásicas, mitosis atípicas y nidos con células PAS reactivas aisladas. Aproximadamente un $60 \%$ de los casos se diagnostica en las glándulas salivales mayores y un $35 \%$ en las glándulas menores. El carcinoma mucoepidermoide de glándulas salivales menores es más común en el paladar, debido a la alta concentración de esas glándulas, particularmente en la unión de los paladares duro y blando. La mucosa bucal, los labios, el piso de la boca y la lengua también pueden verse afectados, pero en mucha menor frecuencia. En la presente comunicación destacaremos los factores pronósticos del carcinoma mucoepidermoide realizando su diagnóstico diferencial con otras neoplasias malignas y benignas y patologías congénitas de la lengua.

\section{THE EVOLVING PRIMATE MANDIBLE} Namita A. SHARMA

Bharati Vidyapeeth Dental College and Hospital, Pune, India

Tracing the lineage of modern man: The order "Primates" includes the taxonomic family Hominidae which incorporate the extant genera Homo, Pan, Gorilla, and Pongo, collectively forming the 'Great 
Apes'. Of these, since Homo and Pan evolved from the same tribe Hominini, they enjoy greater phylogenetic proximity as compared to genera Gorilla and Pongo. In fact, modern humans (Homo sapiens sapiens) and chimpanzees (Pan troglodytes) last shared a common ancestor as recently as 5-7 million years ago making chimpanzees our closest living evolutionary relative. Various fossil species of the genus Homo existed on the planet for variable time periods beyond the PanHomo divergence and their discovery and subsequent study provides a more holistic idea of the evolutionary processes that lead to the final emergence of the anatomically modern man. Further, despite all 'modern humans' being included within the same sub species of Homo sapiens, the various human populations that inhabit the world today demonstrate well defined morphological variations; and though globalization is increasingly evident and is resulting in breaking phylogenetic barriers, it is of recent onset and was preceded by centuries of cultural, regional and religion wise gene pools. It would thus not be amiss to contemplate the introduction of population clusters for the most evolved primate, based on genomic or phenotypic variability. Mandible as a possible pointer towards primate evolutionary trends; aim of this study: The human primate, in his most recent form, is distinct from other extinct or extant relatives by the ability for complex verbal exchange. Moreover, extra oral food processing, ubiquitous for modern man, has dramatically diminished the masticatory forces required. Thus, environmental influences resulting in sculpting the mandible to its present form would decidedly include dietary habits and verbal skills. While the former has resulted in evolutionary gracilization of the modern human jaw, it could not possibly effect variations within modern human ethnic clusters. Speech however, by virtue of the phonetics peculiar to each language, would result in subjecting the mandible to diverse sets of bio-mechanical stresses with an eventual manifestation of indigenous diversities of mandibular metrics. Thus, in this study, we compare the morphometrics of mandibles belonging to Chimpanzees (Pan paniscus and Pan troglodytes schweinfurthii) as against those of various geographically and ethnically distinct modern human clusters including specimens from India, Nigeria, Egypt and Spain. Some specimens of the Pampa and Chubut tribes of Argentina have also been included. Further, inter-ethnic data has been statistically analyzed and the results discussed.

\section{ENSEÑANDO A DIBUJAR Y PINTAR LA ANATOMÍA}

\section{Osvaldo VELÁN}

José M Parragón dice en su libro "Cómo dibujar la anatomía del cuerpo humano" que no se puede dibujar la figura humana sin haber aprendido anatomía jamás. En forma análoga podemos decir que no se puede aprender ( $\mathrm{y}$ agrego o enseñar) la anatomía humana sin haberla dibujado jamás. Nada más cierto entonces que por lo menos una parte de la medicina es ciencia y arte. El dibujo es una gran herramienta dentro de la educación. ¿Pero cómo lo incorporamos a la enseñanza y aprendizaje? Hay varios pasos: E primero, fundamental, es vencer la barrera de la autolimitación y repetir yo puedo porque dibujar como lo dice M Raya Delgado no es un don, es una habilidad que se adquiere como andar en bicicleta, leer o escribir. Luego, se deben incorporar la o las técnicas adecuadas recurriendo a la búsqueda bibliográfica y a la práctica. Betty Edwards con su libro aprender a dibujar con el lado derecho del cerebro que lleva varias ediciones y traducciones nos introduce en como utilizar las técnicas para el dibujo artístico y en el campo de la educación basándose en las diferentes funciones de los hemisferios cerebrales y su dominancia. Su lectura y la ejecución de los ejercicios que propone es una muy buena manera de introducirnos en el tema. Podemos agregar la técnica de la cuadrícula, utilizada desde el tiempo de los antiguos egipcios, que consiste en dividir cualquier dibujo en un cuadriculado como mosaicos, luego armamos otro cuadriculado y trasladamos el dibujo de cada mosaico repitiendo las líneas que lo componen y pintando las superficies que delimitan. Dibujar y pintar la anatomía le sirve al educador que utiliza solo lo esencial para la enseñanza eliminando lo superfluo o intrascendente. Dibujar y pintar la anatomía le sirve al estudiante porque está de acuerdo con su época en la que predomina la generación visual de estímulos y porque construye lo que está aprendiendo. Ambos se benefician con el saber hacer. Un curso para enseñar las técnicas básicas se puede armar con un mínimo de dos horas de actividad presencial y una hora de trabajo en el hogar. En nuestra institución se encuentra incluido dentro del programa de la materia optativa Formación de Ayudantes.

\section{SIGNIFICANCE OF USAGE OF NEW STEREOLOGICAL METHODS IN BIOLOGICAL RESEARCHES}

Ferruh YÜCEL

Department of Anatomy, Faculty of Medicine, Eskişehir Osmangazi University, Eskişehir, Turkey

Stereology is a technique that enables researcher to obtain data on the number of identifiable objects in a three-dimentional structure by sampling in two dimensions, and for the people studying with biological materials using stereological methods are absolutely essential. To reveal the effects of any agent on the different biological tissues of interest these techniques can be applied at cell levels of each biological organization from the organelle to the whole organ and can be employed to estimate number of particles, lengths, surface area and volumes. For precise and accurate estimation, different kind of images such as physical or optical sections, CT scans and MRI slices of a biological tissue must be sampled so as to be random in orientation and/or position. In modern scientific researches, it is imperative to use quantitative stereological design-based methods such as disector and fractionator for estimating partical number. To achive estimates of structural quantities in the interested tissue a systematic volume probe is used. While fractionator gives the total number of particles within an object, the disector yields numerical density $(\mathrm{Nv})$. Therefore, to reach the total number the obtained numerical density must be combined with reference volume of the tissue or organ estimated by Cavalieri methods. It is strongly recommended that component densities must be converted to absolute quantities before biological interpreations are made. Because numerical density is sensitive to volume of tissue. 


\title{
IV CONGRESO ARGENTINO DE ANATOMÍA CLÍNICA. I CONGRESO INTERNACIONAL DE ANATOMÍA CLÍNICA. XII CONGRESO DE LA SOCIEDAD ARGENTINA DE ANATOMÍA CLÍNICA. I SIMPOSIO DEL FORO ARGENTINO DE CÁTEDRAS DE ANATOMÍA Y CIENCIAS MORFOLÓGICAS
}

\author{
Buenos Aires, Argentina, 24 al 26 de Setiembre de 2015
}

\section{Presentaciones libres}

\section{BASES ANATOMO-QUIRÚRGICAS PARA EL ABORDAJE AL SISTEMA DE LA VENA CAVA INFERIOR \\ Rubén D ALGIERI ${ }^{1,2}$; María de las M BERNADOU ${ }^{1,2}$; Sebastián UGARTEMENDIA ${ }^{1,2}$; Nicolás AHUALLI ${ }^{1,2}$; Andrea SINNONA ${ }^{1,2}$; Carolina BROFMAN ${ }^{1,2}$. \\ ${ }^{1}$ III Cátedra de Anatomía. Facultad de Medicina. \\ Universidad de Buenos Aires. ${ }^{2}$ Servicio de Cirugía General. Hospital Aeronáutico Central. CABA.} Introducción: En trauma, las lesiones vasculares abdominales tienen un alto índice de morbi-mortalidad, siendo variable las de vena cava inferior $(\mathrm{VCl})$ según porción afectada. Para abordaje de lesiones de $\mathrm{VCl}$, se requiere su exposición anatómica en el retroperitoneo para lograr el adecuado control vascular. Material y métodos: Revisión bibliográfica de maniobras de abordaje de $\mathrm{VCl}$ e instrucción en material cadavérico formalizado al $10 \%$, a 12 médicos residentes de cirugía general. Se evaluaron las bases anatómicas de maniobras quirúrgicas para abordaje y control vascular de lesiones de $\mathrm{VCl}$ en material cadavérico fresco. Finalmente, se evaluó la simulación de maniobras quirúrgicas para abordaje de la $\mathrm{VCl}$ en modelos porcinos vivos. Resultados: 9 (75\%) identificaron correctamente las zonas del retroperitoneo en cadáveres formalizados; 5 (41.67\%) identificaron todas las estructuras anatómicas vasculares del retroperitoneo. En cadáveres frescos, 7 $(58.33 \%)$ reprodujeron satisfactoriamente la técnica de movilización visceral derecha, 4 (33.33\%) la movilización hepática completa, 11 (91.66\%) la exclusión vascular total hepática y $8(66.67 \%)$ el shunt atrio-cava. En porcinos, 8 (66.67\%) simularon satisfactoriamente la movilización visceral derecha; 6 (50\%) la movilización hepática completa; 11 (91.66\%) la exclusión vascular total hepática y 7 (58.33\%) el shunt atrio-cava. Discusión: Para el manejo y tratamiento de lesiones de $\mathrm{VCl}$ es necesario un intensivo entrenamiento mediante observación y disección cadavérica con reconocimiento de estructuras anatómicas, así como realización de maniobras en material cadavérico y en modelos porcinos vivos para su abordaje en el retroperitoneo, durante la formación del cirujano general.

\section{BASES ANATOMICAS DE PROCEDIMIENTOS BASICOS EN LA URGENCIA MÉDICA PARA AUXILIARES DOCENTES DE ANATOMIA \\ Rubén D ALGIERI; Juan P FERNÁNDEZ; Fabiana FRANCO ALANIS; Sofía CIPOLLONE; Nicolás AHUALLI; Ivana FATICA \\ III cátedra de Anatomía- Facultad de Medicina- UBA Servicio de Cirugía General- Hospital Aeronáutico Central. CABA \\ Introduccion: Los requerimientos en la enseñanza de} las ciencias de la salud, exigen a las instituciones educativas, la búsqueda permanente de nuevos recursos. Nuestra función como docentes es generar el aprendizaje conceptual y procedimental mediante la anatomía aplicada. Material y Métodos: clases teóricopracticas para 47 auxiliares docentes de anatomía de la III cátedra de Anatomía-Facultad de Medicina-UBA, durante un período de 2 meses, para la realización de maniobras básicas como la colocación de un tubo endotraqueal, una sonda nasogástrica, una punción cricotiroidea, una pericardiocentesis y el drenaje de un neumotórax hipertensivo. Luego se realizó una encuesta de evaluación de su utilidad. Resultados: de los 47 auxiliares docentes $9(19.15 \%)$ cursa $2^{\circ}$ año de la carrera, $8(17.02 \%) 3^{\circ}$ año, $13(27.66 \%) 4^{\circ}$ año, 10 $(21.28 \%) 5^{\circ}$ año, 7 (14.89\%) $6^{\circ}$ año. 38 (80.85\%) no tenían estos conocimientos previamente, mientras que $9(19.15 \%)$ si. De los 47 , solo $15(31.91 \%)$ realizan guardias, y de ellos 12 (80\%) pudieron aplicar estos conocimientos en las mismas. El 100\% respondió que les resultó útil la realización de las clases teórico- 
prácticas y todos ellos (100\%) lo aplicarian en las clases con sus alumnos. Discusion: La anatomía humana se estudia en el primer año pero su utilización debe ser recordada para la realización de maniobras médicas básicas. De aquí se desprende el concepto de biosimulación, que mediante la utilización de material cadavérico, permite abordar diferentes situaciones de aprendizaje, brindando el mayor grado de realismo posible.

\section{BASES ANATOMICAS Y SIMULACION EN LA EDUCACION DE RESIDENTES DE CIRUGÍA GENERAL PARA EL CONTROL DEL PEDICULO PULMONAR}

Rubén D ALGIERI; Cristian A FLORES; Fabiana

FRANCO ALANIS; Gustavo M VASSIA; Humberto INSFRAN; Ivana FATICA

Servicio de Cirugía General. Hospital Aeronáutico

Central; III Cátedra de Anatomía. Facultad de Medicina- UBA. CABA

Introducción: Las lesiones torácicas constituyen una causa importante de morbi-mortalidad. El desconocimiento anatómico del pedículo pulmonar y su distribución puede ocasionar daño de sus estructuras si el cirujano no tiene un manejo adecuado. Material y Métodos: Evaluación a 11 cirujanos en formación, con material cadavérico formalizado al $10 \%$, mediante listas de chequeo (Mayo/2013) y disección anatómica de 10 cadáveres formalizados al $10 \%$ identificando las estructuras del pedículo pulmonar (Junio/Septiembre 2013). Se realizaron técnicas de control vascular pulmonar en 2 cadáveres frescos; reproduciéndose en modelos porcinos vivos (Octubre/2013-Junio/2014). Resultados: el tronco de arteria pulmonar, su bifurcación, arterias pulmonares y bronquios principales, fueron las más identificadas por $7(63.63 \%)$ residentes; y de las relaciones fueron el esófago, la aorta descendente y el cayado aórtico por 8 (72.73\%) residentes. Durante la disección, 5 (45.46\%) identificaron correctamente estructuras anatómicas; 4 (36.36\%) reconocieron entre 60 y $70 \%$; 2 (18.18\%) entre 40 y $50 \%$. $8(72.73 \%)$ pudieron describir y reproducir la técnica de control del pedículo pulmonar en cadáveres y $3(27.27 \%)$ requirieron asesoramiento. En modelos porcinos, 9 (81.82\%) pudieron realizar la técnica en tiempo estimado con resultados satisfactorios. Discusión: La observación y disección anatómica en material cadavérico ofrece un satisfactorio método de enseñanza y capacitación para residentes de cirugía. La realización de autopsias y la utilización de modelos animales vivos para la adquisición de destrezas y aptitudes pertinentes en el control del pedículo pulmonar, se consideran métodos educativos. La supervisión y evaluación mediante listas de chequeo es una alternativa para mejorar el proceso de enseñanza/aprendizaje.

\section{ORIGEN DE LA VENA YUGULAR EXTERNA}

Diego ALVAREZ; Mariano PERONA; Alejandra

MANSILLA; Sofía MANSILLA, Emilia CERCHIARI

Departamento de Anatomía Clínica, Facultad de Medicina, UDELAR, Montevideo, Uruguay

Introducción: Se propone identificar el origen más frecuente de la vena yugular externa (VYE) dado que no existe consenso en la bibliografía clásica y contemporánea. Materiales y Métodos: Se disecaron 20 regiones infratemporales, parotídeas y carotideas en material cadavérico fijado con solución de formaldehido. Se registró la presencia de la VYE y sus venas de origen y la distinta conformación venosa en el origen de la misma. Resultados: Se identificó la presencia de la vena yugular externa en $90 \%$ de los casos. La vena temporal superficial se identificó en el $100 \%$ de los preparados, mientras que la vena maxilar interna estaba ausente únicamente en un caso. La vena auricular posterior se identificó en el $70 \%$ de los casos. La vena retromandibular estaba presente en el $75 \%$ de los casos. El origen más comúnmente hallado fue la anastomosis de la vena retromandibular con la auricular posterior en el $66 \%$ de los casos disecados. En el $28 \%$ se originó de la unión de la vena temporal superficial y maxilar interna. En un solo caso la VYE se originó directamente de la rama posterior de la vena retromandibular. Discusión: Nuestros resultados sugieren que el origen de la vena yugular externa más frecuente es a partir de la vena retromandibular y auricular posterior, sin olvidar la gran variabilidad del sistema venoso superficial del cuello. Creemos necesario, con fines didácticos, que la bibliografía anatomía uniformice la definición y origen de tan importante vena superficial del cuello.

\section{COLLATERAL VENOUS CIRCUITS: THEIR RELEVANCE IN THE ANOMALIES OF THE SUPERIOR AND INFERIOR VENA CAVA VENOUS RETURN}

M AMORE, R BERNARDEZ, R ENRIQUEZ, H ALONSO $^{3}$, A CHACALTANA VILLACORTA $^{3}, \mathrm{JL}$ $\mathrm{CIUCCl}$

Introduction: From obstruction or compression of the deep venous system, derivatives or substitutes venous circuits become important, trying to compensate for the high venous pressure. Objective: To contribute to the correct anatomical and functional description of derivatives venous circuits. In them we include the venous network of the abdominal wall, the vertebral plexus and azygous system. Material and Methods: 14 human cadavers, 10 term fetuses and 4 adults were employed. All cadavers were subjected to injection procedures with colored latex, and fixed by soaking with aqueous formaldehyde $5 \% \mathrm{v} / \mathrm{v}$. Here they were discussed, dissected and photographed. In the final stage, an image correlation was performed, objectified by contrasting phlebography, all of them belonging to Phlebology and Lymphology Unit of the Hospital Militar Central. Results: In our study the close relationship of the vertebral venous plexus and the azygos system with the intracranial venous system, especially with the dural sinuses, thereby connecting the pelvis to the base of the skull evidenced. On superficial level, the presence of the venous network of the abdominal wall, obstruction or low compressions compensate showed, interconnecting system with superior vena cava and inferior vena cava, mainly through the epigastric vessels. Discusion: Vicariant venous circuits often dismissed, act as true bypass of the central venous circulation trying to compensate in case of compressions or obstructions. 


\section{DESHIDRATACIÓN Y DESECACIÓN APLICADAS A LA CONSERVACIÓN DE DISECCIONES DE LARINGE}

Gustavo J ARMAND UGON; Diego ÁLVAREZ; Natalia V LÓPEZ; Virginia L CUELLO; Eduardo A OLIVERA Depto. de Anatomía, Facultad de Medicina - UDELAR. Uruguay

Introducción: La laringe presenta una anatomía compleja que constituye un reto tanto para el estudiante como para el docente. La disección del órgano, si bien compleja y laboriosa, permite obtener material de indudable valor didáctico pero muy delicado para su manipulación y de difícil conservación. El objetivo del presente trabajo es comunicar nuestra experiencia en la conservación de disecciones de laringe mediante las técnicas de deshidratación y desecación. Material y Métodos: Se utilizaron laringes obtenidas de cadáveres adultos formolados. Se realizó la disección del órgano ex situ, utilizando material de micro disección. Obtenido el preparado a conservar, se procedió a la deshidratación por inmersión en soluciones de alcohol a concentraciones crecientes. Completada la deshidratación se procede a fijar el preparado en su posición definitiva y a la desecación bajo campana de vidrio y resguardado de la luz solar directa. Completado el proceso los preparados se conservan expuestos al aire ambiente. Resultados: Se obtuvieron preparados que mantienen sus dimensiones y no se deforman, que permiten la observación y el estudio de diferentes estructuras anatómicas. Preparados que permanecen secos y pueden manipularse sin guantes, aunque pueden presentarse húmedos al tacto si la humedad ambiente es alta. Discusión: La deshidratación y la desecación son dos viejas técnicas de conservación cadavérica de fácil realización y de muy bajo costo, y, sin dudas, aún vigentes. Permiten lograr preparados de fácil conservación, cuyo mantenimiento es prácticamente nulo, y de larga vida útil.

\section{EXONERACIÓN DEL EXAMEN FINAL DEL CURSO DE ANATOMÍA CLÍNICA. SU IMPACTO EN EL RENDIMIENTO DE LOS ESTUDIANTES}

Gustavo J ARMAND UGON, Ana C SANTAMARÍA, Alejandro M RUSSO, Eduardo A OLIVERA.

Depto. de Anatomía, Facultad de Medicina - UDELAR. Uruguay.

Introducción: El curso de Anatomía Clínica se desarrolla en 16 semanas, agrupándose los contenidos en 5 módulos (neuroanatomía, aparato locomotor, cara y cuello, tórax, abdomen y pelvis). Las evaluaciones parciales al finalizar cada módulo permiten aprobar el curso y obtener derecho a examen final. Cambios en el reglamento de cursos y exámenes, en 2013, permiten la exoneración del examen final del curso a aquellos estudiantes con un rendimiento del $80 \%$ o más en los parciales. El objetivo del presente estudio es evaluar el impacto de este cambio en el rendimiento de los estudiantes, tanto en las evaluaciones parciales como en el examen final. Material y Métodos: Estudio descriptivo, retrospectivo. Los datos fueron obtenidos de las actas de los parciales y los exámenes finales. Se analizaron los resultados de las evaluaciones parciales y de los exámenes finales correspondientes al año previo a la exoneración (2012) y a los 2 primeros años de ésta (2013-2014). Resultados: Evidenciamos un aumento en el porcentaje de aprobación del curso de 69 a 83\%, así como en la exoneración del examen, que aumentó del 39 al 44\% (2013 y 2014 respectivamente). Si sumamos el porcentaje de estudiantes que salva el examen final en el primer período a los que exoneran evidenciamos que aumentó del $21,3 \%$, previo a la exoneración, al $58,7 \%$. Discusión: La posibilidad de exoneración del examen final impacta positivamente en el rendimiento de los estudiantes, tanto en las evaluaciones parciales como en el examen final.

\section{EL DESAFÍO ANATOMOIMAGENOLÓGICO COMO RECURSO MOTIVADOR Y DE AUTOEVALUACIÓN}

Cecilia BAUCKHAGE ${ }^{1}$; Stefania SOLANOT' ${ }^{1}$; Renzo N MARTÍNEZ ${ }^{1, ;}$ Gustavo HRA OTEGU1, ${ }^{1,2,3}$,

${ }^{1}$ Lab. de Imágenes, $2^{a}$ Cát. de Anatomía, Facultad de

Medicina, U.B.A., C.A.B.A.; ${ }^{2}$ Instituto de Morfología

J.J. Naón, Fac.de Medicina, U.B.A., C.A.B.A.; ${ }^{3}$ Dep.

Biomédico, Escuela Superior de Ciencias de la Salud, U.N.C.P.B.A., Olavarría, B.A. Argentina

Introdución: clásicamente la mayoría de las configuraciones didácticas en anatomía están basadas en una pedagogía de la respuesta. El objetivo del presente trabajo es implementar un recurso didáctico (desafío anatomo-imagenológico) y valorar en qué medida los alumnos adquieren una nueva tradición epistémica, centrada en la pedagogía de la pregunta. Materiales y Métodos: Semanalmente se presenta un "desafío anatomo-imagenológico" con preguntas motivadoras centradas en problemas cuya respuesta es una hipótesis o conjetura generada por los estudiantes para dar cuenta del problema: normalidad-patología, normalidad-variación, técnica 1 y técnica 2 , momento 1 y momento 2 en el estudio dinámico de una estructura, etc. Estudios de mucosografía en tubo digestivo, estudios vasculares con tiempos distintos (arterial y venoso), etc. Se entrevistó a los docentes que evaluaron cualitativamente el impacto sobre los estudiantes y se valoró el cambio de las consultas en la página del Laboratorio. Resultados: La expresión del razonamiento deductivo por parte de los estudiantes se hizo evidente cuando los mismos fueron puestos en un contexto de problematización. Las diferencias morfológicas observadas constituyeron "indicadores de algo" que debía ser explicado. Dar sentido a lo observado implicó "teorizar" sobre lo que estaba sucediendo en esa secuencia de cambios morfológicos. Discusión: los recursos didácticos generados introducen innovaciones en la enseñanza de la anatomía. Introducen al estudiante en una nueva tradición epistémica cuyo centro es la problematización de la realidad. Ya no se necesitan solo respuestas sino que se pretende saber cuáles son las preguntas correctas.

\section{LAS IMÁGENES DIAGNÓSTICAS COMO RECURSO DIDÁCTICO PARA APRENDER ANATOMÍA FUNCIONAL}

Gabriela BLATESKY ${ }^{1}$, Eugenia FERNÁNDEZ

TALAVERA ${ }^{1}$, Sol FERREYRA ${ }^{1}$, Gustavo HRA OTEGUI ${ }^{1,2,3}$, 
${ }^{1}$ Laboratorio de Imágenes, $2^{a}$ Cátedra de Anatomía, Facultad de Medicina, U.B.A., C.A.B.A.; ${ }^{2}$ Instituto de Morfología J.J. Naón, Facultad de Medicina, U.B.A., C.A.B.A; ${ }^{3}$ Departmento Biomédico, Escuela Superior de Ciencias de la Salud, U.N.C.P.B.A., Olavarría, B.A. Argentina

Introdución: en línea con el marco epistémico llamado $3^{a}$ paradigma (investigación-descubrimiento), usamos las imágenes diagnósticas para aprender anatomía en un contexto de investigación y de aplicación médica que genere motivación intrínseca y enseñe a pensar críticamente. El objetivo del presente trabajo es corroborar la efectividad didáctica en el desarrollo de la capacidad de teorizar y de integrar forma y función a partir de los "datos" ofrecidos por las imágenes. Materiales y Métodos: Se aplicaron los siguientes recursos: a) modelo de anatomía del lenguaje: PET y RMIf y tractografía; b) modelo de ciclo cardíaco: RMIf, RMI y TC y c) modelo de filtración, conducción, almacenamiento de orina $y$ diuresis: urograma excretor, arteriograma renal, cistouretrografía; d) modelo de fonación: RMI y RMIf. Se entrevistó a los docentes que aplicaron el método para recoger evidencia sobre el impacto del nuevo recurso en la generación de competencias orientadas al uso del pensamiento crítico y la capacidad de teorización. Resultados: La expresión del razonamiento deductivo por parte de los estudiantes se hizo evidente cuando los mismos fueron puestos en un contexto de relacionar estructuras con función. Los cambios morfológicos observados constituían "indicadores" de función. Dar sentido a lo observado implicó "teorizar" sobre lo que estaba sucediendo en esa secuencia de cambios morfológicos. Discusión: el recurso didáctico generado introduce innovaciones en la enseñanza de la anatomía. Sin renunciar al estudio cadavérico. Estos modelos que presentamos abren la posibilidad de pensar la anatomía desde un lugar diferente. Key words: imágenes diagnósticas, modelos didácticos, anatomía funcional.

\section{ANATOMÍA DEL DESARROLLO CARDIOVASCULAR: LA ECOGRAFÍA COMO RECURSO DIDÁCTICO}

Franco BOVA ${ }^{1}$; Agustina SANTÁNGELO²; Juliana LESZCZYNSKI '; Gustavo HRA OTEGU1, $1,3,4$

${ }^{1}$ Lab. de Imágenes, $2^{a}$ Cát. de Anatomía, Facultad de Medicina, U.B.A., C.A.B.A.; ${ }^{2}$ Lab. de Ciencias Morfológicas, $2^{a}$ Cát. de Anatomía, Fac. de Medicina, U.B.A., C.A.B.A.; ${ }^{3}$ Instituto de Morfología J.J. Naón, Facultad de Medicina, U.B.A., C.A.B.A.; ${ }^{4}$ Departmento Biomédico, Escuela Superior de Ciencias de la Salud, U.N.C.P.B.A., Olavarría, B.A. Argentina Introdución: la curricula actual de la carrera de medicina viene sufriendo cambios acelerados y profundos. La tendencia es hacia la mayor integración horizontal y vertical, y un uso cada vez más importante de las nuevas tecnologías de la información y la comunicación (TIC). Por otro lado el avance en el diagnóstico por imágenes ha conducido a la anatomía por imágenes a lo que hemos dado en llamar el $3^{\mathrm{a}}$ paradigma (investigación-descubrimiento). En línea con el $3^{\circ}$ paradigma, este trabajo pretende hacer un aporte a la resolución de la carencia de recursos didácticos para enseñar anatomía del desarrollo en un contexto de innovación curricular. El propósito de este trabajo es generar recursos didácticos aplicados a la enseñanza de la anatomía del desarrollo del sistema cardiovascular. Materiales y Métodos: se recogieron imágenes ecográficas de estudios de fetos con fines de diagnóstico médico. Las mismas se obtuvieron de bases y bancos de imágenes de Hospitales vinculados al Laboratorio de Imágenes ( $2^{\mathrm{a}}$ Cátedra de Anatomía, Facultad de Medicina, UBA). Resultados: Se presentan imágenes seleccionadas que muestran la posición anatómica del corazón, sus cavidades y sus respectivas relaciones, la indemnidad de las válvulas, el tabicamiento cardíaco, los grandes vasos, la aorta en casi todo su trayecto con sus relaciones, la vascularización encefálica, etc. Discusión: mostramos evidencia que corrobora el $3^{\circ}$ paradigma de la anatomía imagenológica que nos permite investigar, descubrir, diagnosticar y describir detalladamente la estructura y función del sistema cardiovascular fetal.

\section{CARACTERÍSTICAS DE LA POBLACIÓN ESTUDIANTIL DE LA PRIMERA COHORTE DE LA FACULTAD DE MEDICINA UNT SEDE SALTA Y SU PERCEPCIÓN SOBRE LA ENSEÑANZA-APRENDIZAJE DE ANATOMÍA NORMAL}

Manuel BRAHIM, Sergio TAMAYO, A. CARO, S. LACHS, S. QUISPE

Cátedra de Anatomía Normal Universidad Nacional de Tucumán, Sede Salta, Argentina

Introducción: En esta comunicación quisimos determinar las fortalezas y debilidades durante la implementación del primer año de la carrera de Medicina en la provincia de Salta, en cuanto al dictado de la materia de Anatomía Normal. Materiales $y$ Métodos: Se utilizo una encuesta con preguntas semi estructuradas, anónima y auto administrada a 55 de los 68 alumnos del $1^{\circ}$ año de la carrera de Medicina, UNT sede Salta, que cursan la materia Anatomía Normal. Las variables analizadas fueron: sexo, edad, nivel académico del ingresante, títulos terciarios y universitarios previos, opinión con respecto al dictado y contenidos de clases teóricas y trabajos prácticos. Resultados: Reconocimos que la principal dificultad planteada por los alumnos fue el reconocimiento de estructuras anatómicas en preparados cadavéricos y la compresión delos libro de textos referentes a la materia. Discusión: En vista de estos datos sugerimos hacer énfasis, en los cursos de ingresos pre universitario, en la compresión de textos, y en el desarrollo de la materia, durante su cursada regular, la procuración y disección de piezas anatómicas propias.

\section{COMPONENTES INSULARES DEL}

\section{FASCÍCULO LONGITUDINAL SUPERIOR}

Martín BRESNAL ${ }^{1}$; Gabriel MORÁN ${ }^{1}$; Pablo BUOSI ${ }^{1}$; Gustavo HRA OTEGUI ${ }^{1,2,3}$

${ }^{1}$ La. de Neurobiología, $2^{a}$ Cát. de Anatomía, Fac.de Medicina, U.B.A.; ${ }^{2}$ Instituto de Morfología J.J. Naón, Facultad de Medicina, U.B.A., C.A.B.A.; ${ }^{3}$ Departmento Biomédico, Escuela Superior de Ciencias de la Salud, U.N.C.P.B.A., Olavarría, B.A. Argentina

Introducción: si bien algunos autores han propuesto que el fascículo longitudinal superior (FLS) estaría 
constituido por más de un fascículo, no existe unanimidad de opiniones sobre cuáles serían éstos componentes. Ninguna de las descripciones existentes hasta la fecha ha aportado evidencia sobre la existencia de fibras aferentes o eferentes conectadas con el lóbulo de la ínsula que constituyan parte del FLS. El presente trabajo se propuso identificar la conectividad insular y reconocer componentes fibrilares de FLS que conecten con el lóbulo de la ínsula. Materiales y Métodos: se estudiaron 5 hemisferios cerebrales humanos, fijados en solución hiperosmótica de formol al $50 \%$. La disección se realizó con espátulas de madera y pinzas sin dientes de ratón. Se usó el método de tracción fibrilar por planos. Progresivamente se fueron resecando los planos superficiales hasta alcanzar el nivel subcortical del lóbulo de la ínsula. Se usó una máquina fotográfica "Canon PowerShot SD1100 IS" para documentar la sucesión de planos. Se superpusieron los planos disecados y se procesaron con el programa Adobe Photoshop CS6®. Resultados: hemos identificado 3 componentes del subsistema insular: a) ínsulo-frontal, que conecta ínsula con los giros orbitarios y giros frontales dorsolaterales, b) ínsulo-parietal, que conecta ínsula con giros angular y supramarginal e c) ínsulotemporal, que se distribuye de manera preponderante en el giro temporal superior. Discusión: en base a la evidencia recogida se sugiere que estos fascículos podrían constituir la base de la integración conductual y comportamental del individuo e intervenir en el lenguaje.

\section{VARIACIÓN ANATÓMICA DE PATELA (RÓTULA) EN GUIJARRO EN MUJER COLOMBIANA: REPORTE DE CASO}

Myriam BUITRAGO, Martha BERNAL

Semillero de Investigación en Anatomía RENASCI,

Programa de Medicina, Facultad de Ciencias de la

Salud, Universidad de Boyacá, Tunja, Boyacá Colombia

Introducción: La patela (rótula), es un hueso sesamoideo corto, triangular y aplanado. Las variaciones anatómicas clasificadas por Wiberg son detalladas en tres tipos: el I, con facetas medial y lateral cóncavas y de igual tamaño; el II, ambas facetas cóncavas, la medial más pequeña que la lateral; y el III, con una pequeña faceta medial convexa. Baumgartl agregó la de tipo IV, en gorro de cazador alpino y la de guijarro. El reporte del presente caso describe la variación anatómica de la patela en guijarro, en una paciente, con historia clínica de luxación recidivante de la patela. Métodos: Diseño de estudio de un solo caso, descriptivo con fundamentación comparativa y cualitativa. Recolección y análisis de datos de la historia clínica, de una paciente de 19 años de edad. Se realizaron mediciones de los ángulos de congruencia y del surco intercondíleo sobre tomografía axial femoropatelar; Test de mala alineación sobre ortorradiografía y de Insall-Salvati sobre Radiografías laterales de rodilla derecha e izquierda. Resultados: Las imágenes diagnósticas reportan luxación rotuliana bilateral y ángulo del surco femoral aplanado bilateral. Se evidencia disminución del tamaño de la patela e inadecuada relación femoropatelar y de la patela en el trayecto trolear. Reportando patela en guijarro por las carillas articu-lares aplanadas y ángulo de apertura superior a $140^{\circ}$. Discusión: Las características anatómicas de la variación inciden en la biomecánica de la rodilla, alineación femoropatelar y línea de tracción del cuádriceps, condicionando de manera importante la inestabilidad patelar.

\section{ESTUDIO ANATÓMICO DEL ORIGEN DE LA ARTERIA FEMORAL PROFUNDA: \\ IMPLICANCIAS EN LOS PROCEDIMIENTOS ENDOVASCULARES}

N CANCELA; JP MACADAM; A RUSSO; G ARMAND UGON

Departamento. de Anatomía, Facultad de Medicina,

Universidad de la República, Montevideo, Uruguay Introducción: La arteria femoral (AF) representa una de las principales vías de acceso endovascular. Algunas de las complicaciones de este procedimiento están vinculadas a la punción incidental de la arteria femoral profunda (AFP), por lo que el conocimiento de su anatomía y su disposición es fundamental. El objetivo de esta comunicación es estudiar la disposición del origen de la AFP. Material y Método: Para este fin, se utilizaron 31 regiones inguinales $(n=31)$ de cadáveres fijados previamente en solución en base a formol. Se registró: género (femenino o masculino), distancia del origen de la $A F$ al origen de la AFP (D1), topografía del origen de la AFP respecto a la $\mathrm{AF}$ (anterior, medial, lateral, posterior, posterolateral) y angulación entre la AF y el origen de la AFP. Resultado: De los 31 casos, 13 (42\%) fueron masculinos y $18(58 \%)$ femeninos. D1 presentó una media de $32,13 \mathrm{~mm}$ (rango $17-55 \mathrm{~mm}$ ). Con respecto a la topografía del origen de la AFP: 15 fueron posteriores $(48,4 \%), 14$ póstero-laterales $(45,2 \%), 1$ caso de origen lateral $(3,2 \%)$ y 1 caso medial $(3,2 \%)$ respectivamente. La angulación entre el origen de la AFP y la AF fue de media $14,77^{\circ}$ (rango $10-20^{\circ}$ ). Discusión: De acuerdo a nuestros hallazgos existe una distancia promedio de $3 \mathrm{~cm}$ de la AF proximal al origen de la AFP. En la mayoría de los casos la AFP se origina de la cara posterior de la $A F$ y en un ángulo agudo, no mayor a $20^{\circ}$. Este conocimiento debe ser tenido en cuenta tanto para el cirujano vascular, radiólogo intervencionista y hemodinamista en vistas al abordaje endovascular de la AF.

\section{DISECCIÓN DE SUSTANCIA BLANCA: NUESTRA EXPERIENCIA}

Emilia CERCHIARI; Verónica BENTANCOURT; Verónica de los SANTOS

Departamento de Anatomía Clínica, Facultad de Medicina, UdelaR. Montevideo, Uruguay

Introducción: La cirugía destinada al tratamiento de la epilepsia temporal ha demostrado mejorar la calidad de vida en pacientes con epilepsia refractaria. Sin embargo, pueden aparecer secuelas neurológicas vinculadas a la lesión de tractos de sustancia blanca localizados en el lóbulo temporal. El objetivo del presente trabajo es estudiar detalladamente los mismos utilizando el método de Klingler para su disección. Materiales y Métodos: Se utilizaron 5 hemisferios cerebrales de cadáveres adultos, fijados con solución de formaldehido al $5 \%$. Se congelaron 8 días a $0^{\circ} \mathrm{C}$, y se descongelaron para su disección por 
técnica de Klingler. Resultados: En relación al asta temporal del ventrículo lateral se visualizaron las radiaciones ópticas. Se observó la disposición del loop de Meyer, a $5 \mathrm{~cm}$ del polo temporal, el cual puede ser lesionado durante la lobectomía temporal anterior, determinado alteraciones campimétricas. Formando parte de los circuitos del sistema límbico vinculados a la memoria, se observaron la formación hipocampal, fimbria y fórnix. Se observó el fascículo unciforme, vinculando los lóbulos temporal y frontal. Finalmente se visualizó la disposición del fascículo arciforme vinculando las áreas de Broca y Wernicke. Su lesión determina alteraciones del lenguaje. Discusión: Si bien la cirugía en pacientes con epilepsia temporal refractaria mejora francamente la calidad de vida de los pacientes, la disposición de los tractos de sustancia blanca en el lóbulo temporal determina que puedan aparecer secuelas neurológicas tan invalidantes como la patología misma. El conocimiento anatómico detallado permite prevenir complicaciones.

\section{PRIMER ESTUDIO ARGENTINO DE VOLUMETRÍA CEREBRAL Y MEDULAR EN LA POBLACIÓN GENERAL: RESULTADOS PRELIMINARES}

J CHOMONT ${ }^{2}$; F FERRARO ${ }^{2}$; C RUGILO ${ }^{2}$, L GUTIERREZ ${ }^{1}$; M CULLARI ${ }^{1}$, M BENDERSK $^{1,2}$

${ }^{1}$ Laboratorio de Anatomía Viviente, III Cátedra de Anatomía Normal, Facultad de Medicina, Universidad de Buenos Aires; ${ }^{2}$ Servicio de Diagnóstico por Imágenes, Hospital Británico de Buenos Aires Introducción: Diversas enfermedades afectan el tamaño del cerebro y la médula espinal. Es frecuente el hallazgo neurorradiológico de aparente reducción del volumen cerebral y medular. Mediante Resonancia Magnética (RM) es posible cuantificar el área y el volumen cerebral y medular. Materiales y Métodos: Se enrolarán 200 pacientes que concurran a realizarse RM de cerebro. Se les administrará un cuestionario que contempla variables antropométricas, hábitos, consumo de fármacos y antecedentes familiares de enfermedades, entre otras. El post-procesamiento se realizará mediante el software Jim-Xinapse 7. Las técnicas estadísticas a utilizar incluyen regresión múltiple, coeficientes de correlación y test de t. Resultados (preliminares): Se enrolaron 7 pacientes, con edad promedio de 42,28 años. Volúmenes promedio (ml): LCR: 221,57; sustancia gris: 698,25 ; sustancia blanca: 516; cerebro: 1214,25; cerebro + LCR: 1445; volumen medular: 4287,52mm3. El análisis de regresión mostró que a mayor edad, menor volumen de sustancia gris y mayor de sustancia blanca. El volumen medular se correlaciona con el volumen cerebral, no encontrándose por ahora correlación con otras variables Discusión: Se ha podido perfeccionar la técnica y calcular el volumen de las diversas estructuras. Impresiona haber una correlación entre la edad y el volumen de sustancia gris y blanca; y entre volumen cerebral y medular. Con el aumento del número de pacientes, se arrojarán resultados más significativos.

ASIMETRÍA DEL FASCÍCULO UNCINADO

Marcela CIMMINO ${ }^{1}$; Fernanda ALONSO ${ }^{1}$; Juliana C. SIRONI ${ }^{1}$; Martín BRESNAL ; Gabriel MORÁN ${ }^{1}$; Gustavo HRA OTEGUI ${ }^{1,2,3}$
${ }^{1}$ Laboratorio de Neurobiología, $2^{a}$ Cátedra de Anatomía, Facultad de Medicina, U.B.A., C.A.B.A.;

${ }^{2}$ Instituto de Morfología J.J. Naón, Facultad de Medicina, U.B.A., C.A.B.A.; ${ }^{3}$ Departmento Biomédico, Escuela Superior de Ciencias de la Salud, U.N.C.P.B.A., Olavarría, B.A. Argentina Introdución: el fascículo uncinado es parcialmente responsable del comportamiento en contextos grupales o sociales. Hasan el al (2009) encontraron en niños menores de 16 años que el fascículo uncinado derecho era de mayor volumen que el izquierdo en la mayoría de los casos. Esta asimetría desaparece en los mayores de 16 años. En los esquizofrénicos con grado importante de deterioro conductual, se observó asimetría de FU, siendo el derecho habitualmente mayor que el izquierdo. El presente trabajo, exploratorio y descriptivo, se propuso caracterizar el grado de asimetría entre los fascículos uncinados de ambos hemisferios cerebrales de Bos taurus. Materiales y Métodos: se estudiaron 30 encéfalos de Bos taurus, sin distinción etaria ni sexual. Los mismos fueron fijados en solución hiperosmótica de formol al $50 \%$. La disección se realizó con espátulas de madera y pinzas sin dientes de ratón. Se usó el método de tracción fibrilar por planos. Resultados: encontramos asimetría (diferencia de volumen derecha-izquierda mayor o igual al $10 \%$ ) en el $90 \%$ de las muestras. En el $50 \%$ de las asimetrías el FU derecho fue mayor que el izquierdo y en el $40 \%$ el FU izquierdo fue el que tuvo mayor volumen. Discusión: aunque pareciera que lo menos frecuente es la simetría del FU, es difícil saber que diferencia conductual emerge de tal asimetría. Posteriores estudios deberán diferenciar el rol del ambiente en el desarrollo de la asimetría / simetría.

\section{TRAUMATISMOS HEPÁTICOS. IMPORTANCIA DE LA ANATOMÍA HEPÁTICA EN LA MEDICINA FORENSE}

D COSTI'; GD PRAT; FE SIRIS MACHADO; EN RAITI SPOSATO; MP BONINI; FS SCARPELLI; BC LOREA; $P$ OSÁCAR

Laboratorio de Investigaciones Morfológicas Aplicadas, Facultad de Medicina, U.N.L.P., L.P. Argentina

Introducción: El trabajo tiene como objetivo estudiar las lesiones traumáticas hepáticas ocasionadas por traumatismos tóracoabdominales. Se describen los procedimientos médico legales implementados, las lesiones hepáticas y asociadas y las causales de muerte. Materiales y Métodos: Se seleccionaron 7 casos que ingresaron a la Morgue Policial de La Plata desde el año 2011 al 2014. Todos correspondieron al sexo masculino. El rango de edad varía de 24 a 60 años, con un promedio de 41,8 años. Se describen las lesiones, su ubicación y se procede a realizar una revisión de los protocolos de autopsia médicolegal. Se documentó el tipo de lesiones, compromiso parenquimatoso y lesiones traumáticas asociadas. Se fotografío el procedimiento de la necropsia, no alterando la evidencia por su posterior implicancia médico legal. Resultados: Se observa un incremento significativo de lesiones hepáticas producidas por traumatismos tóracoabdominales (desde simples laceraciones hasta estallido hepático y graves lesiones concomitantes). Se debe destacar que en el $100 \%$ de 
los casos el lóbulo derecho fue el más afectado. Como lesiones concomitantes destacamos compromiso de la celda renal, fracturas costales con hemotórax y compromiso de estructuras pelvianas. En la mayoría de los casos la causa de muerte se debió a un cuadro de shock hipovolémico con hemorragia cataclísmica. Discusión: Se describen las lesiones hepáticas constatadas en los traumatismos tóracoabdominales, destacándose los procedimientos médico legales necesarios a los efectos de determinar la causa de muerte y no alterar el valor probatorio de la evidencia pericial, de suma importancia en medicina legal.

ANASTOMOSIS DE RICHE - CANNIEU

Luis E CRIADO DEL RÍO, Yesica D CHAP, Sofía REVIGLIO, Agustina MANÍAS, Jhimy B TERCEROS, Gisela A CEJAS

Cátedra de Anatomía Normal, Facultad de Ciencias Médicas, U.N.C., Córdoba, Argentina

Introducción: La anastomosis de Riche-Cannieu (ARC) es una variación anatómica formada entre el nervio mediano (NM) y el nervio cubital (NC). Debido a su importancia clínica y electromiográfica, su descripción anatómica es de gran interés, ya que gracias a esta variación anatómica existen distintas formas de inervación motora a nivel de la mano. Materiales y Métodos: Se realizaron disecciones cadavéricas en 38 manos (19 cadáveres) de ambos sexos formolizados al $5 \%$ y entre 50 y 70 años de edad. Se utilizó instrumental y técnicas convencionales de disección. Resultados: La rama profunda del NC tiene una anatomía constante y finaliza su recorrido en el músculo aductor del pulgar. De aquí emerge una rama que en el $86,84 \%$ de los casos se anastomosa con el NM de diferentes formas. Esta rama anastomótica en el $50 \%$ de las manos era una arcada nerviosa de considerable calibre entre el NC y NM que daba ramas motoras a los músculos de la eminencia tenar. Discusión: El conocimiento de esta anastomosis es muy importante ya que, en casos de lesión del nervio mediano o cubital, puede causar confusión clínica, quirúrgica y en los hallazgos electromiográficos. Debido a su alta frecuencia fue considerada un rasgo anatómico normal.

\section{ANATOMÍA DE LA RAMA PROFUNDA DEL NERVIO CUBITAL EN LA MANO}

Luis E CRIADO DEL RÍO, Agustina ZULLI, Ramiro A A VARGAS AIGNASSE, Pedro A JUAN, Julieta ABATEDAGA, Gerónimo RUFFINO

Cátedra de Anatomía Normal, Facultad de Ciencias Médicas, U.N.C., Córdoba, Argentina

Introducción: La lesión del nervio cubital (NC) puede resultar en una pérdida extensa de la inervación sensitiva y motora de la mano. Su rama profunda (RPNC) es la encargada de inervar a la mayoría de los músculos de la mano incluso en la eminencia tenar. Materiales y Métodos: Se realizaron disecciones cadavéricas en 38 manos (19 cadáveres) de ambos sexos formolizados al $5 \%$, y entre 50 y 70 años de edad. Se utilizó instrumental y técnicas convenciónales de disección. Resultados: El ramo profundo del NC discurre entre los músculos flexor y abductor del meñique y pasa a través del oponente del meñique. Desciende hasta los músculos interóseos, surca el borde distal de la apófisis unciforme del ganchoso y traza un arco a nivel profundo de la palma de la mano dentro de la concavidad del arco palmar profundo. Da ramas motoras para los tres músculos hipotenares, los dos lumbricales del lado cubital, todos los interóseos, el aductor del pulgar y el vasto interno del flexor corto del pulgar. Discusión: La RPNC cumple un rol fundamental en la motilidad de la mano. Coincidimos con la literatura en que tiene una anatomía constante en su trayecto y ramas colaterales. Finaliza su recorrido en el espesor del músculo aductor del pulgar dando inervación motora a éste músculo y al flexor corto del pulgar.

\section{REALIDAD ANATÓMICA DEL BRONQUIO LOBAR INFERIOR DERECHO: CORRELACIÓN ANATOMO-RADIOLÓGICA} $S$ CUBAS $^{1}$, R MADERA $^{1}, J^{\prime}$ GARCI $^{1,2}$, A RUSSO $^{1}, P^{\prime}$ DIBARBOURE ${ }^{1,3}$, G ARMAND UGÓN ${ }^{1}$

${ }^{1}$ Dep. de Anatomía, Fac. de Medicina, Univ. de la República; ${ }^{2}$ Dep. de Imagenología, Hosp. de Clínicas,

Fac. de Medicina, Univ. de la República; ${ }^{3}$ Servicio Cirugía de Tórax, Hosp.Maciel. Montevideo, Uruguay Introducción: avances en cirugía torácica obligan a profundizar los conocimientos de anatomía aplicada de la distribución lobar y segmentaria del árbol traqueobrónquico. La lobectomía inferior derecha es una resección reglada y el tiempo de sección bronquial un paso clave. Se encuentran en la literatura disimiles definiciones anatómicas y quirúrgicas respecto a la presencia de un verdadero bronquio lobar inferior (BLI). Objetivo: Determinar la presencia de un verdadero $\mathrm{BLI}$ de donde nacen todos los bronquios segmentarios del lóbulo ipsilateral. Material y Método: se utilizaron 35 pulmones derechos $(n=35)$ de cadáveres fijados previamente en solución formol y 35 tomografías de alta resolución con reconstrucción tridimensional de la vía aérea $(n=35)$. Se registró en ambos: el origen del bronquio apical (BA) respecto al bronquio lobar medio (BLM)(por encima, al mismo nivel o por debajo) y la distancia que separaba a éstos. Resultados: en ningún caso cadavérico el BA nació por debajo del BLM (0\%). En 13 casos (36\%) el BA nacía por encima del BLM a una distancia promedio de $6 \mathrm{~mm}$ (rango 2-10) y en los restantes 23 $(64 \%)$ al mismo nivel. En las tomografías, 12 casos (35\%) el BLM nacía por encima del BA a una distancia promedio de $2.4 \mathrm{~mm}$ (rango 1-4,4) y en los restantes $24(65 \%)$ al mismo nivel. Discusión: nuestros hallazgos tanto cadavéricos como tomográficos desmienten en la mayoría de los casos la existencia de un BLI, este hecho tiene una doble importancia, por un lado para la lobectomía inferior derecha como para la terminología anatómica.

\section{LÓBULO PULMONAR DE LA ÁCIGOS: UN} LÓBULO POCO HABITUAL

Matias CULLARI ${ }^{1}$, Matias NICOLAS ${ }^{2}$, Lucas GUTIERREZ1 ${ }^{1}$, David SMITH ${ }^{2}$, Cesar GOMEZ ${ }^{1}$, Mariana BENDERSKY ${ }^{2,3}$

${ }^{1}$ Lab. de Anatomía viviente, III Cátedra de Anatomía Normal, Fac. de Medicina, UBA; ${ }^{2}$ Servicio de cirugía General, Hospital Italiano; ${ }^{3}$ Instituto Universitario, Esc. de Medicina, Hospital Italiano. Buenos Aires

Introducción: La vena ácigos mayor surge de la vena cardinal posterior, la cual se localiza lateral al vértice 
del pulmón derecho. En su desarrollo normal, la vena cardinal se desplaza hacia medial quedando ubicada en el mediastino posterior. Si este desplazamiento no ocurre, se va a formar lo que se conoce como lóbulo de la ácigos. Diagnóstico: El lóbulo de la ácigos puede ser visto en una simple radiografía de tórax de frente, como así también en una tomografía computada de tórax con contraste endovenoso, siendo esta última, la que aporta mayor precisión en el caso de evaluar una resección del lóbulo superior derecho. Presentación de caso: Se presenta el caso de una paciente de sexo masculino, ex tabaquista, al cual en una tomografía de rutina se detecta una masa pulmonar a nivel del lóbulo superior derecho. Como hallazgo de interés se puede distinguir a nivel del lóbulo superior derecho el lóbulo de la vena ácigos. Podemos destacar la importancia del reconocimiento previo a la intervención, puesto que para realizar la lobectomía superior derecha y asegurar un margen adecuado fue necesario ligar a nivel del origen de la vena ácigos el cayado y previo a la desembocadura en la VCS. Conclusión: El lóbulo de la ácigos es una variable anatómica pulmonar infrecuente pero de relevancia clínica a la hora de interpretar estudios complementarios o planificar el abordaje de una resección pulmonar que compromete el lóbulo superior derecho.

\section{PREPARACIONES ESPECIALES PARA} EXPLICAR ANATOMÍA FUNCIONAL CARDÍACA Sofía A ESTRADA ${ }^{1}$; Matías E SALDEÑA ${ }^{1}$; Agostina D TOBAL ${ }^{1}$; Ezequiel ZACANIÑO ${ }^{1}$; Gustavo HRA OTEGUI, ${ }^{1,2,3}$

${ }^{1}$ Lab. de Preparaciones Especiales, $2^{a}$ Cátedra de Anatomía, Facultad de Medicina, U.B.A. ${ }^{2}$ Inst. de Morfología J.J. Naón, Fac. de Medicina, U.B.A., C.A.B.A.; ${ }^{3}$ Dep, Biomédico, Esc, Superior de Ciencias de la Salud, U.N.C.P.B.A., Olavarría, B.A., Argentina Introdución: Los "preparados de mesa" siguen patrones de disección reglados por los manuales clásicos. Suelen avanzar por planos mostrando las diferentes estructuras. La anatomía clásica descriptiva y topográfica no permite configuraciones didácticas en las que se integren morfología y función, y en las que la segunda puede ser deducida a partir de la primera. El objetivo de este trabajo es diseñar modelos (preparaciones especiales) para explicar la anatomía funcional del corazón. Materiales y Métodos: se usaron como muestras corazones de bovinos y porcinos. Los mismos fueron procesados mediante inyección-corrosión, inyección-disección, disecciones del sistema valvular y del trígono fibroso, secciones planares. Se identificó y señalizó el sistema de conducción cardíaco. Resultados: Se obtuvieron preparaciones para dar cuenta de las siguientes funciones: a) ciclo cardíaco y fases del mismo, b) manejos de presión sistémica y pulmonar, c) ritmo cardíaco y electrocardiograma. Discusión: el diseño de estas piezas introduce innovaciones importantes que permiten valerse de la estructura para dar cuenta de la función. Estos recursos no solo satisfacen la posibilidad de explicar la función deduciéndola de la estructura sino que estimulan al alumno a pensar de forma crítica imaginando que pasaría si no existiese esa estructura, o bien si la estructura fuera afectada por alguna patología determinada. podemos imaginar lesiones valvular con soplos, lesiones vasculares y del sistema de conducción que generan alteración del ritmo, trasposición de los grandes vasos o bien estenosis aórtica que afecta la presión de los circuitos pulmonar y/o sistémico.

\section{FORMACIONES VENOSAS SUPERFICIALES DE LA FOSA DEL CODO: ESTUDIO MORFOLÓGICO Y ESTADÍSTICO EN POBLACIÓN ARGENTINA}

Micaela AR FELDMAN ${ }^{1}$; María V ROJAS ORTIZ1. Micaela L MARTíNEZ1; María L TARTAGLIA ${ }^{1}$; Rubén D ALGIERI ${ }^{1,2}$

${ }^{1}$ III Cát. de Anatomía, Facultad de Medicina, U.B.A.;

${ }^{2}$ Hospital Aeronáutico Central. C.A.B.A., Argentina Introducción: Las venas superficiales del codo han sido estudiadas por muchos anatomistas a lo largo de la historia, debido su gran importancia y aplicación clínica. El objetivo del presente trabajo fue estudiar la disposición de las venas superficiales de la fosa del codo en cadáveres adultos de origen argentino y establecer el patrón predominante según la clasificación propuesta por del Sol et al (1988). Materiales y método: Se realizó un estudio analítico de corte transversal en 40 miembros superiores, 19 izquierdos y 21 derechos, de cadáveres humanos provenientes de la Facultad de Medicina, Universidad de Buenos Aires, Argentina. Se procedió a la disección completa de los miembros, observando la formación de las venas superficiales a nivel del antebrazo y la fosa del codo. Resultados: De los 40 miembros superiores disecados, el patrón prevalente fue el II (16 casos, $40 \%$ ). En este patrón, la vena cefálica origina la vena intermedia del codo que se une a la vena basílica. No se encuentra la vena cefálica accesoria del antebrazo, y la vena intermedia del antebrazo drena en la vena basílica. Discusión: La prevalencia del patrón II representa una importante diferencia con respecto a otras poblaciones. En ninguna otra se observó a este patrón ocupando el primer lugar. La vena de mayor calibre promedio es la vena intermedia del codo. Ésto cobra relevancia a la hora de realizar extracciones de sangre venosa. Podría ser de buena práctica ir a buscar esa vena para extraer sangre por venopunción, tanto por su prevalencia como por su adecuado calibre.

\section{ESTUDIO MORFOMÉTRICO DEL SECTOR VISCERAL DE LA AORTA ABDOMINAL: IMPLICANCIAS EN LAS TÉCNICAS EVAR}

Carolina FERNÁNDEZ, Bruno BYK, Crihstian

PEREIRA, Natalia LAGROTTA, Alejandro RUSSO Depto. Anatomía, Facultad de Medicina Montevideo, Uruguay

Introducción: Uno de los recursos más novedosos en la reparación endovascular de los aneurismas de la aorta abdominal yuxtarrenal son las prótesis fenestradas. El diseño adecuado del dispositivo a utilizar requiere de un mapeo anatómico detallado del sector visceral de la aorta (Ao) del paciente cuestión. Todo esto obliga un profundo conocimiento de la anatomía del Ao. Materiales y Método: Para este fin, se utilizaron 12 Ao $(n=12)$ de cadáveres fijados previamente en solución en base a formol. Se registró: distancia tronco celíaco (TC) - arteria mesentérica superior (AMS) 
(D1); distancia TC-arteria renal derecha (ARD) (D2); distancia TC-arteria renal izquierda (ARI) (D3); distancia AMS-ARD (D4); distancia AMS-ARI (D5). Se registró también la topografía circunferencial de la ARD y ARI y los ángulos de TC, AMS, ARD y ARI respecto al Ao. Resultados: D1 media $6.17 \mathrm{~mm}$ (rango $3-12$ ); D2 media $16.42 \mathrm{~mm}$ (rango $32-13$ ); D3 media 19.5mm (rango 7-30); D4 media 11.75mm (3-28); D5 media 12,25mm (4-18). Topografía circunferencial: ARD media hora10 (rango 8-11); ARI media hora 3 (24). Ángulos entre arterias viscerales y Ao: TC media $105^{\circ}$ (rango 70-130); AMS media 61 ${ }^{\circ}$ (rango 43-74); ARD media $63^{\circ}$ (rango 60-90); ARI media $76^{\circ}$ (57110). Conclusiones: Los resultados muestran una gran variabilidad en la disposición de los vasos que se originan del Ao. Esto explica la necesidad de realizar el análisis individualizado de cada paciente para la elaboración de los dispositivos de EVAR con fenestras para las arterias viscerales.

\section{ANATOMIA QUIRURGICA DEL HIGADO: CONTROL VASCULAR Y MOVILIZACION}

María S FERRANTE; Rubén D ALGIERI; María de las M BERNADOU; Juan S UGARTEMENDÍA; Andrea R SINNONA; Carolina C BROFMAN

III Cátedra de Anatomía- Facultad de Medicina- UBA;

Servicio de Cirugía General - Hospital Aeronáutico Central. C.A.B.A. Argentina.

Introducción: Una cirugía exitosa no puede efectuarse sin un adecuado conocimiento de la anatomía quirúrgica, sobre todo en el trauma hepático, donde el conocimiento anatómico juega un rol fundamental a la hora de tomar rápidas decisiones que permitirán salvar la vida de los pacientes con esta patología en la urgencia. Material y Método: Programa de entrenamiento de 2 años de maniobras de control vascular y movilización hepática, para 11 residentes de cirugía general cursando su 2do, 3ro y 4to año. Se utilizaron 3 cadáveres frescos y 20 cadáveres formolizados al 10\%. Resultados: Las diferentes maniobras de movilización y control vascular del hígado fueron realizadas a partir del 2do año de residencia por tres años consecutivos. Se observó una disminución del $57 \%$ en los tiempos de realización de las maniobras y reconocimiento de estructuras en los residentes de 2do año que hicieron esta práctica por 3 años consecutivos, y del $38 \%$ en los residentes de 2 do y $3 \mathrm{er}$ año que lo realizaron por 2 años consecutivos con resultados similares. Discusión: La repetición en la práctica de las maniobras y en el reconocimiento de las estructuras anatómicas mejora el aprendizaje de la anatomía quirúrgica, resultando fundamental a la hora de realizar estas maniobras quirúrgicas cuando se dispone de poco tiempo para resolver una patología de urgencia como lo es el trauma hepático. El conocimiento anatómico en etapa de formación permite mejorar el abordaje quirúrgico del paciente traumatizado, disminuyendo el tiempo de realización de las maniobras y el riesgo de complicaciones.

BASES ANATÓMICAS DEL CONTROL VASCULAR DEL PEDÍCULO RENAL

María S FERRANTE; Cristian A FLORES; Juan P FERNANDEZ; Sofia CIPOLLONE; Gustavo M VASSIA; Humberto R INSFRAN
III Cátedra de Anatomía, Facultad de Medicina, Universidad de Buenos Aires; Servicio de Cirugía

General, Hospital Aeronáutico Central. C.A.B.A. Introducción: El conocimiento de las variaciones de la arteria renal cobra vital importancia a la hora de realizar procedimientos quirúrgicos, principalmente en el caso de: trasplantes renales donde dichas variaciones pueden complicar el procedimiento y comprometer la viabilidad del órgano; reconstrucciones vasculares; nefrectomías por causas tumorales o de urgencia en el trauma renal; entre otras; para lo cual es necesario el conocimiento anatómico minucioso del pedículo renal, para un correcto abordaje y manejo del mismo. Material y Método: Estudio descriptivo y observacional. Se disecaron 36 preparados cadavéricos que no presentaban cirugías aortorenales ni malformaciones congénitas renoureterales demostrables y se analizaron el origen y desembocadura de las arterias renales bilateralmente en el periodo comprendido entre enero y agosto de 2015. Resultados: 25 $(69,44 \%)$ correspondieron a arterias renales de origen único y $11(30,56 \%)$ presentaron variaciones en el número de arterias renales principales y en la existencia de arterias polares accesorias. De las cuales, $4(36,37 \%)$ se dividió inmediatamente a su origen, en $4(36,37 \%)$ se objetivaron arterias renales dobles; $2(18,18 \%)$ presentaban uno el tronco principal más una arteria polar inferior derecha y otro el tronco principal más dos arterias polares izquierdas. Se advirtió un caso $(9,09 \%)$ de arteria renal triple izquierda. Discusión: El conocimiento anatómico de las arterias renales para los médicos residentes de cirugía general es necesario para el adecuado control vascular.

\section{VARIANTES ANATÓMICAS DEL SENO ESFENOIDAL: SU IMPORTANCIA EN LA CIRUGÍA TRANSESFENOIDAL ENDOSCÓPICA}

Fernando M FONTAO; Santiago D MOLINAS; Giuliana B OLMEDO; Pedro V UAD

Instituto Universitario del Hospital Italiano, CABA, Argentina.

Introducción: El seno esfenoidal presenta múltiples variantes anatómicas, algunas de las cuales predisponen a patología y a mayor riesgo de lesiones o complicaciones durante los procedimientos quirúrgicos. La tomografía computada (TC) constituye una herramienta muy útil en el diagnóstico inicial y en el estudio para plantear el tratamiento quirúrgico de sus patologías. Este trabajo se propone ilustrar mediante la TC la anatomía del seno esfenoidal, sus relaciones y variantes anatómicas más frecuentes. Materiales y Método: Se realizo un estudio descriptivo, retrospectivo. Se efectuó la revisión de las historias clínicas electrónicas, del archivo digital de imágenes y de los informes correspondientes a fin de detectar las variantes anatómicas esfenoidales. Resultados: Las variantes anatómicas del seno esfenoidal halladas fueron: seno esfenoidal tabicado, conchal, neumatización del clivus, del ala mayor, de la apófisis pterigoides, de las apófisis clinoides anteriores, de la pars maxilaris, celdillas esfenoetmoidales, protuberancia de la arteria carótida interna, protuberancia del nervio óptico. Discusión: La TC proporciona 
información detallada de la anatomía del seno esfenoidal y juega un papel fundamental en el diagnóstico de sus variaciones anatómicas, así como de sus patologías. Las variantes anatómicas del seno esfenoidal deben ser cuidadosamente analizadas. Su adecuado y oportuno reporte es imprescindible para una mejor orientación en la toma de decisiones sobre los enfoques terapéuticos y quirúrgicos clínicos, actuando como una herramienta esencial para un mejor desempeño de las técnicas quirúrgicas menos invasivas.

\section{TOPOGRAFÍA INTRANEURAL DE LA RAMA PROFUNDA DEL NERVIO ULNAR EN EL ANTEBRAZO DISTAL}

Joaquín GARCÍA, Federico FLEITAS, Bruno

GARBARINO, Emilia CERCHIARI, Andrés POUY

Departamento de Anatomía - Facultad de Medicina, UDELAR, Montevideo, Uruguay

Introducción: La manipulación excesiva del nervio ulnar durante la sección de su rama profunda podría poner en riesgo el éxito de las transferencias nerviosas. El objetivo del presente trabajo es identificar la topografía intraneural de la rama profunda del nervio ulnar en el sector distal del antebrazo. Materiales y Métodos: En 15 miembros superiores formolados se fijó el paquete vasculonervioso ulnar a los planos profundos cada un centímetro, sin movilizar su cara profunda, tomando como referencia el hueso pisiforme. Se disecó bajo microscopio quirúrgico (420x) en sentido proximal la rama profundo del nervio ulnar, y se registró su topografía intraneural en cada centímetro. Resultados: La rama profunda del nervio ulnar ocupó el cuadrante posteromedial del nervio ulnar en el $74,4 \%(66,7-86,7)$, el $92,5 \%(91,7-93,3)$ y el $100 \%$ de los casos entre el $\mathrm{cm} 0-2 \mathrm{~cm}, 3-6 \mathrm{~cm}$ y $6-9 \mathrm{~cm}$, respectivamente. Discusión: La topografía intraneural de la rama profunda del nervio ulnar es casi constante en el antebrazo distal, permitiendo predecir su topografía y evitar la disección extensa en vistas a su sección durante los procedimientos de transferencia nerviosa.

\section{TRIPLE VARIACIÓN ANATÓMICA DEL CÍRCULO ARTERIAL CEREBRAL: REPORTE DE CASO Y REVISIÓN BIBLIOGRÁFICA}

Joaquín GARCÍA, Alejandra GARRETANO, Andrés POUY, Carolina FERNANDEZ

Departamento de Anatomía, Facultad de Medicina, UDELAR, Montevideo, Uruguay

Introducción: El círculo arterial cerebral constituye la principal anastomosis entre los sistemas carotídeo y vértebro-basilar. Su configuración clásica, descrita por Thomas Willis en 1664, presenta una alta frecuencia de variaciones. Materiales y Método: Se presenta el caso de una mujer de 64 años, con cuadro de diplopia progresiva de 2 años de evolución, constatándose al examen físico parálisis completa del nervio abducens derecho. Se revisaron de forma retrospectiva los estudios imagenológicos: TC y angiografía por substracción digital. Se realizó una revisión bibliográfica en PubMed y Scielo. Resultados: Las variaciones anatómicas halladas y su frecuencia fueron: aplasia bilateral del segmento P1 de la arteria cerebral posterior: $1,3 \%$; disposición fetal de la arteria cerebral posterior: $39 \%$; arteria trigeminal persistente: $0,68 \%$. Discusión: Las variantes anatómicas encontradas presentan baja frecuencia, no existiendo reportes de su asociación hasta nuestro conocimiento. Se discuten las implicancias clínicas de los hallazgos.

\section{APLICACIÓN DE LA TERMINOLOGÍA ANATÓMICA EN EL HOSPITAL UNIVERSITARIO}

Joaquín GARCÍA; Alejandra MANSILLA, Nicolás CANCELA, José P MACADAM, Sofía MANSILLA, Andrés POUY

Departamento de Anatomía, Facultad de Medicina, UDELAR y Departamento de Imagenología, Hospital Pasteur. Montevideo, Uruguay

Introducción: En 1997 la Federación internacional de Asociaciones de Anatomistas y el Comité Federativo de Terminología Anatómica aprobaron la última versión de la nomenclatura anatómica, publicada en 1998 como Terminología Anatómica. El objetivo de este trabajo fue identificar su aplicación en la práctica clínica en el hospital universitario de Uruguay. Material y Métodos: Se revisaron 80 informes de ecografía Doppler vascular realizados en el año 2014, 30 de miembros superiores y 30 de miembros inferiores. Se registraron los términos anatómicos presentes en cada uno, y se revisó su adecuación a la Terminología Anatómica. Resultados: Se encontraron 51 términos anatómicos utilizados en los informes revisados. Del total, $24(47 \%)$ no estaban incluidos en la Terminología anatómica, mientras que los 27 restantes (53), si lo estuvieron. Estos últimos correspondieron a términos que no fueron modificados en la Terminología Anatómica. Discusión: A pesar de que ya pasaron más de 17 años desde la adopción de la Terminología Anatómica, nuestro estudio demuestra que la misma ha tenido mínima permeación en el ámbito clínico. Resta por comprobar el efecto de la aplicación exclusive de la Terminología Anatómica en la conducta del médico clínico.

\section{CARACTERÍSTICAS MORFOLÓGICAS E INMUNOHISTOQUÍMICAS DEL ADENOCARCINOMA DE CELULAS BASALES DE PAROTIDA \\ Pedro E GARCÍA ${ }^{1}$, Rodolfo E AVILA ${ }^{1}$, María E SAMAR ${ }^{2}$ \\ ${ }^{1}$ Cátedra de Biología Celular, Histología y Embriología. \\ Facultad de Ciencias Médicas, ${ }^{2}$ Departamento de \\ Biología Bucal. Facultad de Odontología. Universidad Nacional de Córdoba. Argentina}

Introducción: En el año 2005 la OMS definió al adenocarcinoma de células basales (AcCB) (ICD-O Code 8147/3) como una neoplasia epitelial con las características citológicas del adenoma de células basales (ACB) pero con un patrón morfológico de crecimiento infiltrativo indicativo de malignidad. El objetivo del presente estudio fue identificar características morfológicas e inmunohistoquímicas que contribuyen al diagnóstico de AcCB. Material y Métodos: Se resecó un tumor del lóbulo profundo de parótida izquierda en una paciente de 52 años; se realizó biopsia postoperatoria e inmunomarcación con Ki 67, CK19, p63 y alfa actina de músculo liso. Resultados: A la macroscopía se observó una masa 
encapsulada ligeramente lobulada, de $5 \times 1,7 \times 1,2 \mathrm{~cm}$ de color gris violáceo con zonas firmes al corte. Microscopía: Se diagnosticó AcCB mixto sólido y tubular con invasión de la cápsula, nodos linfoides y vasos sanguíneos. No se observó glándula normal. La inmunomarcación con Ki 67, CK19, p63 y alfa actina de músculo liso resultó positiva. Discusión: Las características morfológicas y la inmunomarcación Ki67 positiva le dan el carácter maligno a este tumor, lo que lo diferencia de su contraparte benigna, el ACB. El hallazgo de tejido tumoral dentro de un nodo linfoide indica la presencia de metástasis.

\section{CARACTERÍSTICAS CLÍNICO-HISTOLÓGICAS DE UN CASO DE CARCINOMA INDIFERENCIADO TIPO CÉLULAS GRANDES DE PARÓTIDA \\ Pedro E GARCÍA ${ }^{1}$, María E SAMAR ${ }^{2}$; Rodolfo E AVILA ${ }^{1}$ \\ ${ }^{1}$ Cát. de Biología Celular, Histología y Embriología. Fac. de Ciencias Médicas; ${ }^{2}$ Dep. de Biología Bucal. \\ Fac. de Odontología. Universidad Nacional de Córdoba. Argentina}

Introducción: El carcinoma indiferenciado tipo células grandes (ISD-O Code 8012/3) es un subtipo raro, altamente maligno y agresivo de carcinoma indiferenciado con grandes células de citoplasma eosinofílico pálido y abundante. Se presenta generalmente en varones mayores de 60 años, más frecuentemente en parótida. En este informe describimos las características clínico-histológicas de un carcinoma indiferenciado tipo células grandes de parótida, su potencial proliferativo y realizamos el diagnóstico diferencial con otras neoplasias salivales. Material y Métodos: Paciente varón de 67 años que consultó por un nódulo duro de parótida derecha de 6 meses de evolución, con signos de parálisis facial. Se realizó ecografía y se realizó la extirpación del tumor. Se indicó radioterapia. La biopsia se estudió con H/E y se realizó inmunomarcación con Ki67 para analizar su capacidad proliferativa. Resultados: El tumor, no encapsulado, estaba formado por células grandes, mayores de $30 \mu \mathrm{m}$, con núcleos grandes, redondos y vesiculares, con uno o más nucléolos. En áreas aparecían células ahusadas eosinofílicas y núcleos alargados con cromatina más densa. Se observaron células anaplásicas y células gigantes multinucleadas dispersas entre los otros tipos celulares. Se observaron mitosis, áreas hemorrágicas y de necrosis $e$ invasión vascular. El estroma presentó un infiltrado inflamatorio. La expresión de Ki 67 fue positiva. Discusión: El diagnóstico microscópico corresponde a un carcinoma indiferenciado de células grandes, con potencial proliferativo positivo. Su diagnóstico es histopatológico ya que la clínica no lo diferencia de otros tumores salivales. En su diagnóstico diferencial incluimos carcinoma escamoso y adenocarcinoma pobrementes diferenciados, linfoma anaplásico y melanoma.

SÍNDROME DEL ESPACIO CUADRILÁTERO: ¿INFRECUENTE O INSOSPECHADO?

L GUTIERREZ $Z^{1}$; M CULLIARI ${ }^{1}$; M RANALETTA ${ }^{2}$; TANOIRA ${ }^{2} ;$ C GOMEZ $^{2}$; M BENDERSKY ${ }^{1,3}$
${ }^{1}$ Lab. de Anatomía Viviente, III Cát. de Anatomía, Fac. de Medicina, U.B.A; ${ }^{2}$ Servicio de Ortopedia y Traumatologia, Hosp. Italiano; ${ }^{3}$ Escuela de Medicina, Inst- Universitario Hospital Italiano. C.A.B.A. Argentina Introducción: El síndrome del espacio cuadrilátero (QSS) es un cuadro clínico causado por la compresión nerviosa y/o vascular a nivel del espacio axilar lateral. La prevalencia de este síndrome se desconoce y se cree que es baja, sin embargo formas de presentación incompleta podrían llevar a que el mismo sea subdiagnosticado. Objetivo: Describir un protocolo diagnóstico utilizado en una serie de casos consecutivos de pacientes con omalgia inespecífica y sospecha de QSS. Materiales y Métodos: De manera prospectiva se evaluaron 10 pacientes con omalgia agravada con la rotación externa forzada, uno de ellos con síntomas bilaterales. Se les realizó EMG de deltoides y redondo menor bilaterales, con estudios de conducción nerviosa. Los valores se compararon con el hombro sano, y con un grupo control. El diagnóstico se confirmó mediante resonancia magnética nuclear (RMN). Resultados: El EMG mostró en todos los casos atrapamiento con compromiso axonal de la rama para el redondo menor, con preservación de la inervación del deltoides. La RMN mostró en los 11 hombros afectados atrofia selectiva del redondo menor. Discusión: EI QSS resulta de difícil diagnóstico clínico, sin embargo no parece ser tan infrecuente, y debe ser tenida en cuenta luego de descartar otras causas de omalgia. Resulta imprescindible conocer la anatomía del espacio así como las variaciones del nervio axilar a este nivel.

\section{REPRODUCCIONES EN RESINA EPOXI DE PREPARADOS ÓSTEO-CARTILAGINOSOS PARA SU USO EN LOS TRABAJOS PRÁCTICOS DE ANATOMÍA NORMAL}

Felipe HIGUERA, José VIÑAS, Humberto N JIMÉNEZ VILLARRUEL

Lab. de Anatomía aplicada a la práctica médica, III Cát. de Anatomía Normal, Departamento de Anatomía,

Facultad de Medicina, U.B.A., C.A.B.A. Argentina. Introducción: El objetivo de este trabajo es describir una técnica de reproducción de preparados anatómicos, de aquellas regiones que por su tamaño y fragilidad son difíciles de preservar para la mostración a los alumnos de pregrado; Se hicieron piezas de resina epoxi que, cumpliendo con los requisitos de ser sencilla, económica y accesible, constituyen una solución al problema de la escasez de preparados disponibles durante los trabajos prácticos de la materia. Materiales y métodos: Se utilizaron un carpo óseo de adulto, silicona, resina epoxi cristalina, colorantes y moldes plásticos de tamaño adecuado. En una primera etapa, se confeccionaron moldes de silicona de los huesos del carpo. Luego se procedió a la reproducción de las estructuras utilizando una mezcla de resina epoxi cristalina y distintos colorantes. Resultados: Se obtuvieron piezas de resina epoxi coloreada con alto grado de similitud a las piezas óseas originales y de consistencia adecuada. Discusión: Esta técnica posibilita la realización en grandes cantidades de piezas en resina epoxi para suplir la carencia de piezas óseas o cartilaginosas de difícil obtención o contextura endeble. Consideramos que 
dado el alto grado de fidelidad en las características anatómicas de las piezas obtenidas, la posibilidad de crear grandes cantidades sin desperdiciar material biológico y el bajo costo, la técnica es ideal para suplir la ausencia de huesos del carpo, tarso, cóccix, hioides, cartílagos laríngeos y vertebras con características particulares en la enseñanza de pregrado de Anatomía.

\section{LAS COMPLICACIONES MÉDICAS COMO RECURSO DIDÁCTICO EN LA ENSEÑANZA DE LA ANATOMÍA}

Federico IGLESIAS ${ }^{1}$, Eugenia FERNÁNDEZ TALAVERA ${ }^{1}$, Tatiana RODRÍGUEZ ${ }^{1}$, Patricio BRUNI ${ }^{1}$, Facundo N DÍAZ ${ }^{1,5}$, Gustavo HRA OTEGUI 1, 2,3,4

${ }^{1}$ Lab. de Imágenes, $2^{a}$ Cát. de Anatomía, Fac. de Medicina, U.B.A; ${ }^{2}$ Lab. de Ciencias Morfológicas, $2^{a}$ Cát.de Anatomía, Fac. de Medicina, U.B.A.; ${ }^{3}$ Instit. de Morfología J.J. Naón, Fac. de Medicina, U.B.A; ${ }^{4}$ Depto Biomédico, Esc. Sup. de Cs de la Salud, U.N.C.P.B.A.,

Olavarría, B.A; ${ }^{5}$ Hosp. Italiano. C.A.B.A. Argentina Introdución: En línea con el marco epistémico llamado $3^{a}$ paradigma (investigación-descubrimiento), usamos las imágenes diagnósticas para aprender anatomía en un contexto de aplicación médica que genere motivación intrínseca y enseñe a pensar críticamente. El objetivo del presente trabajo es corroborar la efectividad didáctica de un "caso anatomo-clínico" basado en complicaciones médicas, al ser usado en la enseñanza de la anatomía para desarrollar competencias de razonamiento deductivo y de interpretación anatómica. Materiales y Métodos: Se usó el caso de "complicaciones de la punción prostática guiada por ecografía". Para tal fin se recogieron imágenes diagnósticas y se consignaron en la historia clínica los siguientes signos: hematoquesia, hemospermia, hematuria, colección hemática en espacio pelvisubperitoneal. Se entrevistó a los docentes que aplicaron el método para recogen evidencia sobre el impacto del nuevo recurso en la generación de competencias orientadas al uso del razonamiento deductivo y del pensamiento crítico. Resultados: El razonamiento deductivo se expresó fuertemente al tratar de explicar el modo en que la sangre pudo alcanzar los diferentes lugares mencionados en la historia clínica. La exigencia de realizar diagnósticos diferenciales desarrolló el espíritu crítico al tratar de fundamentar con argumentos y evidencia la localización de la colecciones hemáticas. Discusión: el recursos de didáctico generado introduce el uso de las complicaciones médicas, generando un modelo innovador en la didáctica de la anatomía, con capacidad de interpelar al sujeto que aprende que debe cuestionarse sobre lo que está viendo y relacionarlo con la signo-sintomatología que "su paciente" presenta. Key words: ecografía, modelos didácticos, complicaciones médicas.

\section{IMPRESIONES 3D EN ANATOMÍA: EDUCACIÓN, INVESTIGACIÓN Y DESARROLLO}

Joaquín LANUZA ${ }^{1}$; Hilario BIELSA ${ }^{1} ;$ A Nicolás RIVERO ${ }^{1}$; Gustavo HRA OTEGUI ${ }^{1,2,3}$

${ }^{1}$ Laboratorio de Preparaciones Especiales, $2^{a}$ Cátedra de Anatomía, Facultad de Medicina, U.B.A.; ${ }^{2}$ Instituto de Morfología J.J. Naón, Facultad de Medicina, U.B.A., C.A.B.A.; ${ }^{3}$ Departamento Biomédico, Escuela Superior de Ciencias de la Salud, U.N.C.P.B.A., Olavarría, B.A. Argentina

Introducción: las maquetas más o menos realistas y/o las preparaciones cadavéricas regladas en base a manuales de disección son clásicos en el uso de trabajos prácticos de anatomía. El objetivo del presente trabajo fue desarrollar impresiones 3D obtenidas de la "disección virtual" a partir de fotografías e imágenes diagnósticas. Materiales y Métodos: se usaron fotografías e imágenes diagnósticas que fueron previamente procesadas con software libre y otros programas licenciados como Autodesk $₫$ y Sketchup $®$ para obtener la versión 3D de piezas únicas confeccionadas a medida según requerimientos didácticos o de investigación buscado. Las impresiones $3 D$ se realizaron en un equipo 3D T-Element. $\circledR$ usando el polímero Filamento ABS blanco Trimaker®. Resultados: se obtuvieron piezas "reales" en versiones 3D que pueden ser visualizadas y manipuladas según necesidades educativas, de investígación científica o de extensión-vinculación-transferencia a otras áreas de aplicación. La varia-bilidad de las piezas obtenidas depende del diseño y del material usado para la impresión. La fidelidad de las piezas es aceptable y variable según diseño y limitación de tipos de impresoras usadas. Discusión: el método introduce innovaciones importantes tales como: a) diseño y preparación de piezas únicas con capacidad de reproducción por diferentes medios, incluida la propia impresión 3D; b) prototipado de "originales" cuya versión inicial es una pieza muy frágil (disección de cerebro) o bien no existe en versión cadavérica; c) reproducción y reemplazo de material cadavérico; d) estructuras $3 \mathrm{D}$ reales de piezas que en principio prefieren no disecarse, tales como momias, proceso inicial de autopsias con riesgo de lesiones que oculten información, etc.

\section{CONDUCTO ALVEOLAR INFERIOR - CORRELATO ANATOMO IMAGENOLOGICO E IMPLICANCIA EN LOS PROCEMIENTOS QUIRURGICOS DE MANDIBULA}

\section{Andrés C LIMARDO ${ }^{1,2}$; Belén DE FAZIO ${ }^{1}$; Francisco} LEZCANO $^{1}$; Rodrigo VALLEJOS ${ }^{3}$; Nicolás ABUD ${ }^{1}$; Luis A BLANCO ${ }^{1,4}$

${ }^{1}$ III Cátedra de Anatomía. Facultad de Medicina. U.B.A. CABA; ${ }^{2}$ Cirugía de Cabeza y Cuello, ${ }^{3}$ Servicio de Odontología $y{ }^{4}$ Cirugía General, Hospital Nacional Prof. A. Posadas, Bs. As. Argentina

Introducción: La anatomía del conducto alveolar inferior al parecer es bien conocida pero a pesar de ello las lesiones iatrogénicas del nervio dentario inferior son una complicación bien documentada de cirugías terceros molares, la colocación del implante, osteotomías, o osteosíntesis de mandíbula. Debido a ello se justificaría una descripción más detallada con referencias morfométricas de dicho conducto y a partir de ello realizar una correlación con imágenes. Materiales y método: Se realizo un estudio descriptivo observacional con una muestra de $n=44$ hemimandibulas secas y $n=100$ tomografías computadas de mandíbulas de pacientes al azar. Se utilizaron $n=44$ hemimandíbulas humanas secas, midiendo distancias 
del foramen mandibular con respecto a los bordes anterior, posterior, inferior y escotadura sigmoidea, las distancias del agujero mentoniano al borde basal y la cresta alveolar. Se hicieron cortes en la rama y el cuerpo, para determinar las relaciones con estructuras anatómicas próximas. Además de los preparados anatómicos se utilizaron Tomografías computadas de $n=100$ pacientes las cuales fueron procesadas por el programa Compudent Navigator 3D. Utilizando este programa se pudieron realizar las mismas mediciones que en los preparados anatómicos. En una segunda etapa se realizo una correlación entre los valores morfométricos del estudio anatómico y se comparo con estudios por imágenes (TAC con reconstrucción 3D y Dental Scan). Resultados: Al realizar un minucioso estudio de los preparados anatómicos y de los estudios por imágenes se llego a un acabado conocimiento de la morfología y la morfometria del conducto alveolar inferior. Discusión: Tomando como punto de partida la anatomía y correlacionándola con la imagenologia podemos llegar a evitar lesiones del nervio alveolar inferior en el transcurso de diversos procedimientos realizados en la mandíbula.

\section{HISTORIA DEL DESCUBRIMIENTO DEL SISTEMA DE CONDUCCION}

Sebastián LOBBOSCO, Nicolás PICCO, Facundo

COTON, Gregorio FOSSER, Ignacio de MARCO Laboratorio de Cardioanatomía. Instituto de Morfología JJ Naón. Facultad de Medicina. U.B.A.

Introducción: Durante el siglo 19 hubo dos teorías que explicaban el latido del corazón, la miogénica y la neurogénica. Material y Metodos: Se realizó una revisión bibliográfica sobre los diferentes personajes responsables. Resultados: El iniciador fue Purkinje quien, en 1839 describió una red gris plana y gelatinosa de fibras en el subendocardio ventricular del corazón de la oveja. En 1880 Gaskell observo la conducción del impulso cardiaco auriculo-ventricular, estudiando corazones de tortuga. El identifico una propagación retardada del impulso en la unión auriculoventricular. En 1893 His, Jr encontró un haz muscular que unía la pared septal de la aurícula y el ventrículo. Esto lo logro examinando una serie de secciones del corazón durante diferentes estadios de desarrollo embriológico (técnica aprendida de su padre). En 1906 Tawara, fue capaz de seguir al haz de Hiz hacia proximal donde terminaba en una compacta red de fibras que llamo "Knoten" (nodo) en la base del septum atrial. Mientras que siguiéndolo hacia distal, observo que el haz de Hiz se dividía en dos ramas que se conectaban con un grupo de células musculares dispersos en el subendocardio (fibras de Purkinje).Ese mismo año, Keith y Flack, descubrieron el nodo sinoauricular. En 1910 Lewis realizo la prueba electrofisiológica que confirmo que el nódulo sinusal es el "marcapasos" cardíaco. Discusión: EL sistema de conducción fue descubierto de manera retrograda, yendo de distal a proximal en la vía. Tawara termino de inclinar la balanza hacia la teoría miogénica.

\section{DESCRIPCION MORFOMETRICA DEL MUSCULO TRÍCEPS SURAL: UN ESTUDIO CON MATERIAL CADAVÉRICO \\ Wilson M LOZANO', Luis E BALLESTEROS ${ }^{2}$}

${ }^{1}$ Maestría Ciencias Básicas Biomédicas; ${ }^{2}$ Lab.de Morfología. Departamento Ciencias Básicas, Facultad de Salud, Universidad Industrial. Santander, Colombia. Introducción: La caracterización morfométrica del musculo tríceps sural (MTS) y de sus puntos motores (PM) ha sido claramente descrito en otros grupos poblacionales. El propósito de este estudio fue describir las características biométricas del MTS en una muestra de población colombiana. Métodos y Métodos: Previa disección del compartimento posterior de 32 piernas de especímenes cadavéricos, se registraron las dimensiones del MTS; así como distancia y número de sus PM. Resultados: En el $100 \%$ de los especímenes la cabeza medial del gastrocnemio presentó mayor longitud que la lateral $(401,3 \pm 52,3 \mathrm{~mm}$ y $383,1 \pm 88,9 \mathrm{~mm})$ sin diferencias significativas $(P>0,23)$. Se observó agenesia del gastocnemio medial en un caso. El ancho de la unión de gastrocnemios $(60,3 \pm 21,2 \mathrm{~mm})$ fue menor en $96,9 \%$ de los casos comparada con el ancho del soleo $(78,7 \pm 31,4 \mathrm{~mm})$; sin diferencias estadísticamente significativas. La longitud para el tendón calcáneo fue de $68,9 \pm 14 \mathrm{~mm}$. El musculo soleo presento 83 puntos motores $(38,24 \%)$, mientras que el numero de puntos motores para los gastrocnemio medial y lateral fue de 67 para cada uno $(30,87 \%)$. Las distancias de los PM fue de 364,$1 ; 360,5$ y $304,1 \mathrm{~mm}$ para gastrocnemio medial, lateral y soleo respectivamente. No se evidencio predominio de lateralidad en relación con la cantidad de puntos motores (Chi $\left.\left(X^{2}\right)=0,54\right)$. Discusión: El conocimiento detallado de la morfometría del MTS, la identificación de variantes anatómicas y determinación del área de dispersión de sus PM es útil para la toma de decisiones de carácter diagnostica y de intervención médica, quirúrgica y terapéutica.

\section{EXPRESIÓN MORFOLÓGICA DEL MUSCULO PLANTAR EN ESPECÍMENES CADAVÉRICOS DE UNA POBLACIÓN COLOMBIANA}

Wilson M LOZANO ${ }^{1}$; Luis E BALLESTEROS ${ }^{2}$

${ }^{1}$ Maestría Ciencias Básicas Biomédicas; ${ }^{2}$ Lab- de

Morfología. Dep. Ciencias Básicas, Facultad de Salud, Universidad Industrial de Santander, Colombia. Introducción: El musculo plantar (MP) se origina en el extremo inferior de la línea supracondilea lateral del fémur y el ligamento poplíteo oblicuo; su tendón discurre por el borde medial del tríceps sural. El objetivo de este trabajo es describir la expresión morfológica del musculo plantar en una muestra de especímenes cadavéricos de la ciudad de Bucaramanga-Colombia. Métodos y Métodos: Mediante disección del compartimento posterior de 32 piernas de especímenes cadavéricos, se registraron las dimensiones del tendón plantar, su punto de inserción y área de dispersión de los puntos motores. Resultados: Se observo agenesia del MP en el $21,9 \%$. La longitud total del MP fue de $391,9 \pm 42,5 \mathrm{~mm}$ y de su tendón $312,7 \pm 36,7 \mathrm{~mm}$. En el $43,5 \%$ de los casos la inserción del tendón plantar fue en el borde medial del tendón calcáneo. Así mismo, se registro el ancho del tendón a nivel proximal $(0,77 \pm 0,03 \mathrm{~mm})$ y a nivel de su inserción $(1,18 \pm 0,23 \mathrm{~mm})$; sin diferencias estadísticamente significativas con relación a lateralidad $(P>0,23)$. Además, solo el $8 \%$ registro dos puntos motores. El área de dispersión de los puntos motores 
oscilo entre 305-400mm. Discusión: El MP puede formar parte de los componentes musculares del tríceps sural, en este caso seria podría llamarse cuádriceps sural. Repercutiendo directamente en la función muscular y da relevancia quirúrgica, como injerto en las lesiones ligamantarias y tendinosas. Así mismo, al conocer el área de inserción en el tendón calcáneo y sus dimensiones permitirá que sea utilizado quirúrgicamente de manera mas precisa.

\section{RAZONAR CLINICAMENTE A PARTIR DE PREPARACIONES ANATÓMICAS ESPECIALES}

Juan I LUNA MOZZI ${ }^{1}$; David OLMEDO ${ }^{1}$; Antonella A BAGÚ $^{1}$; Gustavo HRA OTEGUI ${ }^{1,2,3}$,

${ }^{1}$ Lab. de Preparaciones Especiales, $2^{a}$ Cát. de Anatomía, Fac. de Medicina, U.B.A.; ${ }^{2}$ Instituto de Morfología J.J. Naón, Fac. de Medicina, U.B.A., C.A.B.A.; ${ }^{3}$ Dep. Biomédico, Esc. Superior de Ciencias de la Salud, U.N.C.P.B.A., Olavarría, B.A. Argentina Introducción: es común que los docentes de anatomía que son médicos o estudiantes de medicina avanzados, hagan mención a la importancia que un dato anatómico puede tener en la futura práctica profesional. Así mismo es raro o infrecuente encontrar en anatomía recursos didácticos que faciliten u orienten el aprendizaje de los estudiantes. El objetivo de este trabajo es diseñar modelos (preparaciones especiales) para facilitar el aprendizaje de la anatomía clínica del estómago y duodeno. Materiales y Métodos: se usaron las siguientes preparaciones: sección axial de abdomen, inyección-disección de la vascularización del estómago y duodeno, recreación de hemorragias, recreación de ulceras, perforación de ulceras. A las preparaciones se sumaron imágenes radiológicas y endoscópicas y se diseñaron casos clínicos ad hoc. Se diseñó y aplicó la experiencia de enseñanza aprendizaje a alumnos de $1^{\circ}$ año. Resultados: Los docentes encontraron muy útiles los recursos didácticos diseñados para aplicar en este modelo de enseñanza aprendizaje y los estudiantes disfrutaron de los recursos y encontraron que éstos les facilitaban el aprendizaje de la estructura en cuestión, en este caso la anatomía clínica del estómago y el duodeno. Discusión: el diseño de estas piezas introdujo innovaciones importantes que permitieron valerse de la estructura para dar cuenta de las complicaciones de úlceras del estómago y el duodeno. La topografía de la úlcera y su relación con el tipo de complicación surge como evidente a partir del análisis de las preparaciones.

\section{SEMEJANZAS Y DIFERENCIAS - VENTAJAS Y DESVENTAJAS ENTRE LAS TÉCNICAS DE SEPARACIÓN DE COMPONENTES DE RAMÍREZ (1990) Y ALBANESE (1951)}

Sergio D MADEO ${ }^{1,2,3}$; Gabriel E PISTÁN ${ }^{2}$

${ }^{1}$ Hospital Oncológico María Curie; ${ }^{2}$ Cátedra de Anatomía de la Facultad de Medicina (UBA); ${ }^{3}$ Cátedra de Anatomía de la Universidad Nacional de La Matanza (UNLaM). C.A.B.A. Argentina.

Introducción: El tratamiento de la hernia incisional requiere un gran conocimiento anatómico. Cuando no se puede colocar la malla y existen grandes hernias se requieren técnicas que permitan reconstruir la línea blanca. Nuestro objetivo es describir las semejanzas de diferencias entre las Técnicas de Ramírez y de Albanese, analizar sus ventajas y desventajas. Material y Método: Se describen las Técnicas de Ramirez y de Albanese, señalando las semejanzas, diferencias técnicas e indicaciones. Se analizan sus ventajas y desventajas. Resultados: Se asemejan en la apertura del borde medial del anillo herniario (borde medial del músculo recto del abdomen). La incisión sobre el oblicuo externo del abdomen, para Ramírez, es limitada al sector aponeurótico pararrectal y es más lateral, sobre el sector muscular, más larga y amplia para Albanese, quien agrega una 2da incisión de descarga. Entre las ventajas y desventajas, en Ramírez se evita la disección del tejido dermocutáneo, limitando el desplazamiento medial del complejo muscular. Albanese permite un gran avance del colgajo muscular, con una mayor disección dermocutánea y la sección de un sector aponeurótico (oblicuo interno del abdomen) que ampliado caudalmente origina el "abdomen de batracio". Ambas poseen limitaciones infraumbilicales en el desplazamiento medial del colgajo muscular. Estas técnicas son indispensables en la reparación de hernias incisionales cuando no se puede colocar una malla, en hernias grandes con malla, la técnica de Albanese es satisfactoria. Mayoritariamente la Técnica de Ramírez satisface las necesidades de relajamiento de la pared abdominal.

\section{ESTUDIO DE LAS ARTERIAS ORIGINADAS DEL ARCO AÓRTICO: CORRELACIÓN ANATOMO-RADIOLÓGICA}

\section{Alejandra MANSILLA ${ }^{1}$, Alejandra GARRETANO ${ }^{1}$,} Andrés POUY ${ }^{1}$, Sofía MANSILLA ${ }^{1}$, Crihstian J PEREIRA $^{1}$, Joaquín GARCÍA ${ }^{1,2}$, Alejandro M RUSSO ${ }^{1}$

${ }^{1}$ Departamento de Anatomía, Facultad de Medicina; ${ }^{2}$ Departamento de Imagenología, Hospital de Clínicas.

Universidad de la República, Montevideo, Uruguay

Introducción: El advenimiento de la cirugía endovascular demanda conocimiento de la anatomía vascular. El arco aórtico (AA) no escapa a esta regla, en donde el estudio morfométrico de las arterias que éste origina interesa para el "planning" quirúrgico. El objetivo del siguiente trabajo es estudiar la anatomía de las arterias originadas del AA en cadáveres y en tomografía. Método: Se utilizaron 25 cadáveres $(n=25)$ fijados en solución formolada y 25 tomografías con protocolo angioTC $(n=25)$. Se registró: cantidad y qué arterias se originaban del AA, esto permitió definir un AA clásico o variante. Se midió el calibre de las arterias y distancia entre éstas. Resultados: En los cadáveres se encontró 19 (76\%) AA clásicos y 6 (24\%) AA variantes, en las angioTC 17 (68\%) AA clásicos y $8(32 \%)$ variantes. Los calibres en cadáveres en promedio: primer tronco 14,2mm, segúndo $6,7 \mathrm{~mm}$, tercero $9,2 \mathrm{~mm}$, cuarto de existir, $3,5 \mathrm{~mm}$. En las angioTC los calibres en promedio: primer vaso $12,3 \mathrm{~mm}$, segundo vaso $7,8 \mathrm{~mm}$, tercer vaso $11,1 \mathrm{~mm}$, cuarto vaso de existir, $3,3 \mathrm{~mm}$. Las distancias en promedio en cadáveres: entre primer y segundo vaso $17,7 \mathrm{~mm}$, entre primero y tercero 25,5mm, En las angioTC las distancias en promedio: entre primer y segundo vaso $18,8 \mathrm{~mm}$; entre primero y tercero $28,4 \mathrm{~mm}$. Discusión: Existiría un porcentaje no despreciable de variaciones en la disposición así como 
en la morfología de las arterias que se originan en el AA. Esto obliga un conocimiento individualizado de la anatomía del AA y las arterias que éste origina en vistas a la planificación del procedimiento endovascular.

\section{PATRÓN ARTERIAL DE IRRIGACIÓN} MIOCÁRDICA: CONSECUENCIAS CLÍNICAS Cecilia L. MANTELLINI ${ }^{1}$; Victoria MAURO ${ }^{1}$; Gustavo HRA OTEGUI ${ }^{1,2,3}$

${ }^{1}$ Lab. de Ciencias Morfológicas, $2^{a}$ Cát. de Anatomía, Facultad de Medicina, U.B.A.; ${ }^{2}$ Inst.de Morfología J.J. Naón, Fac. de Medicina, U.B.A., C.A.B.A.; ${ }^{3} D e p$. Biomédico, Escuela Superior de Ciencias de la Salud, U.N.C.P.B.A., Olavarría, B.A. Argentina

Introducción: la caracterización de los infartos como subendocárdico o transmurales supone diferencias en la vascularización o bien en el modo en que los vasos transcurren e irrigan esa pared. En este trabajo nos propusimos caracterizar la relación entre el patrón de distribución arterial y la disposición arquitectural de las fibras miocárdicas de Bos taurus. Materiales y Métodos: se estudiaron 5 corazones de Bos taurus. Ambas arterias coronarias fueron inyectadas con látex coloreado y luego los corazones fueron hervidos en agua durante 3 horas. Se conservaron fijados en formol al $2 \%$. La disección se realizó mediante técnica tradicional y se usó el método de tracción fibrilar por planos para evidenciar la disposición de las fibras de miocardio. Resultados: a) nivel subepicárdico: predominio de arterias circunferenciales que siguen la dirección de las fibras, b) nivel medio: predominio de arterias perforantes y c) nivel subendocárdico: predominio de arterias tangenciales al plano lumina de los ventrículos y perpendiculares a la dirección de las fibras. Discusión: la disminución del flujo sanguíneo por el alto grado de tensión intramural de la pared ventricular, afectaría fundamentalmente a los vasos de menor calibre del nivel subendocárdico. Por otro lado la disposición arterial del subendocardio sufre el cruce perpendicular de las fibras miocárdicas disminuyendo el flujo sanguíneo. La mayor frecuencia de infartos subendocárdicos se explicaría, al menos parcialmente por la anatomía de este sector de la pared ventricular.

\section{LOS CONTRAEJEMPLOS QUE REFUTAN EL MODELO DE BANDA MIOCÁRDICA VENTRICULAR}

Emilio O MARCHETTI ${ }^{1}$; Mayra A BENEGA ${ }^{1}$; Ángeles S ANTUÑA ${ }^{1}$; Verena B FRANCO RIVEROS ${ }^{1}$; Gustavo HRA OTEGUI ${ }^{1,2,3}$

${ }^{1}$ Lab. de Ciencias Morfológicas, $2^{\text {a }}$ Cát. de Anatomía, Fac. de Medicina, U.B.A.; ${ }^{2}$ Instituto de Morfología J.J. Naón, Facultad de Medicina, U.B.A., C.A.B.A.; ${ }^{3}$ Dep. Biomédico, Escuela Superior de Ciencias de la Salud, U.N.C.P.B.A., Olavarría, B.A. Argentina Introdución: Torrent Guasp acuñó el término "Banda miocárdica ventricular (BMV)" para denotar e concepto de organización helicoidal con el cual describió la disposición de las fibras del miocardio ventricular. La Banda miocárdica ventricular de Torrent Guasp, consta de 2 lazadas: a) Lazada basal, constituida por dos segmentos (derecho e izquierdo), y b) lazada apexiana, constituida también por dos segmentos (descendente y ascendente). El presente trabajo se propuso contrastar el modelo de banda miocárdica ventricular de Torrent Guasp (TG). Materiales y Métodos: se estudiaron 7 corazones de Bos taurus hervidos en agua corriente durante 4 a 5 horas, según su tamaño. Se removió grasa, vasos y se los fijó en una solución de alcohol etílico al $10 \%$. Para la tracción de fibras se empleó una pinza tipo Adson y una esteca metálica sin filo. Resultados: a) Cada uno de los cuatro segmentos de las dos lazadas está constituido por más de una capa de fibras miocárdicas, b) no existen planos de clivaje entre segmentos, c) las fibras "aberrantes" de TG se tienden entre segmentos, d) los vasos sanguíneos del miocardio ventricular se disponen atravesando segmentos, e) ventrículo derecho e izquierdo deben ser separados seccionando a nivel del surco interventricular. Discusión: la banda miocárdica ventricular es una construcción hipotética que solo puede ser corroborada por los artificios de técnica enumerados en los resultados. Tal como fue formulada por Torrent Guasp no puede sostenerse. Los segmentos carecen de la individualidad que se les atribuye.

\section{DIAFRAGMA: ÓRGANO OLVIDADO EN TRAUMA TORACOABDOMINAL PENETRANTE}

Adela C MARTÍNEZ CERANA ${ }^{1,2}$, Leonardo COMOLY MARQUIONI ${ }^{1}$, Valeria A FORLIZZI ${ }^{1}$

1 II Cátedra de Anatomía, Facultad de Medicina, U.B.A.; ${ }^{2}$ Departamento de Urgencias, Hospital Juan A. Fernández. C.A.B.A. Argentina

Introducción: El conocimiento anatomofisiológico de la región toracoabdominal es imprescindible para el diagnóstico y terapéutica de las lesiones del diafragma. El traumatismo toracoabdominal origina lesiones de elementos anatómicos del tórax y del abdomen, tanto parietales como intracavitarios. En el traumatismo penetrante el agente agresor atraviesa el diafragma o múltiples injurias afectan ambas cavidades. Para diagnosticar las lesiones hay que pensar en ellas. Material y Métodos: Se analizó fisiopatológicamente el mecanismo lesional de cinco pacientes que ingresaron con heridas de arma blanca toracoabdominales en el Departamento de Urgencias del Hospital Fernández. Se realizaron disecciones de tres cadáveres fijados en solución de formaldehido para establecer los parámetros anatómicos de la morfología diafragmática. Resultados: Se presenta un algoritmo de manejo de estos pacientes desde el punto de vista anatomofisiológico. Paciente hemodinámicamente inestable: la conducta es inequívocamente quirúrgica. Paciente hemodinámicamente estable: se realiza radiografía de tórax, ecografía FAST (Focused Abdominal Sonography Trauma), lavado peritoneal diagnóstico y/o laparoscopía diagnóstica. Si el trauma es en la región dorsolateral se agrega tomografía axial computada. De acuerdo a los resultados se decide la conducta terapéutica. Discusión: Las heridas penetrantes en el área de incursión del diafragma deben ser pensadas anatomofisiológicamente. Las lesiones recibidas en flanco y dorso pueden manejarse en forma no operatoria. Se deben agudizar los métodos y sospechas diagnósticos para que no pasen desapercibidas. Las heridas de diafragma representan un desafío diagnóstico y terapéutico. 


\section{INERVACIÓN DE LA ARTICULACIÓN INTERFALÁNGICA PROXIMAL DE LOS DEDOS}

Ezequiel F MARTÍNEZ, Federico FRANCISCO, Martín J PASTRANA, Carlos R ZAIDENBERG

Unidad de Aparato Locomotor, $1^{\circ}$ Cát. de Anatomía,

Facultad de Medicina, U.B.A., C.A.B.A. Argentina Introducción: La articulación interfalángica proximal (IFP) de los dedos resulta esencial en la biomecánica digital. De afectación poco frecuente, una vez instalada produce una significativa incapacidad. Su anatomía osteoarticular es conocida en detalle, no así su inervación. Gray \& Gardner ${ }^{1}$ la describen dada por ramos de los nervios digitales palmares y nervios digitales dorsales. Schultz ${ }^{2}$ las considera inervadas exclusivamente por ramos de nervios digitales palmares. Nuestro propósito es describir la inervación de las articulaciones interfalángicas proximales de los dedos y sus relaciones regionales. Materiales y Métodos: $\mathrm{Se}$ disecaron 27 dedos no fijados, con magnificación de 3.5 - $6.0 \mathrm{X}$, inyectados vía arterial con látex coloreado. En todos se realizó una incisión longitudinal en la línea media para exponer los pedículos neurovasculares. Se cuantificó el número de ramos articulares en ambos lados de los dedos. Resultados: Los filetes nerviosos se presentaron en promedio de 1 por cada borde del dedo, sólo en 4 articulaciones fueron vistos 2 . Estos emergieron del nervio digital palmar propio, a $17 \mathrm{~mm}$ promedio (rango $9-25 \mathrm{~mm}$ ) del tercio medio de la falange proximal, repitiéndose tanto en borde radial como cubital de los dedos. Discusión: En nuestras disecciones la articulación IFP es inervada por un ramo articular constante, coincidiendo con los resultados de Schultz et al. (1984). No observamos ramos provenientes de los nervios digitales dorsales. Proponemos una inervación análoga a la distribución sensitiva cutánea palmar digital, que no guarda relación con la inervación sensitiva cutánea dorsal.

\section{ESTUDIO ESTADÍSTICO SOBRE LA DOMINANCIA CORONARIA EN LA PROVINCIA DE MENDOZA}

Francisco J PEÑALVER, Nicolas E PEREZ CACERES

Área de Anatomía Normal, Departamento de

Morfofisiología, Facultad de Ciencias Médicas, UNCuyo, Mendoza, Argentina

Introducción: Los estudios de dominancia coronaria realizados en diversos grupos poblacionales han reportado gran variabilidad. Pero la mayoría de los autores describe que en el $85 \%$ de la población la arteria coronaria derecha es dominante, mientras que en el $15 \%$ restante la dominancia es izquierda. El propósito de este trabajo es determinar el patrón de irrigación dominante en una muestra de la población mendocina. Materiales y Métodos: Se evaluarán 120 corazones (50 angiográficos, 50 angiotomográficos y 20 preparados cadavéricos). Se obtendrá una muestra que cumplirá los siguientes criterios de inclusión: Personas entre 18 y 70 años, de cualquier raza, sin signos de trauma cardíaco previo, con o sin síntomas de origen cardíaco. $Y$ los siguientes criterios de exclusión: Personas menores de 18 y mayores de 70 años, con patología cardiaca previa y patología congénita conocida. Se analizarán angiografías, angiotomografias y preparados cadavéricos observan- do la dominancia de la irrigación cardíaca (origen de la arteria Descendente Posterior). Resultados: por encontrase en fase de proyecto, aun no hay resultados disponibles. Discusión: la pregunta surge de la lectura de muchos libros de anatomía, americanos y europeos los cuales hablan de los patrones de irrigación cardiacos más frecuentes, pero basadas en estadísticas realizadas en dichas regiones. Hasta el momento, se desconoce la dominancia coronaria en la provincia de Mendoza. Este trabajo puede contribuir con el diagnostico, pronostico y tratamiento de patologías cardiovasculares.

\section{ANATOMÍA RADIOLÓGICA DEL} ENVEJECIMIENTO AÓRTICO NORMAL

Rodrigo J PERALTA ${ }^{1}$; Agustina LADOUX ${ }^{1}$; Tamara BARJA $^{1}$; Griselda BRATTI ${ }^{1,2}$; Lucas M GUTIERREZ ${ }^{1}$; Mariana BENDERSKY ${ }^{1,2}$

${ }^{1}$ Lab. de Anatomía Viviente, 3ra Cát. de Anatomía Normal, Fac. de Medicina, U.B.A.; ${ }^{2}$ Inst. Universitario Esc. de Medicina, Hospital Italiano. C.A.B.A. Argentina Introducción: No hay duda en que envejecemos porque los hacen nuestras células, lo mismo sucede con su irrigación. A partir de la infancia comienza un proceso que se denomina arterioesclerosis, caracterizado por engrosamiento y perdida de elasticidad de la pared arterial. Material y Métodos: Se evaluaron retrospectivamente 210 radiografías de perfil de columna lumbar de pacientes de ambos sexos, mayores de 18 años que concurrieron al servicio de patología espinal del Hospital Italiano de Buenos Aires entre mayo y julio 2015. Resultados: De los 210 pacientes estudiados, 7 fueron excluidos debido a mala técnica radiográfica. De los restantes pacientes 135 son de sexo femenino y 68 sexo masculino. Las edades estuvieron comprendidas entre 19 y 90 años, con un promedio de 63,45 años. En cuanto a factores de riesgo modificables o controlables, 103 pacientes tienen hipertensión arterial, 23 diabetes, 26 tabaquistas y 64 con dislipemias. Discusión: Las calcificaciones vasculares aumentan exponencialmente el riesgo de los pacientes de sufrir eventos cardiovasculares (infarto agudo de miocardio, accidentes cerebrovasculares, etc) por lo que es preciso poder diagnosticar el compromiso y la severidad de las calcificaciones en nuestra población. En este estudio se pudo evaluar que la edad juega un importante papel en el grado de calcificación aórtica, siendo independiente de los clásicos factores de riesgo mencionados anteriormente.

TALLER DE MANEJO DE LA VOZ EN DOCENTES: BASES DE ENTRENAMIENTO $Y$ PREVENCIÓN VOCAL

Nicolas E PEREZ CACERES

Área de Anatomía Normal, Departamento de

Morfofisiología, Facultad de Ciencias Medicas, UNCuyo, Mendoza, Argentina

Introducción: La voz es el principal instrumento natural de comunicación y expresión de los seres humanos. La actividad docente implica un ejercicio vocal continuo y sostenido, para el cuál en general, los docentes no se encuentran preparados. Este proyecto busca incentivar el cuidado de la voz mediante la incorporación de medidas de higiene vocal y nociones 
básicas de técnica de la voz hablada, identificando los factores de riesgo y malos hábitos vocales. Materiales y Métodos: aula, pizarrón, colchonetas, computadora y proyector multimedia. Actividades: tres encuentros teórico-prácticos destinados a concientizar sobre la producción de la voz, hábitos vocales y técnica vocal. Destinatarios: ayudantes del Área de Anatomía $(n=32)$. Instrumentos de evaluación: encuesta a los participantes y entrevista al encargado de las actividades. Resultados: Se determinó que el $69 \%$ de los asistentes detectó, con la ayuda del fonoaudiólogo Páez, algún mal habito vocal, de los cuales, un $45,45 \%$ se trata de mala técnica respiratoria y un $22,72 \%$ de esfuerzo vocal. Discusión: pese a ser la patología vocal la principal enfermedad profesional docente, no se incluye en las currículas de las carreras de profesorados, la enseñanza de una adecuada técnica vocal, lo que hace de vital importancia ofrecer a nuestros docentes un espacio para la incorporación de buenos hábitos vocales y la corrección de vicios foniátricos, para prevenir las patologías derivadas de éstos últimos. Este trabajo puede servir de puntal para estudios más específicos y profundos, sobre cuan beneficiosa es la educación foniátrica, para la salud vocal.

\section{ENFISEMA MEDIASTINAL ESPONTÁNEO. IMPORTANCIA ANÁTOMO- QUIRÚRGICA} GD PRAT ${ }^{1,2} ;$ D COSTi $^{1} ;$ FE SIRIS MACHADO $^{1} ;$ EN RAITI SPOSATO ${ }^{1}$; MP BONINI ${ }^{1}$; FS SCARPELLI ${ }^{1}$; C RUIZ ${ }^{1}$

${ }^{1}$ Lab. de Investigaciones Morfológicas Aplicadas,

Facultad de Medicina, U.N.L.P, ${ }^{2}$ Servicio de Cirugía

Torácica, Sanatorio Argentino. La Plata, Argentina Introducción: El enfisema mediastinal consiste en la presencia de aire en el mediastino. Dicho aire proviene principalmente de las vías aéreas, en la mayoría de los casos del pulmon. Se dice que es espontáneo cuando la ruptura alveolar ocurre sin mediar factores traumáticos. El resultado final es un enfisema mediastinal que puede llevar al colapso circulatorio, neumotórax y compresión cervical. Materiales y Métodos Las manifestaciones clínicas más comunes observadas fueron dolor torácico, disnea y enfisema subcutáneo cervical, evidenciable por la crepitación a la palpación de las fosas supraclaviculares. Los métodos de imágenes empleados fueron radiografía y tomografía axial computada. Resultados: El enfisema ocurre principalmente en adultos jóvenes. El aire que infiltra el mediastino ingresa a partir de la ruptura de las vías aéreas o del parénquima pulmonar. Las vainas perivasculobronquiales se encuentran alrededor de los componentes del pedículo de cada segmento pulmonar y de las estructuras mediastinales,y vasculorespiratorias. Estas vainas presentan continuidad con el mediastino, lo que representa una comunicación directa con el pulmón. A estas vainas son de importanciaral en el neumomediastino, donde se cree que el aire procedente de la ruptura alveolar y/o bronquial diseca a través de estas vainas para finalmente acceder a otras estructuras. Discusión: Mediante el estudio de las vainas perivaculobronquiales hemos interpretado la fisiopatología de ciertas entidadespatologicas y la causa de procesos ocasionados en el mediastino (enfisema) o patologías cervicales (flemones) pueden producir mediastinitis por la migración a través de las vainas mencionadas.

\section{RADIOLOGÍA BÁSICA EN EL COMPONENTE PRÁCTICO DE LA ASIGNATURA DE MORFOLOGÍA HUMANA. SEGUIMIENTO DE UN SEMESTRE ACADÉMICO Melisa PRIETO ${ }^{1}$, Martha BERNAL ${ }^{2}$ \\ ${ }^{1}$ Lab. de Morfología, Servicio Social Obligatorio. ${ }^{2}$ Coordinación Unidad Académica de Morfología.}

Programa de Medicina, Fac. de Ciencias de la Salud.

Universidad de Boyacá. Tunja. Boyacá. Colombia

Introducción: En diferentes programas de medicina, la asignatura de morfología humana integra la identificación anatómica sobre radiografías en la formación básica. Este estudio presenta una experiencia de aula con propósito evaluativo sobre adquisición de la competencia específica y percepción de esta en los estudiantes de anatomía en Medicina de la Universidad de Boyacá. Métodos: Se incluyeron 103 estudiantes con seguimiento de un semestre, en circuitos temáticos prácticos de anatomía osteoarticular de cráneo, tórax, miembro superior e inferior. Cada uno con 5 estaciones para el reconocimiento de las estructuras anatómicas, en las primeras 4 se realizó montaje en cadáveres, especímenes, piezas óseas y modelos anatómicos, la última sobre radiografías. El examen final práctico incluyó preguntas de complejidad baja y media, en radiografías simples de proyecciones anteroposterior, oblicuas y laterales. Al final del semestre se aplicó encuesta. Resultados: De total de los estudiantes evaluados $81 \%$ acertaron las 2 preguntas de complejidad baja y $37 \%$ la pregunta de complejidad media. El $66 \%$ calificaron muy relevante incluir imágenes diagnosticas como herramienta para mejorar la competencia de identificación anatómica, $80 \%$ consideraron muy relevante los conocimientos adquiridos para la práctica profesional y el $56 \%$ destacan como muy relevante el incremento de su interés por la anatomía radiológica. Discusión: La incorporación de imágenes diagnosticas en las prácticas de laboratorio favorece la adecuada correlación de la anatomía ostearticular, los estudiantes destacaron la importancia del abordaje radiológico en el ciclo básico, como estrategia metodológica para la enseñanza y aprendizaje de la anatomía humana.

\section{ANATOMÍA DE LOS VASOS PERFORANTES DE LA ARTERIA EPIGÁSTRICA INFERIOR Y SU UTILIZACIÓN EN EL COLGAJO DIEP María V ROJAS ORTIZ ${ }^{1}$; Yanina D BERGILLI ${ }^{1}$; Micaela AR FELDMAN ${ }^{1}$; Juan S URRUTIA ${ }^{1}$; Rubén D ALGIERI ${ }^{1,2}$ \\ ${ }^{1}$ III Cátedra de Anatomía, Facultad de Medicina, U.B.A; ${ }^{2}$ Cirugía del Hospital Aeronáutico Central. C.A.B.A., Argentina}

La arteria epigástrica inferior (AEI) y sus perforantes se han destacado en las cirugías de reconstrucción mamaria por medio del colgajo DIEP (colgajo de la arteria epigástrica inferior profunda) debido a la obtención de resultados óptimos y duraderos en el tiempo. El objetivo del siguiente trabajo es ampliar la anatomía de la $\mathrm{AEI}$, más precisamente de sus ramas perforantes, haciendo hincapié en su ubicación y 
morfología, a fin de facilitar su localización durante la realización de un colgajo DIEP. Se realizó la disección total de 10 cadáveres humanos provenientes de la Facultad de Medicina, Universidad de Buenos Aires y se realizaron las mediciones pertinentes. En el plano muscular de la pared anterior del abdomen se estudió la localización, cantidad y diámetro de los vasos perforantes de la $\mathrm{AEI}$, obteniendo un predominio de las mismas, con un calibre mayor a $1 \mathrm{~mm}$, entre 4 a 6 $\mathrm{cm}$ hacia inferior y 4 a $6 \mathrm{~cm}$ hacia la izquierda del ombligo, siendo dicha zona la más útil frente a un colgajo DIEP

\section{DESCENSO TESTICULAR; ETIOLOGÍA, ANATOMÍA Y CONSIDERACIONES QUIRÚRGICAS}

E RUIZ BRALO ${ }^{2}$; E RAITI SPOSATO ${ }^{2}$; M BONINI $^{2} ; Z$ LEIVA $^{2}$; M TARZIA ${ }^{2}$; A SOSA $^{2}$; S TOBÍA GOMZALEZ ${ }^{1}$ ${ }^{1}$ Cátedra de Urología; ${ }^{2}$ Cátedra Anatomía. FCM-UNLP Introducción. El mal descenso testicular se puede dividir en testículo no palpable o testículo palpable. Las causas embriológicas que favorecen esta patología son extensamente reconocidas y el conocimiento de las mismas junto al aprendizaje de la anatomía son de vital importancia para la decisión del abordaje quirúrgico frente a este problema. Objetivos. Definir las consideraciones embriológicas y anatómicas implícitas en el descenso testicular y su abordaje quirúrgico. Materiales y Métodos. Se realiza la disección anatómica de 4 fetos de sexo masculino en diferentes estadios gestacionales haciendo especial hincapie en la ubicación de las gónadas y su pedículo. Además se realiza la disección de 5 preparados formolizados de sexo masculino con dos de ellos en recién nacidos a término y 3 adultos realizando la disección del cordón espermático y gónadas. Resultados. Los hallazgos derivados de las disecciones realizadas nos dan como resultado la cronología clásica descripta en el descenso testicular. En los fetos disecados se encontraron los testículos intrabdominales retroperitoneales y en los preparados de recién nacidos y adultos no se encontraron variaciones anatómicas en la conformación del cordón espermático encontrándose todos los testículos intrabdominales. Discusión. E abordaje quirúrgico del testículo mas descendido mal descendido implica el conocimiento exhaustivo de la embriología y la anatomía del descenso testicular normal.

\section{CONSIDERACIONES ANATÓMICAS PARA EL BLOQUEO INTERCOSTAL EN LA CIRUGÍA} RENAL A CIELO ABIERTO

\section{E RUIZ BRALO ${ }^{2}$; F SCARPELLI' ${ }^{2}$; $C$ RUIZ ${ }^{2}$;} BONINI' ${ }^{2}$ S ORTIZ ${ }^{2}$; S TOBÍA GONZALEZ ${ }^{1}$

${ }^{1}$ Cát. de Urología; ${ }^{2}$ Cát. de Anatomía C. FCM-UNLP Introducción. Una de las vías de abordaje más frecuentemente utilizada por los especialistas en urología para resolver las patologías renales es la vía lumbar dado que ofrece una puerta de entrada directa al riñón y a las vías urinarias superiores retroperitoneal. Una de las complicaciones de esta vía de abordaje es el dolor pos operatorio ya que en muchos casos incluso hay que realizar una resección parcial del décimo segundo arco costal por lo cual es muy importante el bloqueo intercostal para el manejo del dolor pos operatorio. Objetivo. Identificar los reparos anatómicos para la realización del bloqueo intercostal. Materiales y Métodos. Se realiza la disección anatómica de 12 preparados formolizados de ambos sexos, teniendo especial atención en los arcos costales inferiores $\left(10^{\circ}, 11^{\circ}, 12^{\circ}\right)$ y sus relaciones musculo nerviosas. Resultados. En la totalidad de los preparados disecados se corroboró la conformación clásica del paquete vasculonervioso intercostal. El $12^{\circ}$ nervio es el único de los 3 analizados previamente que describe un trayecto subcostal. La localización inferior del nervio intercostal permite mediante la palpación del borde inferior del nervio intercostal permite mediante la palpación del borde inferior de la costilla para evitar complicaciones vasculares. Discusión. La realización del bloqueo intercostal en el marco de la cirugía renal por vía lumbar implica el conocimiento en detalle de la anatomía del paquete vasculonervioso intercostal $10^{\circ}$, $11^{\circ}$ y $12^{\circ}$

\section{LYMPHONODAL INGUINAL VEINS: THEIR RELATIONSHIP WITH VARICOSE RECURRENCE}

Victoria SGARBANTI ${ }^{1}$, Luciano G OTONELLI ${ }^{1}$, Michelle DI PAOLO ${ }^{1}$, Iñaki BARONE PAPAIANNI ${ }^{1}$, José S PARRA ${ }^{1}$, Miguel A AMORE ${ }^{2,3}$

${ }^{1}$ Cadaver Lab. Processing and Biosafety; ${ }^{2}$ Vascular Anatomy Lab., III Chair of Anatomy, Fac. of Medicine, Univ. of Buenos Aires; ${ }^{3}$ Phlebology and Lymphology,

Central Militar Hospital. Buenos Aires. Argentina Introduction: Saphenectomy is one of the surgical techniques used to treat the failure of the great saphenous vein, but this is associated with a high recurrence rate. It is known that the section of the tributaries of the arc of the great saphenous vein alters venous and lymphatic drainage of the inguinofemoral region. In recent years, the lymphonodal veins have been studied as one of the causes of recurrent varicose. Material and Methods: 15 human cadavers, 11 adults and 4 fetuses to term were used. Cadavers were subjected to injection procedures with colored latex then fixed by soaking with an aqueous solution of formalin $5 \% \mathrm{v} / \mathrm{v}$. In 3 of the fetus samples a lymphatic injection with Gerota technique with subsequent Spatelholz diaphanization method was performed. Then they were approached, dissected and photographed. Results: The topography of the inguino-femoral lymphonodal veins, its frequency and relationships with the veins of the magna saphenous vein arc is exposed. Discussion: Lymphonodal veins drain on the veins corresponding to the arc of great saphenous vein. The section of these last, during surgery, disrupts the venous drainage of the lymphnode generating subcapsular venous ectasia, a fact that is now considered as a possible cause of varicose recurrences.

\section{BLOQUEO INTERESCALÉNICO PARA CIRUGÍA DE HOMBRO. REPAROS ANATÓMICOS \\ F SIRIS MACHADO ${ }^{2}$; M TARZIA ${ }^{2}$; B LOREA ${ }^{2} ;$ E RAITI'; A SOSA ${ }^{2}$; P OSACAR ${ }^{2}$; S TOBÍA GONZALEZ ${ }^{2}$ \\ ${ }^{1}$ Cát. de Urología; ${ }^{2}$ Cát.Anatomía C, FCM-UNLP} Introducción. El bloqueo interescalénico, es especialmente efectivo para la cirugía de hombro y la porción 
proximal del brazo y es ideal para la reducción de una luxación de hombro. Objetivo. El objetivo del presente trabajo es resaltar la importancia de los reparos anatómicos para efectuar el bloqueo interescalénico. Materiales y Métodos. Se realiza la disección anatómica de la región lateral del cuello y región supraclavicular en 10 preparados formolizados de ambos sexos. Se hace hincapie en la anatomía de la pared lateral de la laringe, el músculo esternocleidomastoideo, la vena yugular externa y de los músculos escalenos, disecando el vientre interescalénico. y las raíces del plexo braquial a la altura del cuerpo vertebral de C-6. Resultados. Realizada la disección anatómica de acuerdo a la descripción de la técnica del bloqueo interescalénico. se logra el hallazgo en todos los preparados de las raíces primarias nerviosas del plexo braquial a la altura del cuerpo vertebral C-6 sin alteraciones ni variantes anatómicas. La vena yugular externa se encontró en todos los vasos sobre el surco interescalénico. a la altura de C-6. El borde externo del músculo escaleno anterior se diferencia a a esta altura del borde del músculo esternocleidomastoideo en todos los preparados disecados. Discusión. Los hallazgos encontrados en este trabajo confirman la constancia de los reparos anatómicos de la región lateral del cuello, lo que corrobora en la práctica del bloqueo interescalénico pueda ser simple y reproducirle.

\section{ANATOMÍA CLÍNICA DE CORTEZA}

PREFRONTAL Y CUERPO AMIGDALINO EN ALCOHÓLICOS MASCULINOS POR RESONANCIA MAGNÉTICA

Elba B TORNESE; Martín J MAZZOGLIO Y NABAR

Laboratorio de Neuroanatomía aplicada a la

Neurociencia, Departamento de Anatomía, Facultad de Medicina, U.B.A., C.A.B.A. Argentina

Introducción: Se estudió la volumetría de corteza prefrontal y cuerpo amigdalino de pacientes alcohólicos por resonancia magnética en relación con controles normales, especificando la correlación morfológica y anátomo-clínica, a fin de determinar su implicancia en la impulsividad. Materiales y Métodos: Las muestras consistieron en 25 imágenes encefálicas de resonancia magnética de pacientes masculinos, edades entre 29 y 51 años, con diagnóstico de trastorno por consumo de alcohol tipo dependencia, con remisión parcial temprana (DSM IV). Se cuantificó la corteza y la sustancia blanca cerebral total (método $\mathrm{ROI}$ ), con especificación de corteza prefrontal y cuerpo amigdalino según protocolo de Witelson, comparando con controles normales apareados por edad. Se realizaron estudios neuropsicológicos y neuropsiquiátricos. Realizamos análisis estadístico para determinar la significación y aplicamos pruebas de correlación (coeficientes $r \mathrm{y} \mathrm{r}^{2}$ ). Se tomaron reparos éticos como el consentimiento informado y la cumplimentación de las disposiciones vigentes (ANMAT 5330/97 y Declaración de Helsinski). Resultados: Se registró reducción volumétrica de corteza del lóbulo frontal (16.2\%), corteza prefrontal (izquierda $23.35 \%$, derecha $19.11 \%$ ) y cuerpo amigdalino (derecho 5. 62\%, izquierdo $5.38 \%$ ), con correlación entre afectación de corteza prefrontal izquierda y cuerpo amigdalino izquierdo como parámetro de impulsividad. Discusión: La corre- lación positiva entre volumetría cortical prefrontal izquierda, cuerpo amigdalino izquierdo e impulsividad sugiere su vinculación con la sensibilidad a las emociones negativas e incapacidad para regular emociones. El compromiso del cuerpo amigdalino derecho atenúa la respuesta emocional e indica severidad del deterioro cognitivo.

\section{CARACTERIZACIÓN MORFOMÉTRICA DEL PRIMER COMPARTIMENTO EXTENSOR DE LA MUÑECA: ESTUDIO ANATÓMICO DIRECTO.}

EA TORRES ${ }^{1,2}$; LE BALLESTEROS ${ }^{2}$

${ }^{1}$ Maestría en Ciencias Básicas Biomédicas; ${ }^{2}$ Grupo de Investig. en Variaciones Anatómicas y Biomecánica

Tendomuscular. Departamento de Ciencias Básicas Biomédicas. Univ. Industrial de Santander, Colombia. Introducción: el primer compartimento extensor, compuesto por los músculos extensor largo (ELPD) y corto del primer dedo (ECPD) y abductor largo del primer dedo (ALPD) y estructuras relacionadas, son fuente de amplia variabilidad morfológica pobremente estudiada, que han sido relacionadas con la fisiopatología de la enfermedad de Quervain. Material y Método: estudio de cadáveres formolados y frescos (25 muestras), de un grupo mestizo colombiano. Mediciones realizadas por el investigador principal, utilizando cinta métrica y calibrador electrónico, evaluando el componente tendomuscular y los puntos motores (PM) y la presencia de septo tendinoso. Resultados: el ALPD mostró 1 tendón en sólo el 4,8\% de los casos (1 caso); la distribución más común del ALPD es de 2 tendones, en $61,9 \%$ de los casos (13 casos), seguida de 3 tendones en $28,6 \%$ ( 6 casos). El $4,8 \%$ corresponde a un caso de 4 tendones. El número más frecuente de $\mathrm{PM}$ es 2 para ALPD (33.33\%), y uno para EBPD $(87,5 \%)$ y ELPD $(61,11 \%)$. El $73,5 \%$ de los PM del ALPD se ubican entre 1 y 5 cms de su origen $(73,5 \%)$; para ECPD la ubicación más común es entre 1 y $4 \mathrm{cms}$ de su origen $(77,77 \%)$ y en el ELPD en el rango de 1,5 a $5,5 \mathrm{cms}$ del origen muscular (83,33\%). Discusión: es importante reconocer la relevancia de los estudios anatómicos en ciencias básicas y clínicas, considerando la amplia variabilidad en estos resultados con respecto al patrón usual y su posible rol en el desarrollo de patologías por trauma repetitivo.

\section{MORFOMETRÍA DEL MÚSCULO TRÍCEPS BRAQUIAL Y BIOMETRÍA DE SUS PUNTOS MOTORES}

EA TORRES ${ }^{1,2}$; LE BALLESTEROS ${ }^{2}$

${ }^{1}$ Maestría en Ciencias Básicas Biomédicas; ${ }^{2}$ Grupo de Investig- en Variaciones Anatómicas y Biomecánica

Tendomuscular. Departamento de Ciencias Básicas Biomédicas. Univ. Industrial de Santander, Colombia Introducción: El conocimiento sobre la expresión anatómica del musculo triceps braquial (MTB) incluidos vientres musculares, estructuras miotendinosas y puntos motores (PM) aporta a aplicaciones clínicas (electroterapia, electrodiagnóstico) y reconocimiento de estructuras susceptibles de iatrogenia durante procedimientos quirúrgicos. Material y Métodos: se evaluó el componente tendomuscular y la presencia, número y ubicación de PM de las tres 
porciones del MTB en una muestra de cadáveres formolados y frescos. Para la medición se utilizó cinta métrica y calibrador electrónico. Results: examinamos 25 muestras de 17 cadáveres. La longitud de las cabezas larga, medial y lateral del MTB fueron 28,5 \pm $26,6 \mathrm{~mm} ; 225 \pm 19 \mathrm{~mm}$ y $256 \pm 19$ respectivamente. La porción miotendinosa de la cabeza larga midió 124 $\pm 20,6 \mathrm{~mm}$; la porción miotendinosa del vientre muscular común midió $137 \pm 18,4 \mathrm{~mm}$. La cabeza larga recibió con mayor frecuencia tres PM $(31,8 \%)$, ubicados en el $85 \%$ de los especímenes a $4-10 \mathrm{cms}$ del origen muscular; la cabeza lateral recibe tres PM en el $52 \%$ de la muestra, ubicados en $85 \%$ de los casos en un área de $4-11 \mathrm{cms}$ a su origen; la cabeza medial recibe dos PM en el $36 \%$ de los casos, ubicados entre 4- $10 \mathrm{cms}$ del origen en la mayoría de los casos. Discusion: existe poca información sobre el MTB a pesar de su relevancia en el ámbito básico y clínico; nuestros hallazgos contribuyen a mejorar su conocimiento. Los resultados parciales de este trabajo muestran la presencia de múltiples PM de ubicación más heterogénea a la referenciada en estudios previos.

\section{ANATOMICAL VARIANTS IN THE INSERTION OF THE PECTORALIS MINOR TENDON ASSOCIATED WITH THE CORACOHUMERAL LIGAMENT}

Mari UOMIZU ${ }^{1}$, Kumiko YAMAGUCHI ${ }^{2}$, Keiichi AKITA ${ }^{2}$

${ }^{1}$ Department of Joint Surgery and Sports Medicine;

${ }^{2}$ Unit of Clinical Anatomy. Graduate School, Tokyo Medical and Dental University Japan

Introduction: The purpose of this study was to evaluate the frequency of the abnormal insertion of the pectoralis minor muscle, and also to investigate the relation between the tendon and the coracohumera ligament. Material and Methods: Eighty-one anatomic specimen shoulders from forty-one cadavers were dissected. The insertion of the pectoralis minor tendon in relation to the coracohumeral ligament was carefully investigated. Results: The pectoralis minor tendon ran beyond the coracoid process and extended to the superior surface of the glenohumeral joint in 28 out of 81 specimens $(34.6 \%)$. Prevalence of the continuations in laterality was almost same (14 shoulders each side). Part of the pectoralis minor tendon dividing the coracoacrominal ligament into two limbs and continuing, as the anterior part of the coracohumeral ligament, to the greater tubercle of the humerus. The continuation was more variable, and consisted of the whole tendon in 6 , the middle part in 15 , the lateral part in 15, and the medial part in 2 specimens. Furthermore, the continuations inserted to the greater tuberosity in 7 to the posterosuperior border of the glenoid in 6 , and both to the glenoid and the greater tuberosity in 15 specimens. Discussion: The prevalence of the anomalous insertion of the pectoralis minor tendon was higher than those in the previous reports. This may suggest that the pectoralis minor tendon together with the coracohumeral ligament plays an important role in the stability of the glenohumeral joint.

ORIGEN ALTO DE LA ARTERIA RADIAL Y ULNAR: REPORTE DE CASO COLOMBIANO Miguel VERTEL, Martha BERNAL
Semillero de Investig. en Anatomía RENASCI, Prog. de Medicina, Facultad de Ciencias de la Salud, Universidad de Boyacá, Tunja, Boyacá Colombia Introducción. El sistema vascular arterial del adulto presenta diversas variaciones anatómicas en el miembro superior una de ellas el origen alto de la artería radial y ulnar. Método. En 13 miembros superiores derechos e izquierdos disecados en 7 cadáveres masculinos, se inspeccionaron la región braquial anterior y del pliegue del codo, en sitio habitual de bifurcación de la arteria braquial en arterias radial y ulnar. Se practicaron morfometrías, calibres de las arterias y la distancia a que se hallaba su origen con respecto a la línea biepicondilar del codo. Resultados. En el miembro superior derecho de un cadáver se encontró la bifurcación de la arteria braquial derecha a 140 milímetros con respecto al acromion y 135 milímetros de la línea biepicondilar de la articulación del codo, el calibre de la arteria braquial, ulnar y radial fue de 6,5 y $4 \mathrm{~mm}$ respectivamente. La arteria radial se ubicó anterior a la arteria ulnar y lateral al nervio mediano en la fosa cubital pasando al antebrazo profunda a la expansión aponeurótica del músculo bíceps braquial, la arteria ulnar profunda al músculo pronador redondo. Los demás miembros superiores no presentaron ninguna variación. Conclusión. El hallazgo de esta variación anatómica es significativo para el ámbito clínico, en los procedimientos vasculares de rutina, diferentes métodos terapéuticos y de radiodiagnóstico, entre otros. Las complicaciones procedimentales médicas de esta variación pueden derivar trombosis, gangrena y demás.

\section{ADAPTACIÓN DEL MATERIAL CADAVÉRICO ANATÓMICO AL COMPONENTE VISUO- ESPACIAL DEL ALUMNO DURANTE LA ROTACIÓN DE APARATO LOCOMOTOR}

José $\mathrm{F}$ VIÑAS, Felipe HIGUERA, Humberto $\mathrm{N}$ JIMÉNEZ VILLARRUEL

Lab. de Anatomía aplicada a la práctica médica, III Cát. de Anatomía Normal, Departamento de Anatomía,

Facultad de Medicina, U.B.A., C.A.B.A., Argentina Introducción: La efectividad de la introducción en los trabajos prácticos de material cadavérico óseo preparado especialmente con el propósito de favorecer el aprendizaje visual y la síntesis teórico-práctica. Material y Método: Se utilizaron dos esqueletos adultos. Sobre uno se pintaron las inserciones musculares correspondientes con acrílico. Se tomó una muestra al azar de 76 alumnos de la III Cátedra de Anatomía Normal de la Facultad de Medicina (U.B.A.) y, divididos en tres grupos aleatorios siendo "A" (25 alumnos), "B" (24 alumnos) y "C" (27 alumnos), se le otorgó al " $A$ " material cadavérico óseo del esqueleto, sin pintar, al "B" material cadavérico óseo pintado mientras que el " $C$ " no recibió material alguno. Luego se realizó una revisión sistemática sobre el tema inserciones, guiada por un docente. Finalmente se efectuó una evaluación de 20 preguntas a todos los alumnos y se tabularon los resultados. Resultados: Los porcentajes de respuestas correctas para cada uno de los grupos fueron: $39,4 \%$ para el grupo "A", $30 \%$ el grupo "B", $16,3 \%$ el grupo "C". Discusión: Los resultados no fueron los esperados con el diseño 
metodológico puesto en práctica. Concluimos que, a futuro, debe diseñarse un método de evaluación que contemple otros factores como la capacidad individual previa, el sentido de responsa-bilidad individual e impartido, la actividad docente, etc. y los elimine del resultado final, con el propósito de obtener resultados fidedignos respecto de la efectividad del material cadavérico.

ISTRIBUTION OF THE MASTICATORY AND FACIAL MUSCLES AT THE LATERAL REGION TO ORBIT

K YAMAGUCHI ${ }^{1}$; K AKITA ${ }^{2}$

${ }^{1}$ Center for interprofessional education; ${ }^{2}$ Department of

Clinical Anatomy. Tokyo Medical and Dental University, Tokyo, JAPAN

Introduction: Orbicularis oculi is one of the facial muscles surrounds each orbital orifice. The outer orbital part is a broad ring that encircles the orbital orifice and extends outward beyond the orbital rim. In the lateral sides of face, masticatory muscles distribute as a large musculature unit. The distribution or overlap of these structures is still unclear. In this study, we dissected the lateral region of the orbicularis oculi to know the underlying supporting structure of the muscle. Material and methods: We dissected nine sides of five Japanese cadavers for this study. In addition, we performed histological analyses with two sides of two heads to understand the layer structures of muscles and connective tissue between skin and skull. Results: In the gross anatomical study, lateral muscle fibers of orbicularis oculi attached to the temporal fascia. In this region, anterior muscle bundle of the temporalis attached to the inner surface of the temporal fascia. In the histological study, at the level of lateral commissure, temporalis was thick in anterior part. Thin muscle layer of the orbicularis oculi was observed in the surface layer to the thick part of temporalis. At the level of eyebrow, temporalis was thin and overlap of these two muscles was also observed. Discussion: The anterior muscle bundle of the temporalis is considered to be important to keep the morphology of orbicularis oculi. This analysis is applicable to evaluate age-related changes of the facial structures, and could contribute to understand the mechanism of facial aging. 